\title{
Isopedopeptins A-H: Cationic Cyclic Lipodepsipeptides from Pedobacter cryoconitis UP508 targeting WHO top-priority carbapenem-resistant
}

\section{bacteria}

Christina Nord,${ }^{\dagger}$ Joakim Bjerketorp, ${ }^{\dagger,}$ đJolanta J. Levenfors, ${ }^{\dagger, \star}$ Sha Cao ${ }^{\S}$ Adam A. Strömstedt, ${ }^{\wedge}$ Bengt Guss, $\|$ Rolf Larsson, ${ }^{\nabla}$ Diarmaid Hughes, ${ }^{\S}$ Bo Öberg, ${ }^{\ddagger \wedge}$ Anders Broberg ${ }^{\dagger, *}$

${ }^{\dagger}$ Department of Molecular Sciences, Uppsala BioCentrum, Swedish University of Agricultural Sciences, P.O. Box 7015, SE-750 07 Uppsala, Sweden

tUltupharma AB, Södra Rudbecksgatan 13, SE-752 36 Uppsala, Sweden

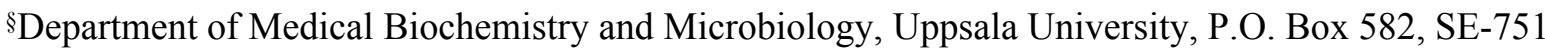

23 Uppsala, Sweden

${ }^{\wedge}$ Department of Medicinal Chemistry, Uppsala University, P.O. Box 574, SE-751 23 Uppsala, Sweden

$\|$ Department of Biomedical Sciences and Veterinary Public Health, Swedish University of Agricultural Sciences, P.O. Box 7036, SE-750 07 Uppsala, Sweden; Bengt.Guss@slu.se

${ }^{\nabla}$ Department of Medical Sciences, Uppsala University, SE-751 85 Uppsala, Sweden

*Correspondence: Anders.Broberg@slu.se; Tel.: +46-18-672217 
METHODS

Table S1. ${ }^{1} \mathrm{H}$ and ${ }^{13} \mathrm{C}$ NMR-data (600 and $150 \mathrm{MHz}$, resp) for compound $1\left(\mathrm{DMSO}_{6}, \mathrm{~d}_{6}, 30^{\circ} \mathrm{C}\right.$ )

Figure S1. ${ }^{1} \mathrm{H}-\mathrm{NMR}$ spectrum of compound 1 (DMSO-d 6 , $\left.600 \mathrm{MHz}, 298 \mathrm{~K}\right)$............................17

Figure S2. ${ }^{13} \mathrm{C}-\mathrm{NMR}$ spectrum of compound 1 (DMSO-d 6 , $\left.600 \mathrm{MHz}, 298 \mathrm{~K}\right)$..........................17

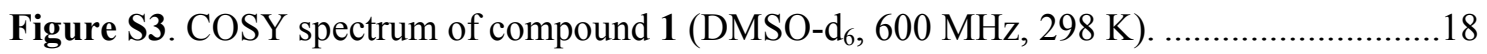

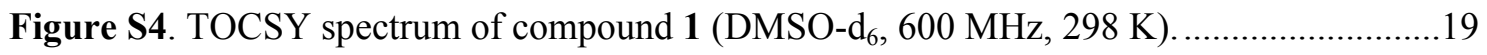

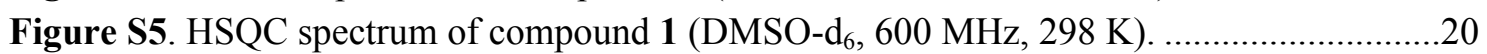

Figure S6. HMBC spectrum of compound 1 (DMSO-d 6 , $600 \mathrm{MHz}, 298 \mathrm{~K})$. ............................21

Figure S7. ROESY spectrum of compound 1 (DMSO-d 6 , 600 MHz, $298 \mathrm{~K})$. Top: Full spectrum. Bottom: Expansion showing the correlation between ABA-NH (10.22 ppm) and the

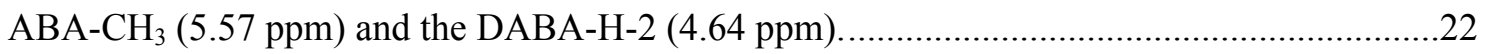

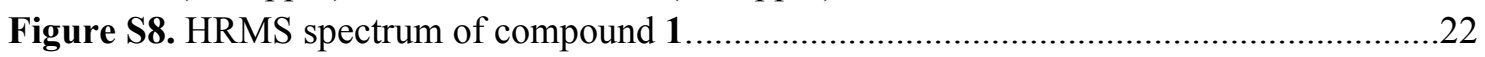
Figure S9. MSMS spectrum of compound 1 after ring-opening with $\mathrm{NaOMe}$ in $\mathrm{MeOH}$. Mass differences between Y-series ions (top) and B-series ions (bottom) are shown in the mass spectrum. Theoretical $\mathrm{m} / \mathrm{z}$-values for the observed $\mathrm{B}$ - and $\mathrm{Y}$-series ions are shown in the structure on top.

Table S2. ${ }^{1} \mathrm{H}$ and ${ }^{13} \mathrm{C}$ NMR-data (600 and $150 \mathrm{MHz}$, resp) for compound $2\left(\mathrm{DMSO}-\mathrm{d}_{6}, 30^{\circ} \mathrm{C}\right)$

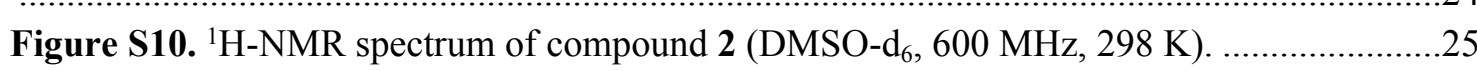

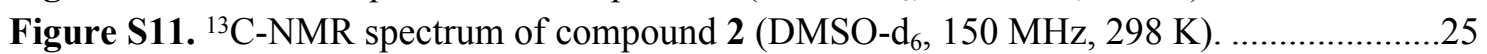

Figure S12. COSY spectrum of compound $2\left(\right.$ DMSO-d $\left._{6}, 600 \mathrm{MHz}, 298 \mathrm{~K}\right)$............................26

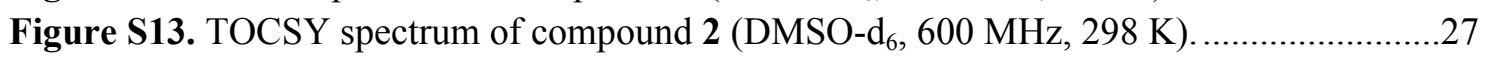

Figure S14. HSCQ spectrum of compound $2\left(\right.$ DMSO-d $\left._{6}, 600 \mathrm{MHz}, 298 \mathrm{~K}\right)$...........................28

Figure S15. HMBC spectrum of compound 2 (DMSO-d $\left.\mathrm{d}_{6}, 600 \mathrm{MHz}, 298 \mathrm{~K}\right)$............................29

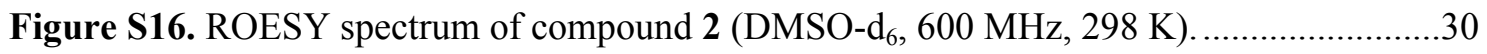

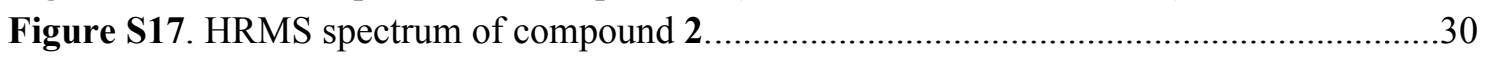

Figure S18. MSMS spectrum of compound 2 after ring-opening with $\mathrm{NaOMe}$ in $\mathrm{MeOH}$. Mass differences between $\mathrm{Y}$-series ions (top) and B-series ions (bottom) are shown in the mass spectrum. Theoretical $\mathrm{m} / \mathrm{z}$-values for the observed $\mathrm{B}$ - and $\mathrm{Y}$-series ions are shown in the structure on top.

Table S3. ${ }^{1} \mathrm{H}$ and ${ }^{13} \mathrm{C}$ NMR-data (600 and $150 \mathrm{MHz}$, resp) for compound $3\left(\mathrm{DMSO}-\mathrm{d}_{6}, 30^{\circ} \mathrm{C}\right.$ )

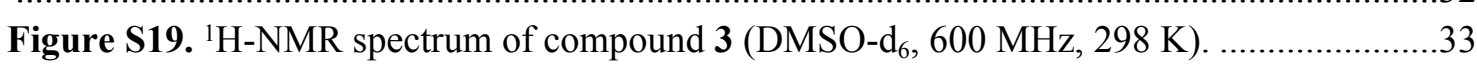

Figure S20. COSY spectrum of compound $3\left(\right.$ DMSO-d $\left._{6}, 600 \mathrm{MHz}, 298 \mathrm{~K}\right)$...........................33

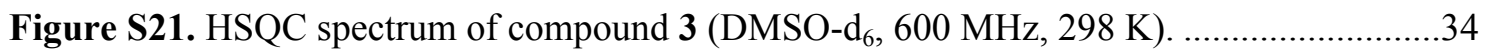

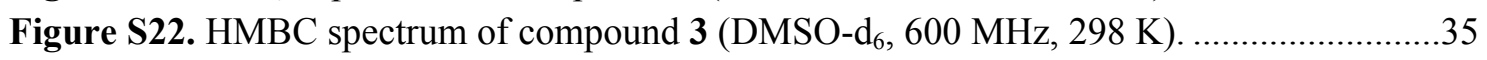

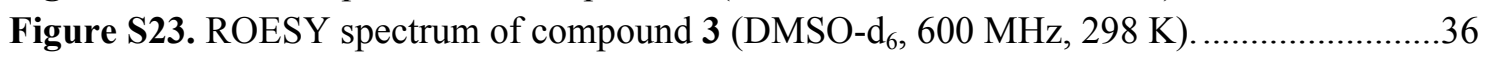

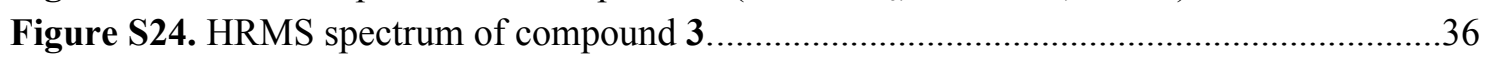

Figure S25. MSMS spectrum of compound 3 after ring-opening with $\mathrm{NaOMe}$ in $\mathrm{MeOH}$. Mass differences between $\mathrm{Y}$-series ions (top) and B-series ions (bottom) are shown in the mass spectrum. Theoretical $\mathrm{m} / \mathrm{z}$-values for the observed B- and $\mathrm{Y}$-series ions are shown in the structure on top.

Table S4. ${ }^{1} \mathrm{H}$ and ${ }^{13} \mathrm{C}$ NMR-data (600 and $150 \mathrm{MHz}$, resp) for compound $4\left(\mathrm{DMSO}_{6} \mathrm{~d}_{6}, 30^{\circ} \mathrm{C}\right)$

Figure S26. ${ }^{1} \mathrm{H}-\mathrm{NMR}$ spectrum of compound $4\left(\mathrm{DMSO}_{-} \mathrm{d}_{6}, 600 \mathrm{MHz}, 298 \mathrm{~K}\right)$.........................39 


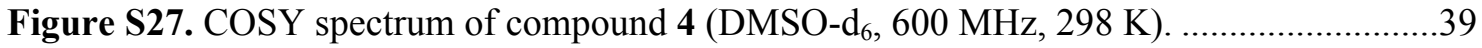

Figure S28. HSQC spectrum of compound 4 (DMSO-d $\left.\mathrm{d}_{6}, 600 \mathrm{MHz}, 298 \mathrm{~K}\right)$.............................40

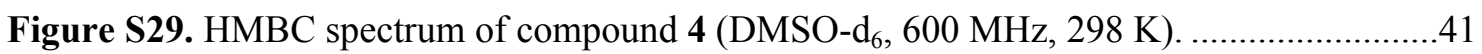

Figure S30. ROESY spectrum of compound $4\left(\right.$ DMSO-d $\left._{6}, 600 \mathrm{MHz}, 298 \mathrm{~K}\right)$...........................42

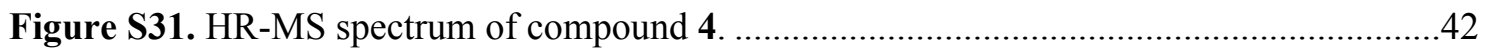

Figure S32. MSMS spectrum of compound 4 after treatment with $\mathrm{NaOMe}$ in $\mathrm{MeOH}$. Mass differences between Y-series ions (top) and B-series ions (bottom) are shown in the mass spectrum. Theoretical $\mathrm{m} / \mathrm{z}$-values for the observed $\mathrm{B}$ - and $\mathrm{Y}$-series ions are shown in the structure on top.

Table S5. ${ }^{1} \mathrm{H}$ and ${ }^{13} \mathrm{C}$ NMR-data (600 and $150 \mathrm{MHz}$, resp) for compound 5 (DMSO- $\left.\mathrm{d}_{6} 30^{\circ} \mathrm{C}\right) 44$ Figure S33. ${ }^{1} \mathrm{H}-\mathrm{NMR}$ spectrum of compound 5 (DMSO-d $\left.\mathrm{d}_{6}, 600 \mathrm{MHz}, 298 \mathrm{~K}\right)$. ........................45

Figure S34. COSY spectrum of compound $5\left(\right.$ DMSO-d $\left._{6}, 600 \mathrm{MHz}, 298 \mathrm{~K}\right)$. ...........................45

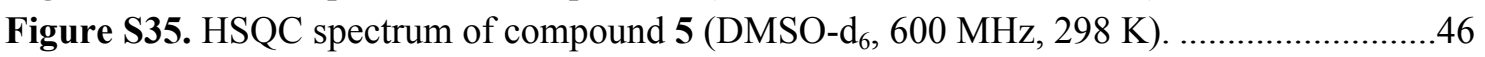

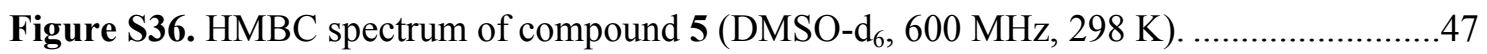

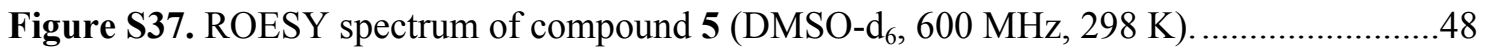

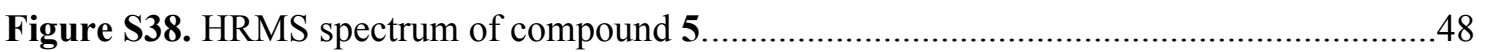

Figure S39. MSMS spectrum of compound $\mathbf{5}$ after treatment with $\mathrm{NaOMe}$ in $\mathrm{MeOH}$. Mass differences between Y-series ions (top) and B-series ions (bottom) are shown in the mass spectrum. Theoretical $\mathrm{m} / \mathrm{z}$-values for the observed $\mathrm{B}$ - and $\mathrm{Y}$-series ions are shown in the structure on top.

Table S6. ${ }^{1} \mathrm{H}$ and ${ }^{13} \mathrm{C}$ NMR-data (600 and $150 \mathrm{MHz}$, resp) for compound $6\left(\mathrm{DMSO}^{-} \mathrm{d}_{6}, 30^{\circ} \mathrm{C}\right)$

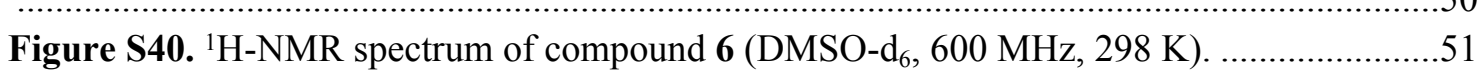

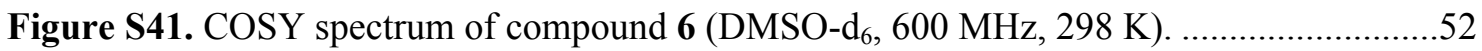

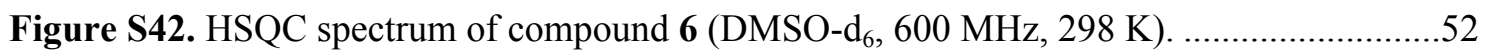

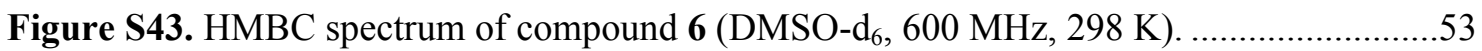

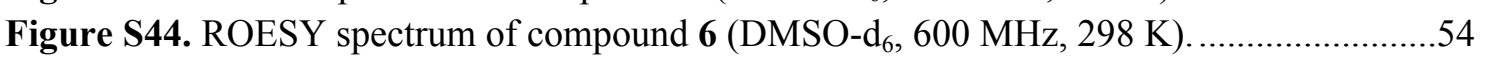

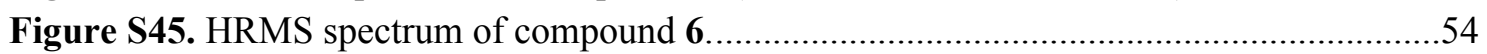

Figure S46. MSMS spectrum of compound 6 after treatment with $\mathrm{NaOMe}$ in $\mathrm{MeOH}$. Mass differences between $\mathrm{Y}$-series ions (top) and B-series ions (bottom) are shown in the mass spectrum. Theoretical m/z-values for the observed B- and Y-series ions are shown in the structure on top.

Table S7. ${ }^{1} \mathrm{H}$ and ${ }^{13} \mathrm{C}$ NMR-data (600 and $150 \mathrm{MHz}$, resp) for compound $7\left(\mathrm{DMSO}^{-} \mathrm{d}_{6}, 30^{\circ} \mathrm{C}\right.$ )

Figure S47. ${ }^{1} \mathrm{H}-\mathrm{NMR}$ spectrum of compound 7 (DMSO-d $\left.\mathrm{d}_{6}, 600 \mathrm{MHz}, 298 \mathrm{~K}\right)$..........................57

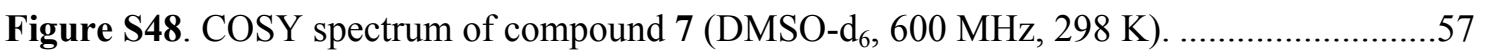

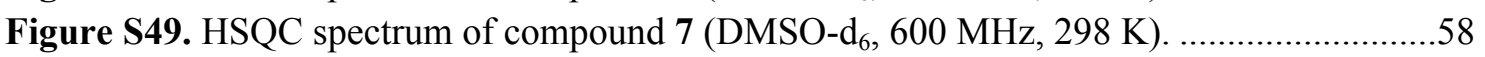

Figure S50. HMBC spectrum of compound 7 (DMSO-d $\left.{ }_{6}, 600 \mathrm{MHz}, 298 \mathrm{~K}\right)$..........................59

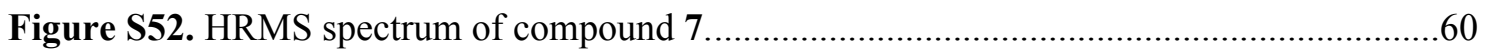

Figure S53. MSMS spectrum of compound 7 after treatment with $\mathrm{NaOMe}$ in $\mathrm{MeOH}$. Mass differences between Y-series ions (top) and B-series ions (bottom) are shown in the mass spectrum. Theoretical $\mathrm{m} / \mathrm{z}$-values for the observed B- and $\mathrm{Y}$-series ions are shown in the structure on top.

Table S8. ${ }^{1} \mathrm{H}$ and ${ }^{13} \mathrm{C}$ NMR-data (600 and $150 \mathrm{MHz}$, resp) for compound $8\left(\mathrm{DMSO}^{-} \mathrm{d}_{6}, 30^{\circ} \mathrm{C}\right)$

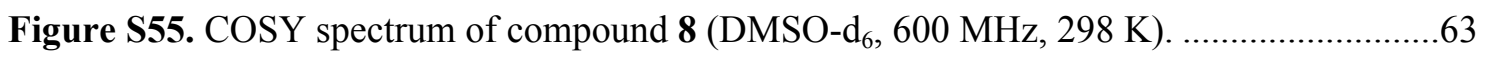

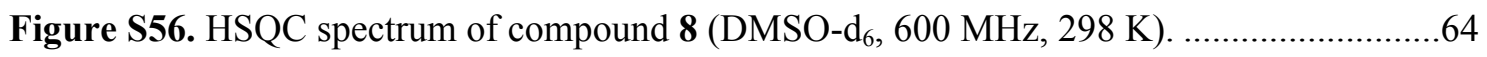

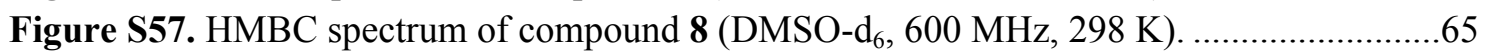




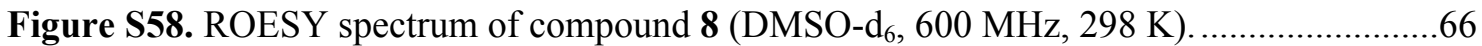

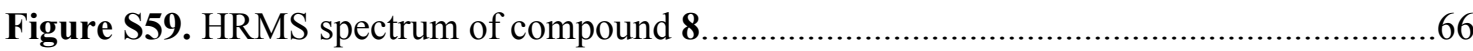

Figure S60. MSMS spectrum of compound 8 after treatment with $\mathrm{NaOMe}$ in $\mathrm{MeOH}$. Mass differences between Y-series ions (top) and B-series ions (bottom) are shown in the mass spectrum. Theoretical $\mathrm{m} / \mathrm{z}$-values for the observed $\mathrm{B}$ - and $\mathrm{Y}$-series ions are shown in the structure on top.

Table S9. Retention times from advanced Marfey's analysis of compounds 1-8 .68 


\section{METHODS}

General. Optical rotation was measured on a PerkinElmer 341, with samples dissolved in $\mathrm{MeOH}$ at room temperature $\left(20^{\circ} \mathrm{C}\right)$. UV spectra were recorded on a Hitachi U-2001 spectrophotometer in $\mathrm{MeOH}$ at room temperature. ${ }^{1} \mathrm{H}$ and ${ }^{13} \mathrm{C}$ NMR data were acquired in DMSO- $d_{6}$ or $\mathrm{CHCl}_{3}-d$ on a Bruker Avance III $600 \mathrm{MHz}$ NMR spectrometer (Bruker Biospin GmBH, Rheinstetten, Germany) equipped with a $5 \mathrm{~mm}$ cryoprobe $\left({ }^{1} \mathrm{H},{ }^{13} \mathrm{C},{ }^{15} \mathrm{~N},{ }^{31} \mathrm{P}\right)$. Standard pulse sequences supplied by the manufacturer were used for determination of ${ }^{1} \mathrm{H}$ and ${ }^{13} \mathrm{C}$ frequencies and connectivities. For structure analysis, 1D ${ }^{1} \mathrm{H}, \mathrm{COSY}$, TOCSY, DEPT-HSQC, HSQC-TOCSY and HMBC were applied. Chemical shifts were determined relative to internal DMSO- $d_{5}\left(\delta_{\mathrm{C}} 39.51 ; \delta_{\mathrm{H}}\right.$ 2.50) or internal chloroform $\left(\delta_{\mathrm{C}} 77.23 ; \delta_{\mathrm{H}} 7.27\right)$. HR-ESIMS and MSMS were performed on a maXis Impact Q-TOF MS (Bruker Daltonic GmbH, Bremen, Germany) connected to an Agilent 1290 Infinity II UHPLC (Agilent, Palo Alto, CA, USA). Preparative HPLC was run on a Gilson 306/306 pump system (Gilson Inc., Middleton, WI, USA) with a Gilson 119 UV/vis detector monitoring at 210 $\mathrm{nm}$ and fractions were collected with a Gilson 204 fraction collector, in polypropylene $2.2 \mathrm{~mL}$ square well plates (VWR, Radnor, PA, USA). HPLC gradient grade MeCN (Sigma-Aldrich, St. Louis, MO, USA) and deionized filtered water (Millipore, Billerica, MA, USA) were used for preparation of HPLC and UHPLC solvents.

Isolation and identification of Pedobacter cryoconitis UP508. The bacterial strain UP508 was isolated from a soil sample collected at the esker Kronåsen, at Ultuna, Uppsala, Sweden $\left(59^{\circ} 49^{\prime} 07.2^{\prime \prime} \mathrm{N}, 17^{\circ} 39^{\prime} 55.6^{\prime \prime} \mathrm{E}\right)$, by pressing a sterile $50 \mathrm{~mL}$ centrifuge tube into the soil surface. Approximately $4 \mathrm{~g}$ of the soil sample was vortexed thoroughly with $40 \mathrm{~mL}$ of sterile PBS and the mixture was allowed to settle for ten minutes. Then, $1 \mathrm{~mL}$ of the supernatant was mixed with $9 \mathrm{~mL}$ of sterile PBS in a $15-\mathrm{mL}$ centrifuge tube. From this dilution, $0.1 \mathrm{~mL}$ was spread onto NBCA isolation plates [Difco Nutrient Broth, 1g/L (Becton Dickinson: BD), Bacto Casamino Acids, 1g/L (BD), Bacto Agar, $15 \mathrm{~g} / \mathrm{L}$ (Saveen \& Werner), cycloheximide $100 \mathrm{mg} / \mathrm{L}$, nystatin $10 \mathrm{mg} / \mathrm{L}$, in deionized water] supplemented with $20 \mathrm{mg} / \mathrm{L}$ of ampicillin (AMP), kanamycin (KAN) and nalidixic acid (NAL). The plates were then incubated at $20^{\circ} \mathrm{C}$ for approximately one week in darkness. Selected bacterial 
colonies were restreaked on Vegetable Peptone Broth Agar (VPA) comprising one third strength Vegetable Peptone Broth (VPB10), 10g/L (Oxoid) and Bacto Agar, 15g/L (Saveen \& Werner) in deionized water, and one of the purified strains was denoted UP508. The strain was afterwards maintained as deep-frozen $\left(-70^{\circ} \mathrm{C}\right)$ cell stocks and transferred to VPA plates prior to culturing.

The isolate UP508 was found to be closest related to P. cryoconitis A37 ( $\geq 99 \%)$ by sequencing the 16S rRNA gene. In short, colony PCR amplification of the 16S rRNA gene was performed with the universal bacterial primers 27F (AGAGTTTGATCMTGGCTCAG) and 1492R (TACGGYTACCTTGTTACGACTT) followed by PCR-purification (QIAquick PCR purifications kit, QIAGEN) and sequencing of the PCR-products (EZ-sequencing, Macrogen). The resulting DNA sequencing chromatograms were manually trimmed and assembled using the Geneious R8 software (Biomatters Ltd., Auckland, New Zealand). The resulting sequence was then submitted to an online Nucleotide BLAST search (https://blast.ncbi.nlm.nih.gov/Blast.cgi) against 16S rRNA sequences (Bacteria and Archeae) to retrieve the closest possible identity of the isolate.

Culture Conditions and Metabolite Sampling. P. cryoconitis UP508 was cultivated in half strength Vegetable Peptone Broth [VPB15, 15 g VPB (Oxoid Ltd) in 1 L deionised water]. Initially, one $150-\mathrm{mL}$ culture in a 500-mL E-flask was studied, and for production of larger amounts of metabolites, the isolate was cultured in half strength VPB $(14$ cultures $\times 300 \mathrm{~mL}$ in $1 \mathrm{~L}$ Erlenmeyer flasks). The cultures were started by transferring a loop $(10 \mu \mathrm{L})$ of $24-48 \mathrm{~h}$-old bacterial colonies grown on VPA plates. Cultures were incubated on a rotary shaker $(130 \mathrm{rpm})$ for $7 \mathrm{~d}$ at $20{ }^{\circ} \mathrm{C}$ in darkness. To collect extracellular metabolites sterile nylon mesh bags containing a polymeric resin, Sepabeads ${ }^{\circledR}$ SP850 (Mitsubishi Chemical Co., Tokyo, Japan), were submerged in actively growing cultures, approximately 16 to 24 hours after inoculation (approximately $8 \mathrm{~g}$ of resin per bag for 150 $\mathrm{mL}$ and $15 \mathrm{~g}$ per bag for 300-mL cultures).

Isolation of compounds 1-8. The resin bag from the 150-mL culture of P. cryoconitis UP508 was washed with de-ionized water, extracted with $2 \times 10 \mathrm{~mL} \mathrm{MeOH}$ and $2 \times 10 \mathrm{~mL} \mathrm{MeCN}$ under sonication, and the pooled extract was dried in a vacuum centrifuge. The dried extract was dissolved 
in $1 \mathrm{~mL} 50 \% \mathrm{MeCN}$, centrifuged and then fractionated by preparative reversed-phase HPLC $(1 \mathrm{~mL}$ injected, Hypersil Gold column, $21 \times 100 \mathrm{~mm}, 5 \mu \mathrm{m})$ using a gradient of $\mathrm{MeCN}$ in water $(10-95 \%$ in $10 \mathrm{~min}, 95 \%$ for $10 \mathrm{~min}, 0.2 \%$ formic acid, $10 \mathrm{~mL} / \mathrm{min}$ ), and $2-\mathrm{mL}$ fractions were collected. The collected fractions were subjected to bioassays and UHPLC-MS analysis. Many fractions, including fractions 23-25 (1 and 2), were subjected to another round of chromatography on the same column, solvents and flow-rate, and for 1 and 2 the gradient was $20-90 \% \mathrm{MeCN}$ in $10 \mathrm{~min}$, followed by $90 \%$ for $10 \mathrm{~min}$, which gave ca 0.4 and $0.5 \mathrm{mg}$ of $\mathbf{1}$ and $\mathbf{2}$, respectively, in semi-pure form. For isolation of more of each compound, the isolation procedure was improved and used on many batches of culture extracts. The description below is representative for the procedure, but the yield of the different compounds differed between batches.

Adsorbent bags from 14 cultures of $P$. cryoconitis UP508 (each $300 \mathrm{~mL}$ in 1-L E-flasks) were extracted with $2 \times 300 \mathrm{~mL} \mathrm{MeOH}(0.2 \%$ formic acid $)$ and $2 \times 300 \mathrm{~mL} \mathrm{MeCN}(0.2 \%$ formic acid $)$ under sonication, and the combined extract was dried under reduced pressure. The extract was dissolved in $15 \mathrm{~mL} \mathrm{50 \%} \mathrm{MeCN} \mathrm{(aq),} \mathrm{centrifuged} \mathrm{(15} 000 \mathrm{rpm}, 5 \mathrm{~min}$ ) and fractionated (HPLC1) on preparative reversed-phase HPLC $(14 \times 1 \mathrm{~mL}$ injected, Luna Omega column, $21 \times 100 \mathrm{~mm}, 5 \mu \mathrm{m})$ using a gradient of $\mathrm{MeCN}$ in water (15-50\% in $15 \mathrm{~min}, 50-95 \%$ in $2 \mathrm{~min}, 95 \%$ for $4 \mathrm{~min}, 0.2 \%$ formic acid), and 2-mL fractions were collected. The following antibacterial fractions were collected and pooled based on results from bioassays and UHPLC-MS analysis (as below): 57-59 (2), 60-65 (1, 3, and 4), 66-70 (5-7), and 71-75 (8). Compounds 1-8 were purified further (HPLC2) using the same column, solvents and flow-rate, but with gradient $20-40 \% \mathrm{MeCN}$ in $17 \mathrm{~min}$ followed by a hold at $40 \% \mathrm{MeCN}$ (for compounds 1, 3-8), or with gradient 15-65\% $\mathrm{MeCN}$ in $17 \mathrm{~min}$, followed by a hold at 65\% MeCN (2). As guided by UHPLC-MS, fractions containing compounds $\mathbf{1 - 8}$ were pooled and dried. The compounds were further purified (HPLC3) on the same column, solvents and flow-rate, with gradient 20-37.5\% $\mathrm{MeCN}$ in $17 \min (\mathbf{1}$ and $\mathbf{3})$, or $20-40 \% \mathrm{MeCN}$ in $17 \min (\mathbf{2}$ and $\mathbf{4})$, or 20-75\% $\mathrm{MeCN}$ in $17 \mathrm{~min}(\mathbf{5})$, or 20-80\% $\mathrm{MeCN}$ in $17 \mathrm{~min}$ (6 and 7), or 20-35\% $\mathrm{MeCN}$ in $25 \mathrm{~min}, 37.5-$ $42.5 \%$ in $8 \mathrm{~min}, 42.5-75 \%$ in $6 \min (\mathbf{8})$. Fractions were analysed by UHPLC-MS, pooled, dried and weighed, which resulted in $7.95 \mathrm{mg}$ of $\mathbf{5}, 5.49 \mathrm{mg}$ of $\mathbf{6}, 3.87 \mathrm{mg}$ of $\mathbf{7}$, and $5.35 \mathrm{mg}$ of $\mathbf{8}$. Compounds 
1-4 were subjected to one final round of chromatography on the same column, solvents and flow-rate, with gradient $17.5-40 \% \mathrm{MeCN}$ in $17 \min (\mathbf{1}, \mathbf{3}$ and 4), or 20-37.5\% $\mathrm{MeCN}$ in $17 \min (\mathbf{2})$. After UHPLC-MS, fractions with the individual compounds were pooled, dried and weighed, to give 0.66 $\mathrm{mg}$ of $\mathbf{1}, 1.28 \mathrm{mg}$ of $\mathbf{2}, 1.97 \mathrm{mg}$ or $\mathbf{3}$, and $0.70 \mathrm{mg}$ of $\mathbf{4}$.

In Vitro Bioassay of chromatographic fractions. Antimicrobial activity of chromatographic fractions was assayed according to an earlier described protocol ("Microtiter plate assay 2 "), ${ }^{1}$ which is based on inhibition of cell growth or spore germination in microtiter plates. The following organisms were used for the bioassays: Escherichia coli LMG15862, Acinetobacter baumannii LMG1041 ${ }^{\mathrm{T}}$, Enterobacter cloacae LMG2783 ${ }^{\mathrm{T}}$, Klebsiella pneumoniae LMG20218, Pseudomonas aeruginosa LMG6395, Staphylococcus aureus LMG15975, Candida albicans H-29 and Aspergillus fumigatus J7. The bacterial isolates originated from the Belgian Co-ordinated Collections of Micro-organisms, Gent, Belgium, whereas the origin of the strains of the yeast Candida albicans and the fungus Aspergillus fumigatus Fres., was as previously described. ${ }^{2}$ In short, aliquots of HPLC fractions were transferred to 96-well microtiter plates and the solvent was evaporated in a fume-hood overnight. Cell suspensions (all bacterial strains and C. albicans) or spore suspensions (A. fumigatus), $100 \mu \mathrm{L}$ at a concentration of $10^{4}$ cells/spores per $\mathrm{mL}$ in VPB for bacteria, malt extract (ME) for A. fumigatus, and yeast extract-malt extract medium $\left(\mathrm{ISP}^{3}\right)$ for $C$. albicans, were added to the wells and incubated at $37^{\circ} \mathrm{C}$ in the dark for 16 to $24 \mathrm{~h}$. The effect on the bacterial/fungal growth was estimated visually according to the following scale: 3 - full growth inhibition, 2 - intermediate growth inhibition, 1 weak growth inhibition, 0 - no growth inhibition. Positive controls were cell/spore suspensions only, and sterile medium was used as negative control.

UHPLC-MS and UHPLC-MSMS analysis. Culture extracts and fractions from preparative reversed-phase HPLC were analyzed by UHPLC-MS on a reversed-phase column $(2.1 \times 50 \mathrm{~mm}, 1.5$

\footnotetext{
${ }^{1}$ Thaning, C., Welch, C. J., Borowicz, J. J., Hedman, R., and Gerhardson, B. (2001) Suppression of Sclerotinia sclerotiorum apothecial formation by the soil bacterium Serratia plymuthica: identification of a chlorinated macrolide as one of the causal agents. Soil Biol. Biochem. 33, 1817-26.

${ }^{2}$ Levenfors, J. J., Hedman, R., Thaning, C., Gerhardson, B., Welch, C. J. (2004) Broad-spectrum antifungal metabolites produced by the soil bacterium Serratia plymuthica A 153. Soil. Biol. Biochem. 36, 677-685.

${ }^{3}$ Shirling, E. B. and Gottlieb, D. (1966) Methods for characterization of Streptomyces species. Int. J. Syst. Bacteriol. 16, 313-340.
} 
$\mu \mathrm{m}$, Accucore Vanquish, Thermo Scientific) using a gradient of MeCN in water, both with $0.2 \%$ formic acid (10-95\% $\mathrm{MeCN}$ in $3 \mathrm{~min}, 95 \% \mathrm{MeCN}$ for $1.2 \mathrm{~min}$, at $0.9 \mathrm{~mL} / \mathrm{min})$. The MS was operated in positive mode with scanning of $\mathrm{m} / \mathrm{z} 50-1500$, and the mass spectra were calibrated against sodium formate clusters.

Before MSMS analysis of compound 1-8, each compound (ca $100 \mu \mathrm{g}$ ) was treated with $300 \mu \mathrm{L}$ $1 \% \mathrm{NaOMe}$ in $\mathrm{MeOH}$ for $20 \mathrm{~min}$ at room temperature, and the reaction was stopped by the addition of $30 \mu \mathrm{L} 2 \mathrm{M} \mathrm{HCl}$ (aq). The samples were analysed by UHPLC-MS as above, but with the gradient $30-60 \% \mathrm{MeCN}$ in $3 \mathrm{~min}(0.9 \mathrm{~mL} / \mathrm{min})$, and MSMS was run in automatic precursor selection mode with $22 \mathrm{eV}$ fragmentation energy.

Advanced Marfey's analysis. ${ }^{4,5}$ Samples of compound 1-8 $(2 \times 100 \mu \mathrm{g}$ each $)$ were hydrolysed in $6 \mathrm{M} \mathrm{HCl}(\mathrm{aq})$ at $120^{\circ} \mathrm{C}$, in evacuated glass ampoules, for $17 \mathrm{~h}$ and $45 \mathrm{~h}$, respectively. The ampoules were opened and the solutions dried under $\mathrm{N}_{2}$ in plastic $1.5-\mathrm{mL}$ tubes. Each sample was then treated with $36 \mu \mathrm{L} 1 \mathrm{M} \mathrm{NaHCO}_{3}$ and $180 \mu \mathrm{L}$ L-FDLA $\left(10 \mathrm{mg} / \mathrm{mL}\right.$ acetone) for $1 \mathrm{~h}$ in $40^{\circ} \mathrm{C}$, and then $20 \mu \mathrm{L} 2$ $\mathrm{M} \mathrm{HCl}$ (aq) was added. Following dilution with $500 \mu \mathrm{L} \mathrm{MeOH}$, the samples ( $2 \mu \mathrm{L}$ injected) were analysed by UHPLC-MS on the same column as above, using $\mathrm{MeCN} / \mathrm{H}_{2} \mathrm{O}$ with $0.2 \%$ formic acid, but with the gradient $30-60 \% \mathrm{MeCN}$ in $6 \mathrm{~min}$ at $0.9 \mathrm{~mL} / \mathrm{min}$. Extracted-ion chromatograms corresponding the $[\mathrm{M}+\mathrm{H}]^{+}$ions of the FDLA derivatives of Asp, OHVal, Val, Phe, DAPA, Thr, ABA, DABA and Leu were constructed and compared with corresponding chromatograms obtained by analysing D/L-FDLA derivatives of commercial reference amino acids. To evaluate possible racemization of amino acids during the hydrolysis, selected samples were hydrolysed in $6 \mathrm{M} \mathrm{HCl}$ in $\mathrm{H}_{2} \mathrm{O} / \mathrm{D}_{2} \mathrm{O}(1: 1)$, and then derivatized and analysed as above.

\footnotetext{
${ }^{4}$ Harada, K., Fujii, K., Mayumi, T., Hibino, Y., Suzuki, M., Ikai, Y., and Oka, H. (1995) Constituent Amino Acids in Peptide --- Advanced Marfey's Method. Tetrahedron Lett. 36, 1515-1518.

${ }^{5}$ Fujii, K., Ikai, Y., Mayumi, T., Oka, H., Suzuki, M., and Harada, K. (1997) A Nonempirical Method Using LC/MS for Determination of the Absolute Configuration of Constituent Amino Acids in a Peptide: Elucidation of Limitations of Marfey's Method and of Its Separation Mechanism. Anal. Chem. 69, 3346-3352.
} 
Mosher's ester analysis. ${ }^{6}$ A sample of 1 ( $6 \mathrm{mg}$ ) was hydrolysed in $300 \mu \mathrm{L} 6 \mathrm{M} \mathrm{HCl}(\mathrm{aq})$, in an evacuated glass ampoule, at $120^{\circ} \mathrm{C}$ for $6 \mathrm{~h}$. The ampoule was opened and the sample was dried under $\mathrm{N}_{2}$ in a 1.5-mL plastic tube. The sample was dissolved in $\mathrm{H}_{2} \mathrm{O}(0.5 \mathrm{~mL})$ and extracted with EtOAc (2 $\times 0.5 \mathrm{~mL}$ ). The combined EtOAc extracts were split into two equal portions in 1.5-mL HPLC vials, and the samples were dried under $\mathrm{N}_{2}$. After dissolving each sample in $600 \mu \mathrm{L}$ dry pyridine- $d_{5}$, one of the two samples obtained from 1 was treated with $5 \mu \mathrm{L}(R)$-MTPA-Cl and the other sample with $5 \mu \mathrm{L}$ (S)-MTPA-Cl. The reactions were kept at room temperature for $6 \mathrm{~h}$ and were then analysed by NMR at $30^{\circ} \mathrm{C}$ without any further purification. Additionally, the samples were dried under $\mathrm{N}_{2}$ and then analysed by $\mathrm{NMR}$ in $\mathrm{CHCl}_{3}-d$.

Isopedopeptin A (1): off-white solid; [ $\alpha]_{\mathrm{D}}^{20}-66^{\circ}$ (c 0.3 in methanol); $\mathrm{UV}(\mathrm{MeOH}) \lambda_{\max }\left(\log _{10} \varepsilon\right)$ 240 (4.0); ${ }^{1} \mathrm{H}$ NMR (DMSO- $d_{6}, 600 \mathrm{MHz}$ ), see Table S1; ${ }^{13} \mathrm{C}$ NMR (DMSO- $d_{6}, 150 \mathrm{MHz}$ ), see Table S1; ESI-QTOFMS $m / z 566.3243[\mathrm{M}+2 \mathrm{H}]^{2+}$ (calcd for $\left.\mathrm{C}_{53} \mathrm{H}_{88} \mathrm{~N}_{12} \mathrm{O}_{15}{ }^{2+} 566.3241\right)$.

Isopedopeptin B (2): off-white solid; $[\alpha]_{\mathrm{D}}^{20}-58^{\circ}$ (c 0.2 in methanol); $\mathrm{UV}(\mathrm{MeOH}) \lambda_{\max }\left(\log _{10} \varepsilon\right)$ 240 (4.1); ${ }^{1} \mathrm{H}$ NMR (DMSO- $d_{6}, 600 \mathrm{MHz}$ ), see Table S2; ${ }^{13} \mathrm{C}$ NMR (DMSO- $d_{6}, 150 \mathrm{MHz}$ ), see Table S2; ESI-QTOFMS $m / z 559.3169[\mathrm{M}+2 \mathrm{H}]^{2+}$ (calcd for $\mathrm{C}_{52} \mathrm{H}_{86} \mathrm{~N}_{12} \mathrm{O}_{15}{ }^{2+}$ 559.3163).

Isopedopeptin C (3): off-white solid; [ $\alpha]_{\mathrm{D}}^{20}-68^{\circ}$ (c 0.3 in methanol); $\mathrm{UV}(\mathrm{MeOH}) \lambda_{\max }\left(\log _{10} \varepsilon\right)$ 240 (4.0); ${ }^{1} \mathrm{H}$ NMR (DMSO- $d_{6}, 600 \mathrm{MHz}$ ), see Table S3; ${ }^{13} \mathrm{C}$ NMR (DMSO- $d_{6}, 150 \mathrm{MHz}$ ), see Table S3; ESI-QTOFMS $m / z 572.3246[\mathrm{M}+2 \mathrm{H}]^{2+}\left(\right.$ calcd for $\mathrm{C}_{54} \mathrm{H}_{88} \mathrm{~N}_{12} \mathrm{O}_{15}{ }^{2+}$ 572.3241).

Isopedopeptin D (4): off-white solid; $[\alpha]_{\mathrm{D}}^{20}-62^{\circ}$ (c 0.2 in methanol); $\mathrm{UV}(\mathrm{MeOH}) \lambda_{\max }\left(\log _{10} \varepsilon\right)$ 240 (3.9); ${ }^{1} \mathrm{H}$ NMR (DMSO- $d_{6}, 600 \mathrm{MHz}$ ), see Table S4; ${ }^{13} \mathrm{C}$ NMR (DMSO- $d_{6}, 150 \mathrm{MHz}$ ), see Table S4; ESI-QTOFMS $m / z 551.3194[\mathrm{M}+2 \mathrm{H}]^{2+}\left(\right.$ calcd for $\left.\mathrm{C}_{52} \mathrm{H}_{86} \mathrm{~N}_{12} \mathrm{O}_{14}{ }^{2+} 551.3188\right)$.

\footnotetext{
${ }^{6}$ Dale, J. A. and Mosher, H. S. (1973) Nuclear magnetic resonance enantiomer reagents. Configurational correlation via nuclear magnetic resonance chemical shifts of diastereomericmandelate, O-methylmandelate, and $\alpha$-methoxy- $\alpha$-trifluorophenylacetate (MTPA) esters. J. Am. Chem. Soc. 95, 512-519.
} 
Isopedopeptin $E$ (5): off-white solid; [ $\alpha]_{\mathrm{D}}^{20}-36^{\circ}$ (c 0.3 in methanol); $\mathrm{UV}(\mathrm{MeOH}) \lambda_{\max }\left(\log _{10} \varepsilon\right)$ 240 (3.8); ${ }^{1} \mathrm{H}$ NMR (DMSO- $d_{6}, 600 \mathrm{MHz}$ ), see Table S5; ${ }^{13} \mathrm{C}$ NMR (DMSO- $d_{6}, 150 \mathrm{MHz}$ ), see Table S5; ESI-QTOFMS $m / z 558.3275[\mathrm{M}+2 \mathrm{H}]^{2+}$ (calcd for $\mathrm{C}_{53} \mathrm{H}_{88} \mathrm{~N}_{12} \mathrm{O}_{14}{ }^{2+} 558.3266$ ).

Isopedopeptin $F$ (6): off-white solid; $[\alpha]_{\mathrm{D}}^{20}-32^{\circ}$ (c 0.05 in methanol); $\mathrm{UV}(\mathrm{MeOH}) \lambda_{\max }\left(\log _{10} \varepsilon\right)$ 240 (3.8); ${ }^{1} \mathrm{H}$ NMR (DMSO- $d_{6}, 600 \mathrm{MHz}$ ), see Table S6; ${ }^{13} \mathrm{C}$ NMR (DMSO- $d_{6}, 150 \mathrm{MHz}$ ), see Table S6; ESI-QTOFMS $m / z 580.3401[\mathrm{M}+2 \mathrm{H}]^{2+}$ (calcd for $\mathrm{C}_{55} \mathrm{H}_{92} \mathrm{~N}_{12} \mathrm{O}_{15}{ }^{2+}$ 580.3397).

Isopedopeptin $G$ (7): off-white solid; [ $\alpha]_{\mathrm{D}}^{20}-49^{\circ}$ (c 0.1 in methanol); $\mathrm{UV}(\mathrm{MeOH}) \lambda_{\max }\left(\log _{10} \varepsilon\right)$ 240 (4.0); ${ }^{1} \mathrm{H}$ NMR (DMSO- $d_{6}, 600 \mathrm{MHz}$ ), see Table S7; ${ }^{13} \mathrm{C}$ NMR (DMSO- $d_{6}, 150 \mathrm{MHz}$ ), see Table S7; ESI-QTOFMS $m / z 571.3356[\mathrm{M}+2 \mathrm{H}]^{2+}$ (calcd for $\mathrm{C}_{55} \mathrm{H}_{90} \mathrm{~N}_{12} \mathrm{O}_{14}{ }^{2+}$ 571.3345).

Isopedopeptin $H$ (8): off-white solid; $[\alpha]_{\mathrm{D}}^{20}-56^{\circ}$ (c 0.2 in methanol); $\mathrm{UV}(\mathrm{MeOH}) \lambda_{\max }\left(\log _{10} \varepsilon\right)$ 240 (4.0); ${ }^{1} \mathrm{H}$ NMR (DMSO- $d_{6}, 600 \mathrm{MHz}$ ), see Table S8; ${ }^{13} \mathrm{C}$ NMR (DMSO- $d_{6}, 150 \mathrm{MHz}$ ), see Table S8; ESI-QTOFMS $m / z 571.3348[\mathrm{M}+2 \mathrm{H}]^{2+}$ (calcd for $\mathrm{C}_{55} \mathrm{H}_{90} \mathrm{~N}_{12} \mathrm{O}_{14}{ }^{2+} 571.3345$ ).

\section{Minimal Inhibitory Concentration (MIC) against the primary panel of microorganisms.}

The MIC for compounds 1-8 was measured by means of a broth micro-dilution method in 96-wells microtiter plates with the addition of E. coli $\mathrm{LMG} 15862$, A. baumannii $\mathrm{LMG} 1041^{\mathrm{T}}$, E. cloacae LMG2783' , K. pneumoniae LMG20218, P. aeruginosa LMG6395, S. aureus LMG15975, C. albicans H-29 and A. fumigatus J7, as test organisms. The test media were AM3 Broth (BD Difco Ltd) mixed with phosphate buffered saline (PBS, Amresco LLC, Solon, USA) in 1:4 ratio (E. coli, A. baumannii, E. cloacae, K. pneumoniae and P. aeruginosa), AM3 Broth mixed with PBS in 1:1 ratio (S. aureus), ME (A. fumigatus) and ISP2 (C. albicans). Prior to MIC determination, the cell concentration of tested bacterial/fungal pathogens was adjusted to $\cong 4 \times 10^{5} \mathrm{CFU} / \mathrm{mL}$ (acceptable range $2-6 \times 10^{5}$ $\mathrm{CFU} / \mathrm{mL}$ ). Cell concentration was confirmed by colony counting after diluting and plating the respective bacterial pathogen on VPA plates [VPA, $10 \mathrm{~g}$ Vegetable Peptone Broth (Oxoid Ltd., Basingstoke,UK), $15 \mathrm{~g}$ Bacto Agar (Difco Ltd, Tyrone) in $1 \mathrm{~L}$ deionised water] directly after each of MIC-tests. The cells of C. albicans were plated on ISP2 agar plates [ISP2, $15 \mathrm{~g}$ Bacto Agar (Difco Ltd) in $1 \mathrm{~L}$ deionised water] and respectively spores of $A$. fumigatus were plated on MEA plates. 
Plates were, subsequently, incubated at $37{ }^{\circ} \mathrm{C}$ in the dark, and viable colonies counted after 16 to $24 \mathrm{~h}$. To estimate MIC values (concentration range between 0.05 and $50 \mu \mathrm{g} / \mathrm{mL}$ ), solutions of the tested compounds (100, 10 and 1 and if needed $0.1 \mu \mathrm{g} / \mathrm{mL}$ in $\mathrm{MeOH})$ were dispensed into wells of microtiter plate(s) and the solvent was evaporated in a fume-hood. Subsequently, suspensions of pathogen cells in the appropriate medium were dispensed to the wells of microtiter plates and the growth of pathogens were observed after 16 to $20 \mathrm{~h}$ of incubation at $37^{\circ} \mathrm{C}$ in the dark. Positive controls were the respective pathogen cells suspended in untreated sterile media without addition of compounds(s) and negative controls were the media only. MIC values were defined as the lowest concentration of each compound with no visible growth of pathogen. All MIC tests were performed in triplicate and repeated at least twice.

\section{MIC determination for compound 2 against an extended panel of bacterial strains.}

Compound 2 was evaluated against a panel of Gram-negative bacteria (Hughes strain collection), including: A. baumannii ATCC 19606, wild-type; BM4454, multidrug-resistant clinical isolate; BM4652, efflux-defective derivative of BM4454; CH9622, colistin-resistant clinical isolate; E. coli ATCC 25922, wild-type; CH3130, efflux-defective $\Delta$ tolC mutant isogenic to ATCC 25922; D22, a drug-hypersensitive lpxC mutant of E. coli; CH3491, multidrug-resistant clinical isolate; $\mathrm{CH} 9623$ and CH9624, colistin-resistant clinical isolates carrying mcr-1; K. pneumoniae ATCC 13833, wild-type; 1161486, wild-type; 1161486a, $\Delta$ tolC mutant isogenic to 1161486; CH3498, multidrug-resistant clinical isolate; CH9625 and CH9626, colistin-resistant clinical isolates; P. aeruginosa PAO1, wildtype; PAO750, efflux-defective mutant isogenic to PAO1. The in vitro antimicrobial activity of each compound was determined by measuring the MIC value using the broth micro-dilution technique in cation-adjusted Mueller-Hinton II broth (Becton-Dickinson, 212322) according to EUCAST and CLSI guidelines. Each compound prepared in MHII medium was dispensed into a 96-well roundbottomed microtiter plate to give final assay concentrations from $64 \mu \mathrm{g} / \mathrm{mL}$ down to $0.25 \mu \mathrm{g} / \mathrm{mL}$ (two-fold dilution series in 10 wells, plus two control wells: medium control with no bacteria or compound, and growth control with bacteria added but no compound). Bacteria were prepared from fresh colonies grown on non-selective MHII agar, then suspended in saline to 0.5 McFarland $(\cong 1.5 \times$ 
$10^{8} \mathrm{CFU} / \mathrm{mL}$ ) with turbidity assessed using a Sensititre Nephelometer (Trek Diagnostics Systems Ltd, UK). $50 \mu \mathrm{L}$ of this bacterial suspension was transferred to $10 \mathrm{~mL}$ of MHII broth to give a final bacterial concentration $\cong 5 \times 10^{5} \mathrm{CFU} / \mathrm{mL}$ (acceptable range $3-7 \times 10^{5} \mathrm{CFU} / \mathrm{mL}$ ). $50 \mu \mathrm{L}$ of bacterial suspension was pipetted into each well (except the medium control well, where $50 \mu \mathrm{L}$ MHII was pipetted). Final volume in each well was $100 \mu \mathrm{L}$. Plates were covered and incubated without shaking for $18-20 \mathrm{~h}$ at $35^{\circ} \mathrm{C} \pm 2{ }^{\circ} \mathrm{C}$. MIC was read visually, as complete inhibition of growth by the unaided eye, using the medium-only wells as the control. Each compound was assayed at least in duplicate. Additionally, the MIC for compound 2 against clinical carbapenem-resistant strains of $A$. baumannii (A219 and A250), E. coli (EC4129 and EC4163) and P. aeruginosa (PS826 and PS992), was determined at the Public Health Agency of Sweden (according to EUCAST recommendations).

In vitro Cytotoxicity Determination. In vitro cytotoxicity was determined by a fluorometric microculture cytotoxicity assay, ${ }^{7}$ based on hydrolysis of fluorescein diacetate to fluorescein by cells with intact plasma membranes. In short, HepG2 cells (hepatocellular carcinoma cells, ATCC), in Eagle's Minimum Essential Medium (ATCC) supplemented with $10 \%$ fetal bovine serum, penicillin/streptomycin (100 U/100 $\mu \mathrm{g} / \mathrm{mL})$ and $2 \mathrm{mM} \mathrm{L-glutamine,} \mathrm{were} \mathrm{seeded} \mathrm{in} \mathrm{384-well} \mathrm{assay}$ plates at a density of 1000 cells/well. The cells were incubated over night at $37^{\circ} \mathrm{C}$ and compounds in $10 \mathrm{mM}$ DMSO were added, to obtain final concentrations $64 \mu \mathrm{M}-0.25 \mu \mathrm{M}$ in two-fold dilutions. After incubation for $72 \mathrm{~h}$ at $37^{\circ} \mathrm{C}$, the cells were pelleted and washed. Fluorescein diacetate was added $(1 \mu \mathrm{L}, 0.5 \mathrm{mg} / \mathrm{mL})$ and the fluorescence $[485 \mathrm{~nm}(\mathrm{exc}) / 530 \mathrm{~nm}(\mathrm{em})$.$] was measured after 50$ min at $37^{\circ} \mathrm{C}$. Bortezomib $(2 \mu \mathrm{M})$ was used as positive control and dose response testing of doxorubicin (top concentration $2 \mu \mathrm{M}$ ) was performed repeatedly to follow assay performance over time. Cytotoxicity was assessed after $72 \mathrm{~h}$ with cell survival presented as survival index (SI, \%) defined as fluorescence in test wells in percent of control cultures with blank values subtracted. Criteria for a successful assay include a signal-to-noise ratio in control cultures $>10, \mathrm{CV}<30 \%$ and a

\footnotetext{
${ }^{7}$ Lindhagen, E., Nygren, P., and Larsson, R. (2008) The fluorometric microculture cytotoxicity assay. Nat. Protoc. 3, 1364-69.
} 
positive control (Bortezomib) SI of $<5 \%$. The half maximal inhibitory concentration $\left(\mathrm{IC}_{50}\right)$ was determined from log concentration-effect curves using non-linear regression analysis.

Frequency of resistance (FoR). For the determination of the FoR, the MIC of compound 2 was first evaluated on solid $\mathrm{MH}$-agar medium prepared in $35 \mathrm{~mm}$ diameter plates. Each plate contained $4 \mathrm{~mL}$ agar with the appropriate amount of compound. Bacterial cultures were grown and prepared as described for the MIC assay. $13 \mu \mathrm{L}$ of bacterial culture diluted to 0.5 MacFarland was inoculated into $1 \mathrm{~mL} 0.9 \% \mathrm{NaCl}$ resulting in $\sim 2 \times 10^{6} \mathrm{CFU} / \mathrm{mL} .5 \mu \mathrm{L}$ of this bacterial suspension was spotted onto the surface of each agar plate $\left(\sim 10^{4} \mathrm{CFU} /\right.$ spot $)$. Plates were sealed and incubated at $37^{\circ} \mathrm{C}$ for 18-20 hours. Agar MIC was recorded according to CLSI guidelines as the lowest concentration of antimicrobial agent that completely inhibits growth from these spots, disregarding a single colony or a faint haze caused by the inoculum. Then $9 \mathrm{~cm}$ plates were prepared with $25 \mathrm{~mL}$ MHII agar medium containing $4 \times$ or $8 \times$ solid MIC concentrations of test compounds and seeded with $100 \mu \mathrm{L}$ of a bacterial preparation, concentrated by centrifugation from overnight cultures and resuspended in $0.9 \%$ $\mathrm{NaCl}$, corresponding to $10^{8} \mathrm{CFU}$ and $10^{9} \mathrm{CFU}$ per plate, and spread on the agar using 4-5 glass beads of $4 \mathrm{~mm}$ diameter. Since CFU were evaluated using the McFarland turbidity standard, the exact CFU number plated was evaluated by plating of serial dilutions of each inoculum preparation on MHII agar plates. Plates were incubated at $37^{\circ} \mathrm{C}$ and colonies were counted at $24 \mathrm{~h}$ and $48 \mathrm{~h}$ post-plating. The frequencies of resistance were then calculated by counting the number of validated resistant colonies growing on antibiotic preparations divided by the evaluated number of CFU in the inoculum.

Hemolysis assay. Compounds were evaluated for hemolytic activity using red blood cells from heparinized human blood. Red blood cells (RBC) were washed three times in Tyrode buffer (130 mM $\mathrm{NaCl}, 4 \mathrm{mM} \mathrm{KCl}, 2.8 \mathrm{mM} \mathrm{NaOAc}, 1 \mathrm{mM} \mathrm{MgCl} 2,10 \mathrm{mM}$ HEPES, $10 \mathrm{mM}$ glucose, $1 \mathrm{mM} \mathrm{CaCl}$, adjusted to $\mathrm{pH}$ 7.4) and resuspended in the same buffer. Final concentrations in the hemolysis assay were: $100 \mu \mathrm{M}$ compound, $1 \% \mathrm{DMSO}$, and $50 \% \mathrm{RBC}$, assayed in a $200 \mu \mathrm{L}$ volume in a microtiter plate. The mixture was incubated at $37{ }^{\circ} \mathrm{C}$ for 45 min with shaking ( $250 \mathrm{rpm}$ ). After incubation, $\mathrm{RBCs}$ were removed by centrifugation $(1000 \times \mathrm{g}$ for $10 \mathrm{~min}), 100 \mu \mathrm{L}$ clear plasma was transferred to a fresh microtiter plate, and the amount of hemoglobin measured using a spectrophotometer at $540 \mathrm{~nm}$. The 
complete lysis control contained 2\% Triton X-100 (in Tyrode buffer) instead of compound; the negative control contained Tyrode buffer but no compound. Percent hemolysis was calculated as: [Abs compound] - [Abs negative control] / [Abs complete lysis control] - [Abs negative control] $\times$ 100. Values greater than $1 \%$ hemolysis at $100 \mu \mathrm{M}$ were regarded as a red flag.

Bacterial membrane permeabilization assay. Liposomes were manufactured and permeabilization assayed as described previously. ${ }^{8}$ Briefly, dry lipid films of E. coli polar lipid extract were formed on round-bottom flask walls. This was achieved by dissolving lipids in chloroform and evaporating the solvent under agitation and nitrogen gas flow, followed by incubation in vacuum chamber. Lipid films were re-suspended by $30 \mathrm{~min}$ stirring $\left(E\right.$. coli) at $55^{\circ} \mathrm{C}$ in an aqueous solution of $100 \mathrm{mM}$ 5(6)-carboxyfluorescein in $10 \mathrm{mM}$ Tris buffer (set to $\mathrm{pH} 7.4$ at $37^{\circ} \mathrm{C}$ ). Suspensions were subjected to repeated extrusion through a $100 \mathrm{~nm}$ pore size polycarbonate membrane in order to reduce multilamellar structures and polydispersity. Un-trapped carboxyfluorescein was removed by gel filtration. Membrane permeability was measured by monitoring carboxyfluorescein efflux from the liposomes to the external low concentration environment, resulting in loss of self-quenching and an increased fluorescence signal. The 96-well plates were prepared with a 2-fold serial dilution of the samples in Tris buffer, as well as negative controls (background) and 0.16\% Triton X-100 (maximum leakage). The plates were pre-heated to incubation temperature $\left(37^{\circ} \mathrm{C}\right)$ and administered a liposome suspension, to a final lipid concentration of $10 \mu \mathrm{M}$ in $200 \mu \mathrm{L}$. The effects of each sample concentration on the liposome system were monitored for $45 \mathrm{~min}$, at which point the leakage increment had largely subsided. Results shown represent the mean from four experiments with standard deviations and are expressed as percent of total leakage generated with Triton X-100 and subtraction of the baseline value. The $\mathrm{EC}_{50}$-values, fixed at $50 \%$ of total leakage, are calculated (where applicable) from a variable slope sigmoidal dose-response curve for the leakage percentage as a function of the sample concentration $(\log 10)$.

\footnotetext{
${ }^{8}$ Strömstedt, A. A., Kristiansen, P. E., Gunasekera, S., Grob, N., Skjeldal, L., and Göransson, U. (2016) Selective membrane disruption by the cyclotide kalata B7: complex ions and essential functional groups in the phosphatidylethanolamine binding pocket. Biochim. Biophys. Acta 1858, 1317-1327.
} 
Table S1. ${ }^{1} \mathrm{H}$ and ${ }^{13} \mathrm{C}$ NMR-data (600 and $150 \mathrm{MHz}$, resp) for compound $\mathbf{1}\left(\mathrm{DMSO}-\mathrm{d}_{6}, 30^{\circ} \mathrm{C}\right)$

\begin{tabular}{|c|c|c|c|c|c|c|c|}
\hline Pos. & ${ }^{13} \mathrm{C}$ & ${ }^{1} \mathbf{H}$ & Mult $(J, \mathrm{~Hz})$ & Pos. & ${ }^{13} \mathrm{C}$ & ${ }^{1} \mathbf{H}$ & Mult $(J, \mathrm{~Hz})$ \\
\hline 3OHFA & & & & Thr & & & \\
\hline 1 & 167.6 & - & - & NH & - & 8.42 & $\mathrm{~d}(7.6)$ \\
\hline \multirow[t]{2}{*}{2} & 39.4 & 2.69 & $\mathrm{dd}(13.8,3.5)$ & 1 & 169.4 & - & - \\
\hline & & 2.17 & $\mathrm{dd}(13.8,4.1)$ & 2 & 59.5 & 4.20 & $\mathrm{dd}(7.8,2.3)$ \\
\hline 3 & 70.7 & 4.97 & $\mathrm{~m}$ & 3 & 65.0 & 4.35 & $\mathrm{dq}(2.5,6.5)$ \\
\hline 4 & 31.2 & 1.49 & $\mathrm{~m}$ & 4 & 20.4 & 1.22 & $\mathrm{~d}(6.5)$ \\
\hline 5 & 26.1 & 1.20 & obsc & DAPA2 & & & \\
\hline 6 & 28.6 & 1.21 & obsc & NH & - & 8.18 & $\mathrm{~d}(8.7)$ \\
\hline 7 & 25.0 & 1.20 & obsc & 1 & 169.1 & - & - \\
\hline 8 & 38.0 & 1.12 & obsc & 2 & 53.2 & 4.22 & $\operatorname{ddd}(8.7,8.7,5.7)$ \\
\hline 9 & 27.0 & 1.49 & obsc & 3 & 40.6 & 3.04 & $\mathrm{dd}(13.1,5.7)$ \\
\hline 10 & 22.1 & 0.84 & $\mathrm{~d}(6.6)$ & & & 2.87 & obsc \\
\hline 11 & 22.1 & 0.84 & $\mathrm{~d}(6.6)$ & Phe & & & \\
\hline DAPA1 & & & & NH & - & 7.26 & $\mathrm{~d}(9.0)$ \\
\hline NH & - & 8.57 & $\mathrm{~d}(9.1)$ & 1 & 171.5 & - & - \\
\hline 1 & 170.8 & - & - & 2 & 53.5 & 4.76 & obsc \\
\hline 2 & 50.6 & 4.73 & obsc & 3 & 37.6 & 2.89 & obsc \\
\hline \multirow[t]{2}{*}{3} & 43.9 & 3.12 & $\mathrm{dd}(13.1,5.4)$ & & & 2.72 & obsc \\
\hline & & 2.97 & $\mathrm{dd}(13.1,4.1)$ & 4 & 137.2 & - & - \\
\hline Leu & & & & $5 / 9$ & 129.2 & 7.34 & $\mathrm{~m}$ \\
\hline NH & - & 8.89 & br s & $6 / 8$ & 127.6 & 7.21 & $\mathrm{~m}$ \\
\hline 1 & 173.1 & - & - & 7 & 125.8 & 7.15 & $\mathrm{~m}$ \\
\hline 2 & 52.8 & 4.33 & obsc & 3OHVal & & & \\
\hline \multirow[t]{2}{*}{3} & 39.1 & 1.65 & $\mathrm{~m}$ & NH & - & 8.59 & $\mathrm{~d}(9.6)$ \\
\hline & & 1.46 & $\mathrm{~m}$ & 1 & 169.4 & - & - \\
\hline 4 & 24.0 & 1.65 & obsc & 2 & 58.0 & 4.72 & obsc \\
\hline 5 & 22.2 & 0.88 & $\mathrm{~d}(6.2)$ & 3 & 70.6 & - & - \\
\hline 6 & 22.2 & 0.84 & $\mathrm{~d}(6.1)$ & 4 & 26.4 & 1.05 & $\mathrm{~s}$ \\
\hline$\overline{\text { DABA }}$ & & & & 5 & 26.5 & 0.92 & s \\
\hline NH & - & 8.65 & $\mathrm{~d}(9.3)$ & Asp & & & \\
\hline 1 & 168.0 & & - & NH & - & 8.52 & $d(9.6)$ \\
\hline 2 & 49.5 & 4.64 & ddd $(9.3,7.0,7.0)$ & 1 & 173.9 & - & - \\
\hline 3 & 29.2 & 1.82 & $\mathrm{~m}$ & 2 & 48.4 & 4.74 & obsc \\
\hline \multirow[t]{2}{*}{4} & 35.4 & 2.75 & $\mathrm{~m}$ & 3 & 40.5 & 2.84 & $\mathrm{dd}(16.1,4.5)$ \\
\hline & & 2.61 & $\mathrm{~m}$ & & & 2.23 & $\mathrm{~d}(16.1,3.8)$ \\
\hline $\mathbf{A B A}$ & & & & 4 & 174.4 & - & - \\
\hline NH & - & 10.22 & br s & & & & \\
\hline 1 & 165.4 & - & - & & & & \\
\hline 2 & 132.6 & - & - & & & & \\
\hline 3 & 114.1 & 5.57 & $\mathrm{q}(7.3)$ & & & & \\
\hline 4 & 12.5 & 1.77 & $\mathrm{~d}(7.3)$ & & & & \\
\hline
\end{tabular}




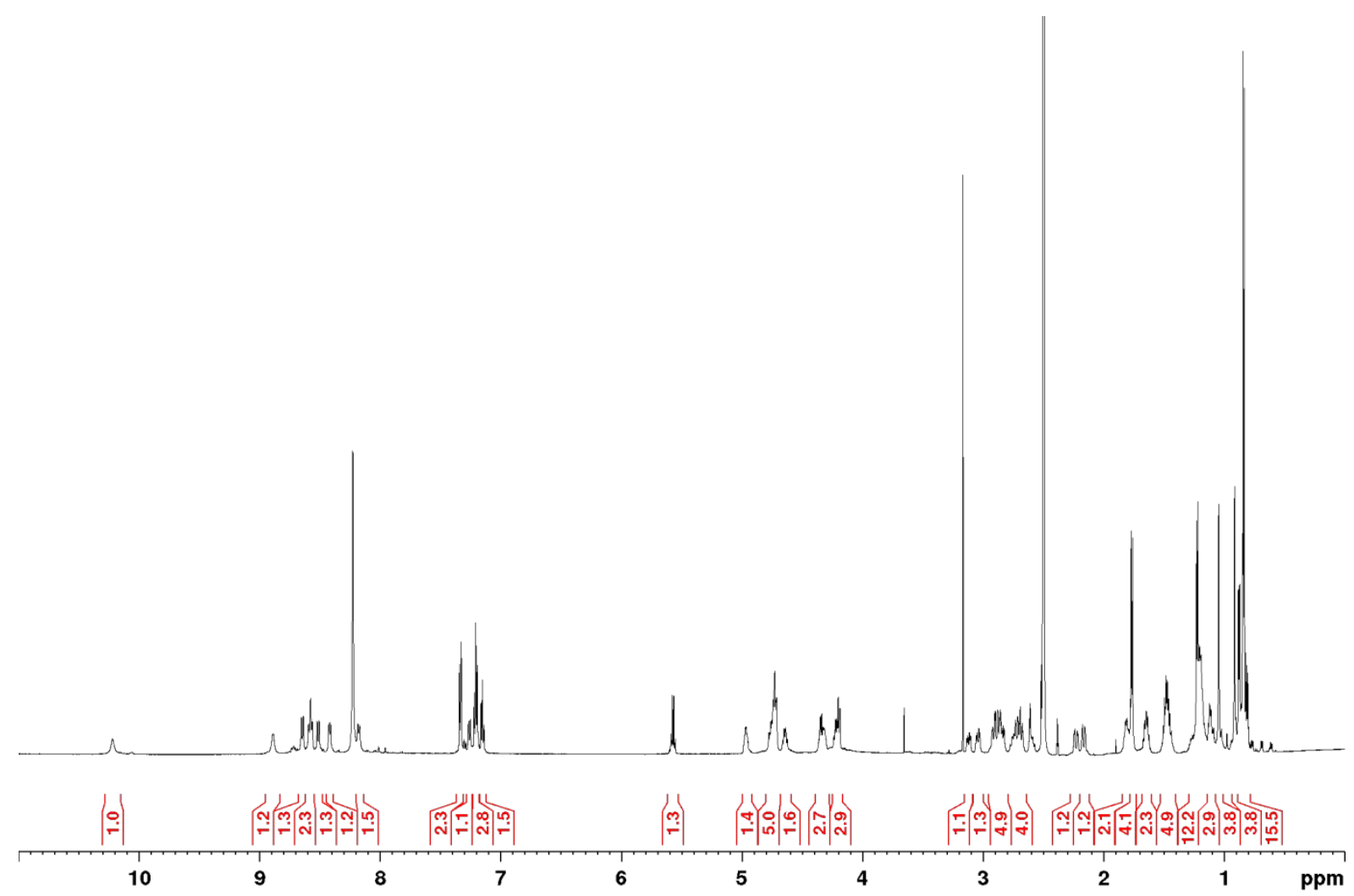

Figure S1. ${ }^{1} \mathrm{H}-\mathrm{NMR}$ spectrum of compound 1 (DMSO-d $\left.\mathrm{d}_{6}, 600 \mathrm{MHz}, 298 \mathrm{~K}\right)$.

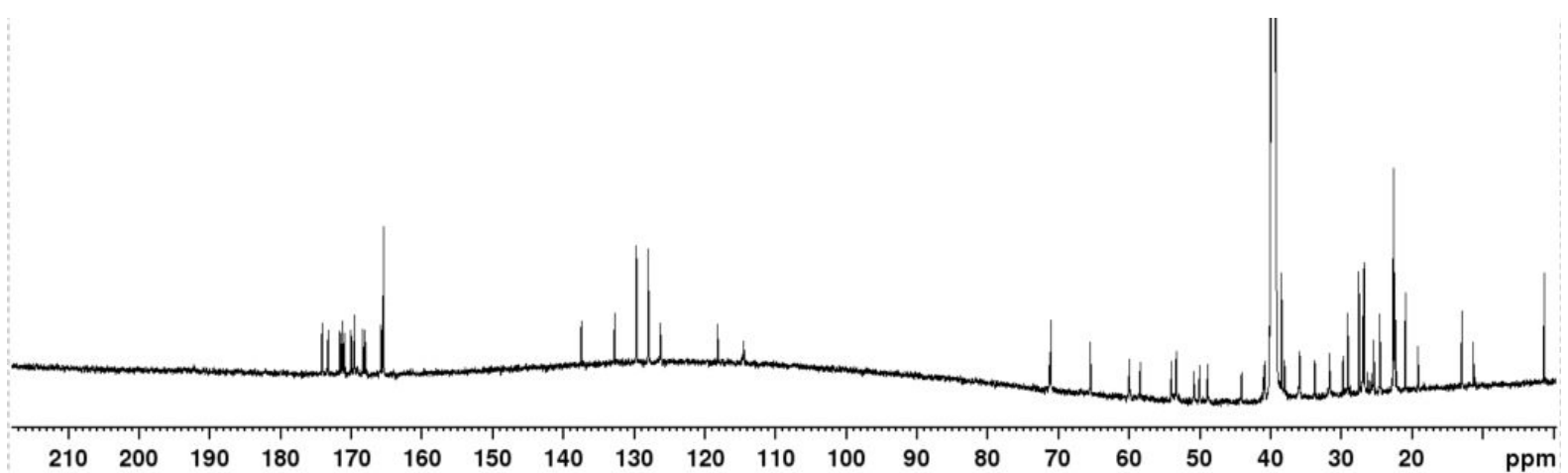

Figure S2. ${ }^{13} \mathrm{C}-\mathrm{NMR}$ spectrum of compound 1 (DMSO-d 6 , $\left.600 \mathrm{MHz}, 298 \mathrm{~K}\right)$. 
Supporting information

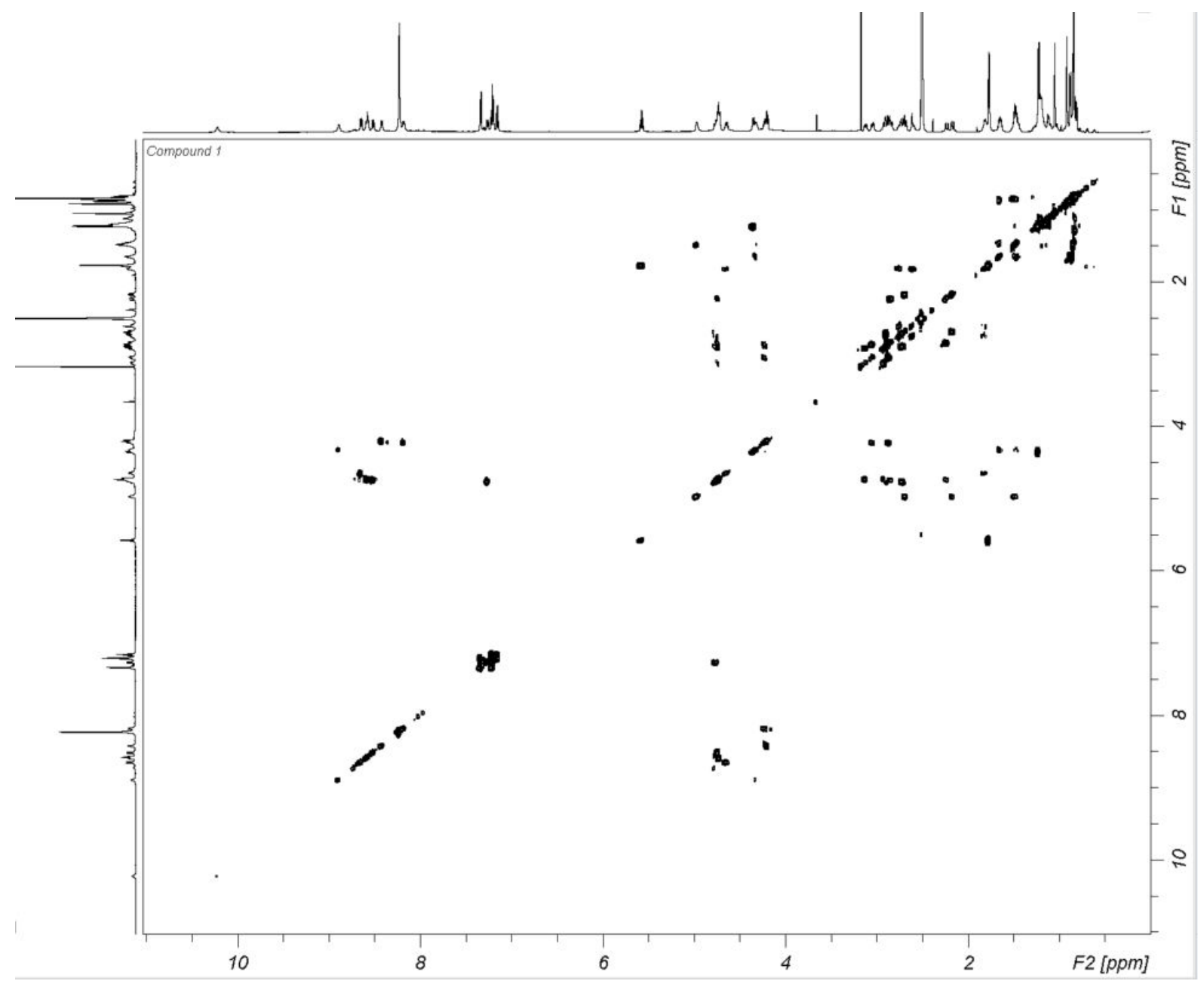

Figure S3. COSY spectrum of compound $1\left(\right.$ DMSO-d $\left._{6}, 600 \mathrm{MHz}, 298 \mathrm{~K}\right)$. 
Supporting information

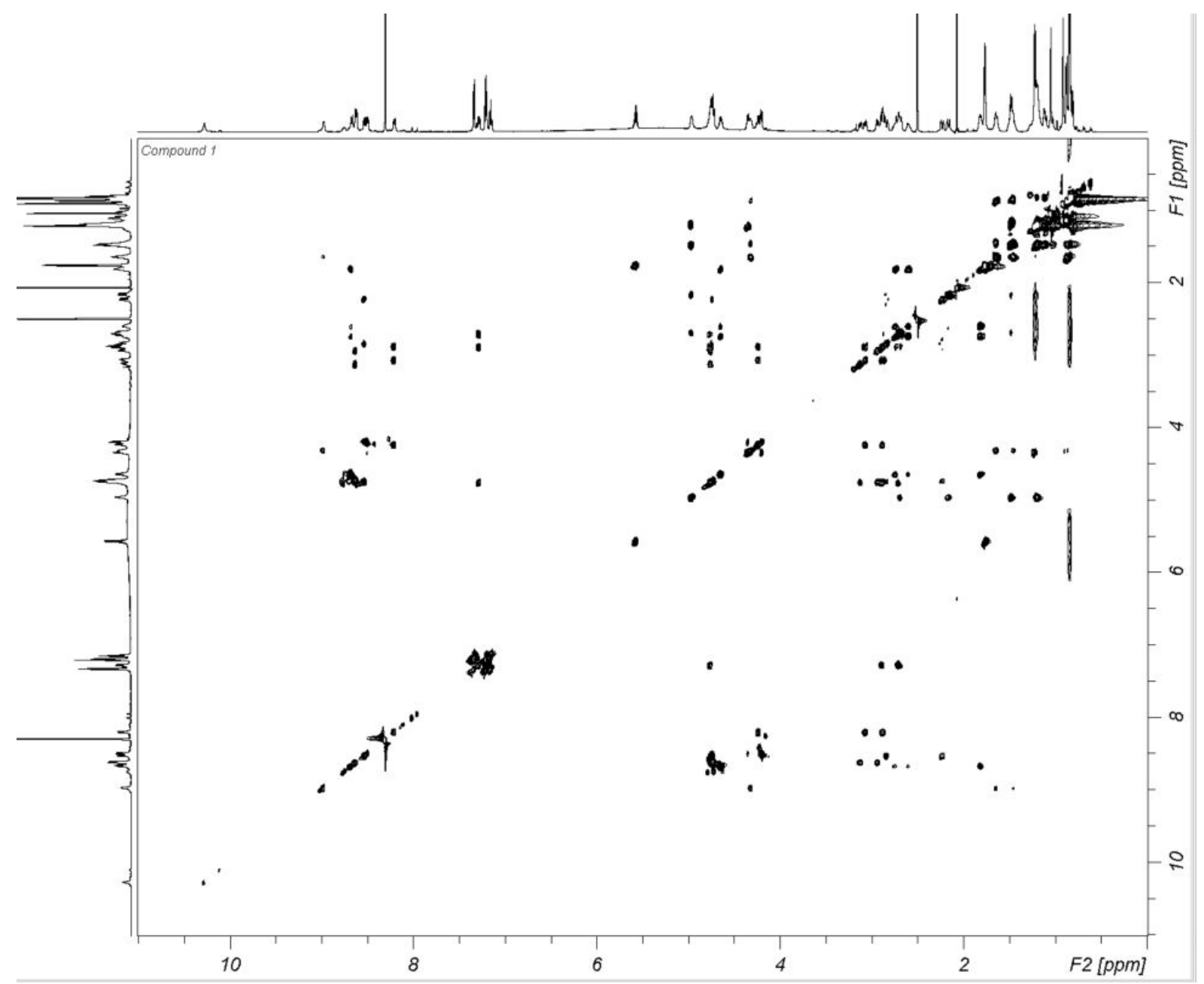

Figure S4. TOCSY spectrum of compound 1 (DMSO-d 6 , $600 \mathrm{MHz}, 298 \mathrm{~K})$. 
Supporting information

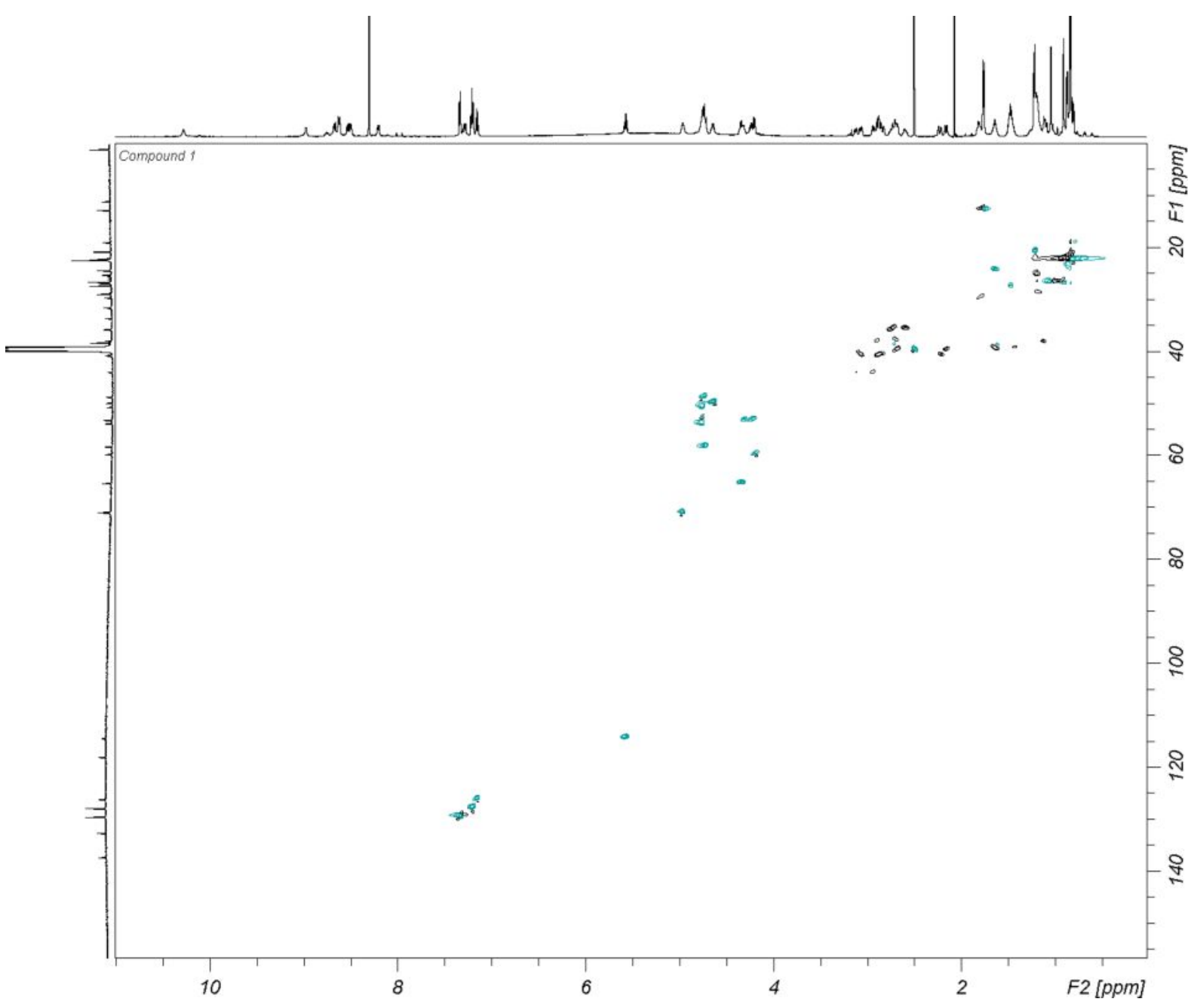

Figure S5. HSQC spectrum of compound 1 (DMSO-d 6 , 600 MHz, 298 K). 
Supporting information

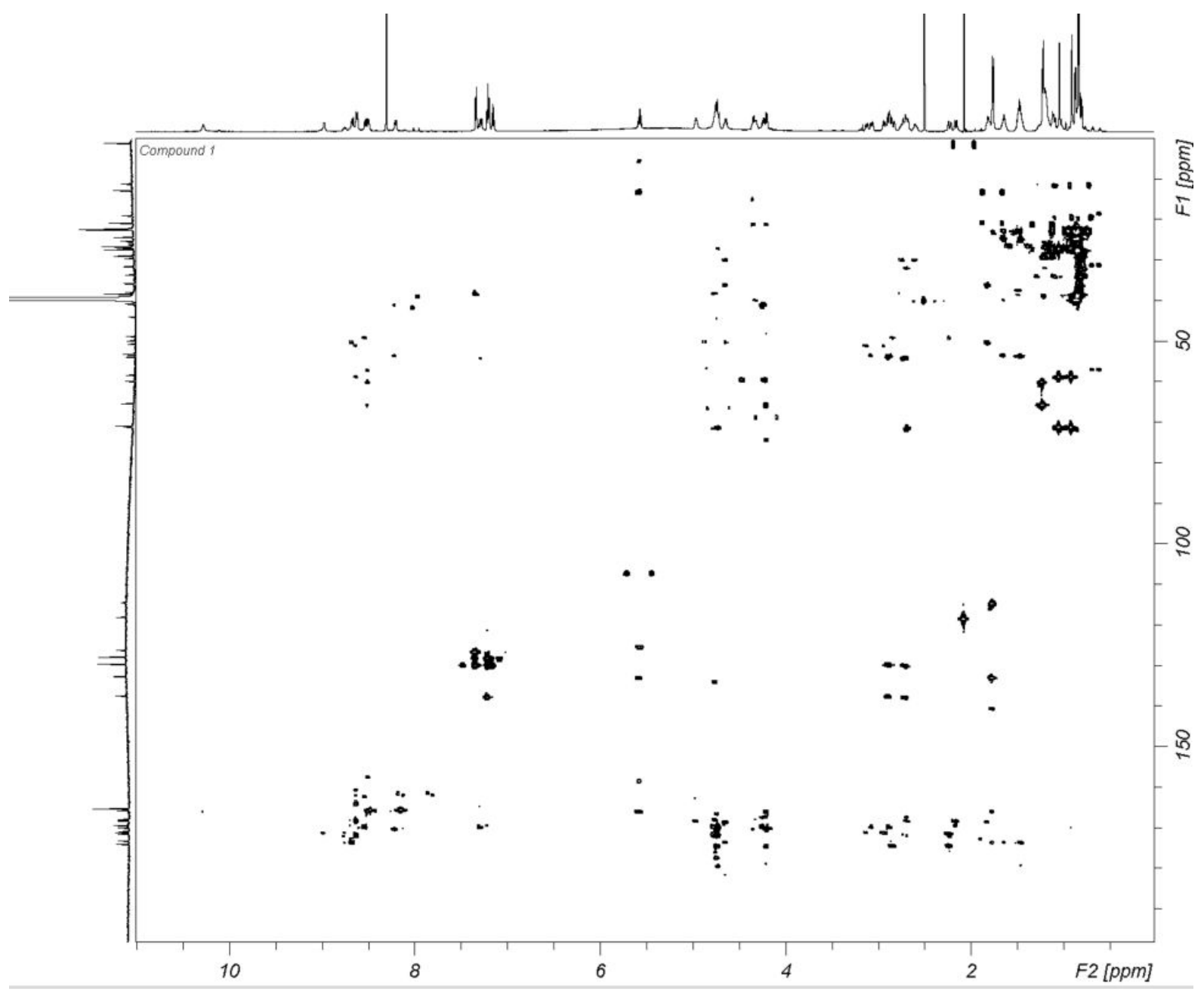

Figure S6. HMBC spectrum of compound 1 (DMSO-d 6 , 600 MHz, 298 K).

21 


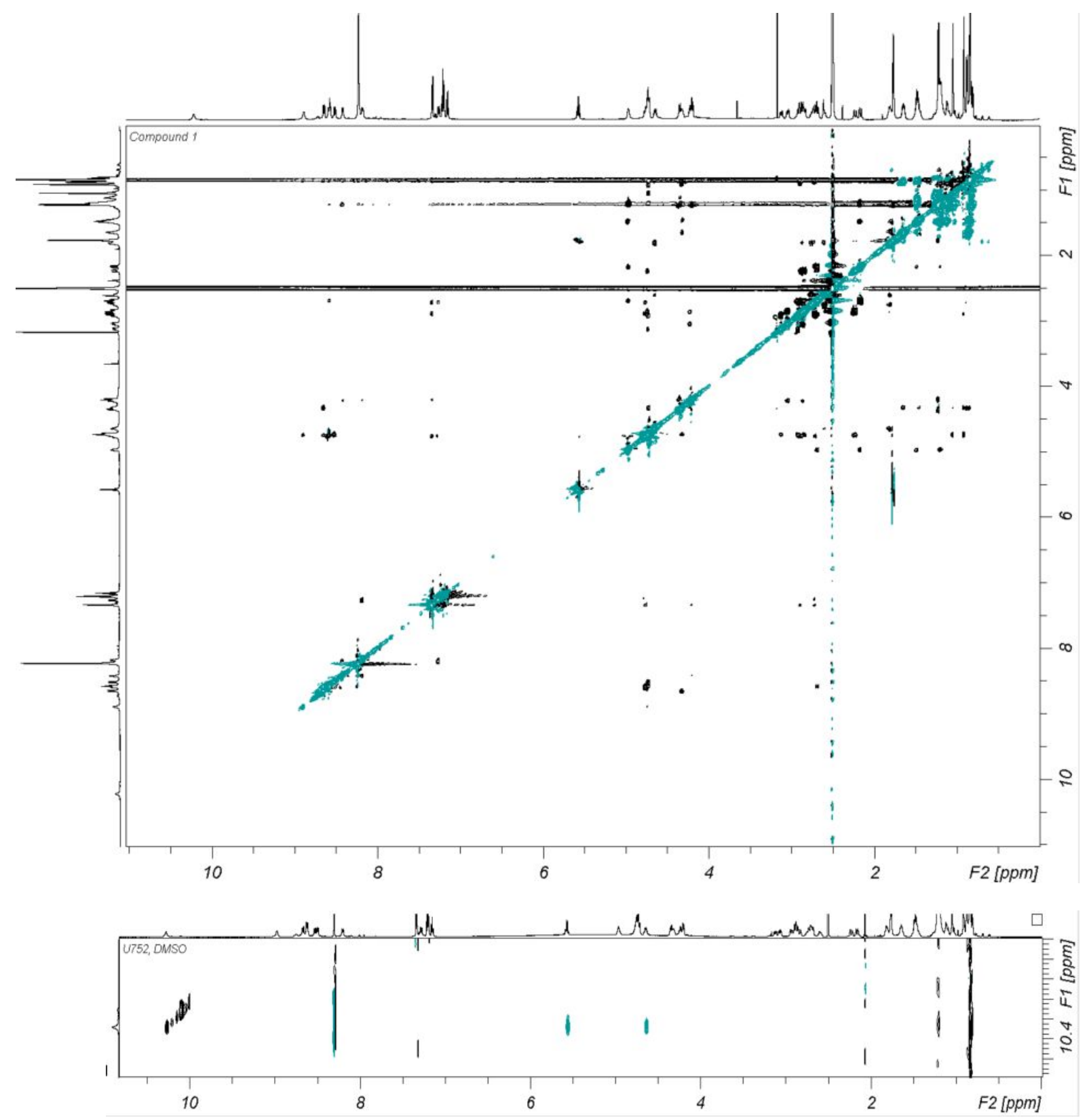

Figure S7. ROESY spectrum of compound 1 (DMSO-d 6 , 600 MHz, 298 K). Top: Full spectrum. Bottom: Expansion showing the correlation between ABA-NH (10.22 ppm) and the $\mathrm{ABA}-\mathrm{CH}_{3}(5.57$ ppm) and the DABA-H-2 (4.64 ppm).

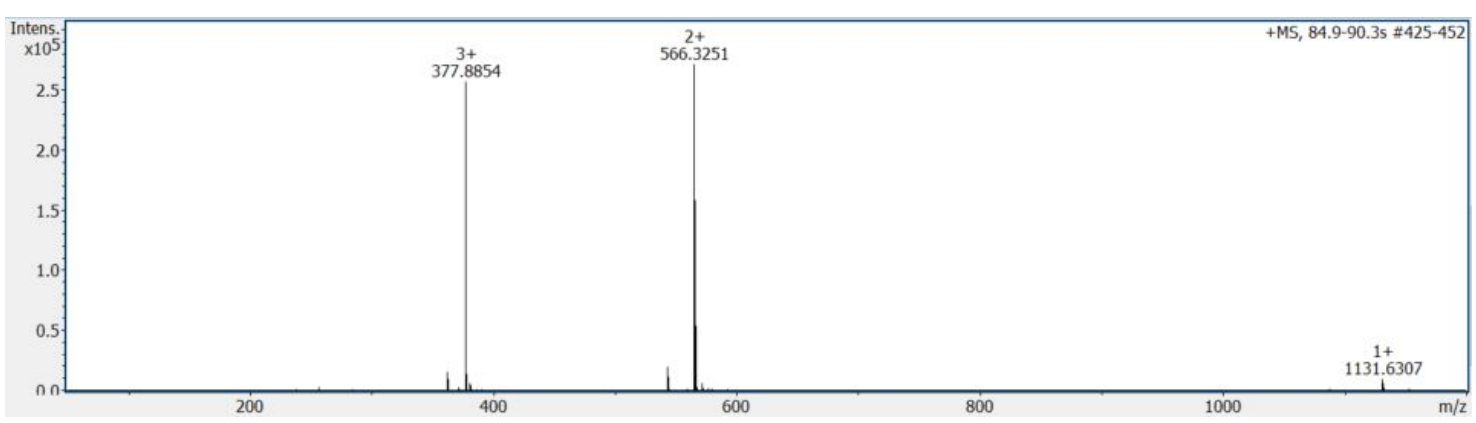

Figure S8. HRMS spectrum of compound $\mathbf{1}$. 

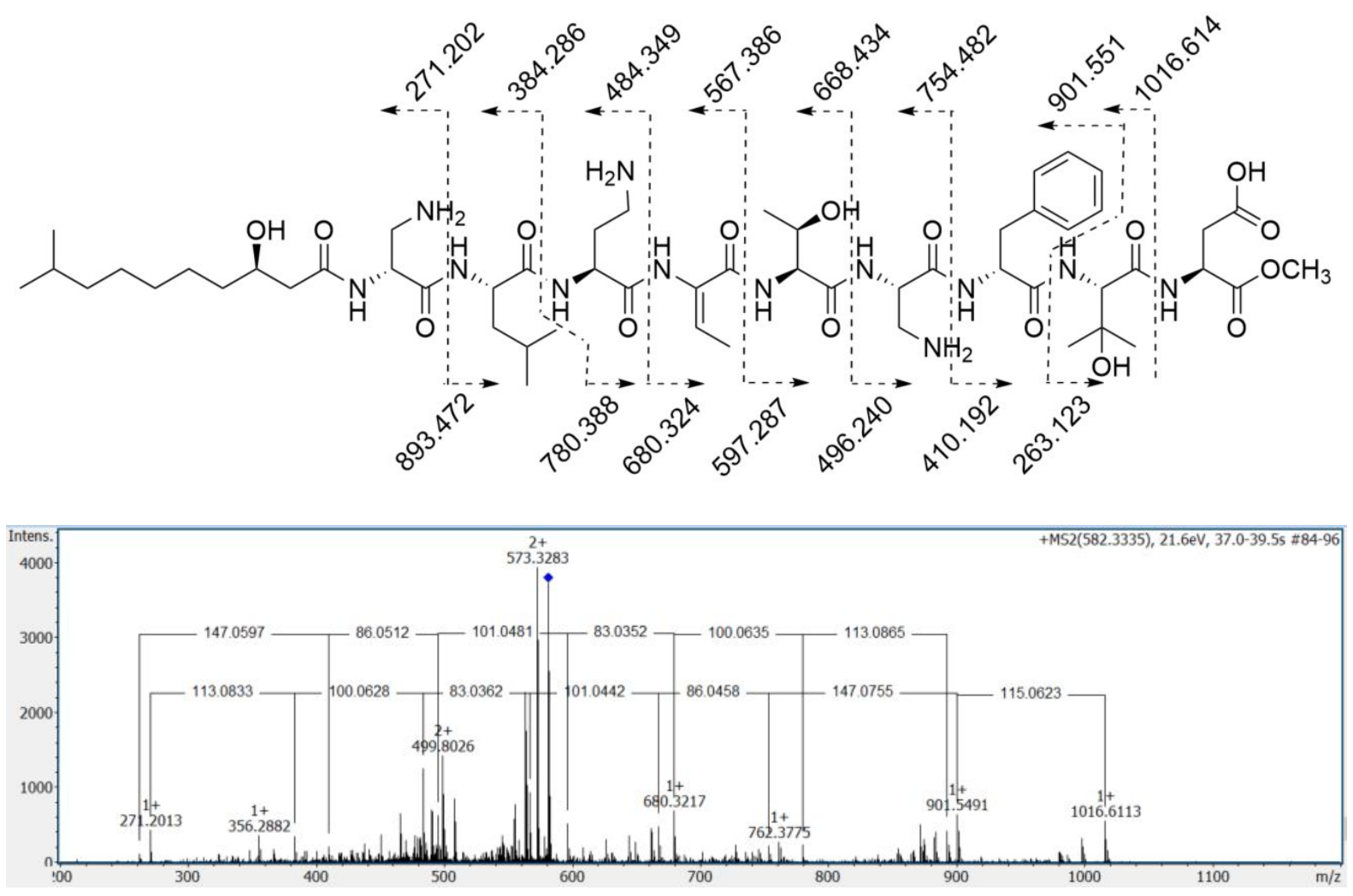

Figure S9. MSMS spectrum of compound 1 after ring-opening with $\mathrm{NaOMe}$ in $\mathrm{MeOH}$. Mass differences between Y-series ions (top) and B-series ions (bottom) are shown in the mass spectrum. Theoretical m/z-values for the observed B- and Y-series ions are shown in the structure on top. 
Table S2. ${ }^{1} \mathrm{H}$ and ${ }^{13} \mathrm{C}$ NMR-data (600 and $150 \mathrm{MHz}$, resp) for compound $2\left(\mathrm{DMSO}-\mathrm{d}_{6}, 30^{\circ} \mathrm{C}\right)$

\begin{tabular}{|c|c|c|c|c|c|c|c|}
\hline Pos. & ${ }^{13} \mathrm{C}$ & ${ }^{1} \mathrm{H}$ & Mult $(J, \mathbf{H z})$ & Pos. & ${ }^{13} \mathrm{C}$ & ${ }^{1} \mathrm{H}$ & Mult $(J, \mathbf{H z})$ \\
\hline 3OHFA & & & & Thr & & & \\
\hline 1 & 168.1 & - & - & NH & - & 8.42 & $\mathrm{~d}(7.1)$ \\
\hline \multirow[t]{2}{*}{2} & 39.6 & 2.68 & $\mathrm{dd}(13.7,4.1)$ & 1 & 169.8 & - & - \\
\hline & & 2.19 & br d (13.7) & 2 & 59.6 & 4.20 & $\mathrm{dd}(7.7,2.0)$ \\
\hline 3 & 70.9 & 4.97 & $\mathrm{~m}$ & 3 & 65.1 & 4.35 & obsc \\
\hline 4 & 31.2 & 1.49 & $\mathrm{~m}$ & 4 & 20.5 & 1.23 & $\mathrm{~d}(7.1)$ \\
\hline 5 & 24.9 & 1.20 & obsc & $\overline{\text { DAPA2 }}$ & & & \\
\hline 6 & 28.3 & 1.21 & obsc & NH & - & 8.26 & $\mathrm{~d}(8.7)$ \\
\hline 7 & 28.3 & 1.21 & obsc & 1 & 169.0 & - & - \\
\hline 8 & 30.8 & 1.21 & obsc & 2 & 52.2 & 4.28 & $\operatorname{ddd}(8.5,8.5,7.7)$ \\
\hline 9 & 21.7 & 1.26 & obsc & 3 & 40.0 & 3.13 & $\mathrm{~m}$ \\
\hline 10 & 22.2 & 0.85 & $\mathrm{t}(7.1)$ & & & 2.89 & obsc \\
\hline DAPA1 & & & & Phe & & & \\
\hline NH & - & 8.53 & $\mathrm{~d}(8.7)$ & NH & - & 7.3 & $d(8.6)$ \\
\hline 1 & 170.4 & - & - & 1 & 171.2 & - & - \\
\hline 2 & 49.8 & 4.80 & $\mathrm{~m}$ & 2 & 53.7 & 4.76 & obsc \\
\hline \multirow[t]{2}{*}{3} & 43.2 & 3.18 & $\mathrm{~m}$ & 3 & 37.5 & 2.89 & obsc \\
\hline & & 3.02 & $\mathrm{~m}$ & & & 2.72 & obsc \\
\hline Leu & & & & 4 & 137.2 & - & - \\
\hline NH & - & 8.97 & br s & $5 / 9$ & 129.2 & 7.34 & $\mathrm{~m}$ \\
\hline 1 & 173.2 & - & - & $6 / 8$ & 127.6 & 7.21 & $\mathrm{~m}$ \\
\hline 2 & 53.0 & 4.33 & obsc & 7 & 125.9 & 7.16 & $\mathrm{~m}$ \\
\hline \multirow[t]{2}{*}{3} & 39.2 & 1.65 & $\mathrm{~m}$ & 3OHVal & & & \\
\hline & & 1.48 & $\mathrm{~m}$ & NH & - & 8.60 & $\mathrm{~d}(9.8)$ \\
\hline 4 & 24.1 & 1.66 & obsc & 1 & 169.3 & - & - \\
\hline 5 & 22.2 & 0.89 & $\mathrm{~d}(6.9)$ & 2 & 58.1 & 4.70 & $\mathrm{~d}(9.8)$ \\
\hline 6 & 22.2 & 0.85 & $\mathrm{~d}(6.0)$ & 3 & 71.3 & - & - \\
\hline DABA & & & & 4 & 26.4 & 1.05 & $\mathrm{~s}$ \\
\hline NH & - & 8.65 & $\mathrm{~d}(9.2)$ & 5 & 26.6 & 0.91 & $\mathrm{~s}$ \\
\hline 1 & n.d. & - & - & $\overline{\text { Asp }}$ & & & \\
\hline 2 & 49.6 & 4.63 & ddd $(7.6,7.5,7.5)$ & NH & - & 8.49 & $\mathrm{~d}(9.6)$ \\
\hline 3 & 29.1 & 1.81 & $\mathrm{~m}$ & 1 & 171.7 & - & - \\
\hline \multirow[t]{2}{*}{4} & 35.6 & 2.73 & $\mathrm{~m}$ & 2 & 48.5 & 4.75 & obsc \\
\hline & & 2.61 & $\mathrm{~m}$ & 3 & 40.6 & 2.84 & $\mathrm{dd}(15.8,4.7)$ \\
\hline$\overline{\mathbf{A B A}}$ & & & & & & 2.25 & br d (15.8) \\
\hline NH & - & 10.23 & br s & 4 & 173.8 & - & - \\
\hline 1 & 165.6 & - & - & & & & \\
\hline 2 & 133.0 & - & - & & & & \\
\hline 3 & 114.4 & 5.58 & $\mathrm{q}(7.3)$ & & & & \\
\hline 4 & 12.7 & 1.77 & $\mathrm{~d}(7.3)$ & & & & \\
\hline
\end{tabular}


Supporting information

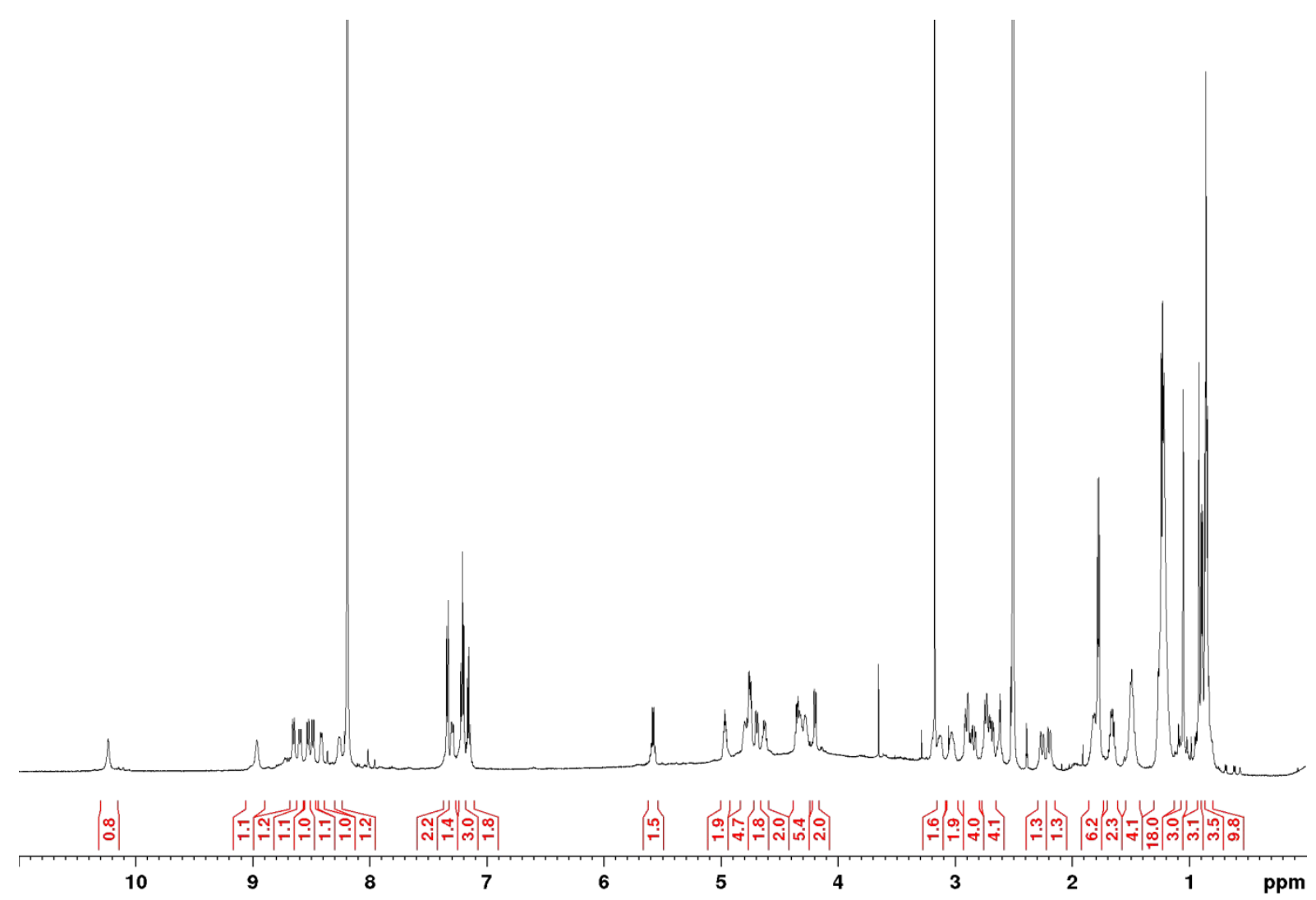

Figure S10. ${ }^{1} \mathrm{H}-\mathrm{NMR}$ spectrum of compound $2\left(\mathrm{DMSO}^{\mathrm{d}}{ }_{6}, 600 \mathrm{MHz}, 298 \mathrm{~K}\right)$.

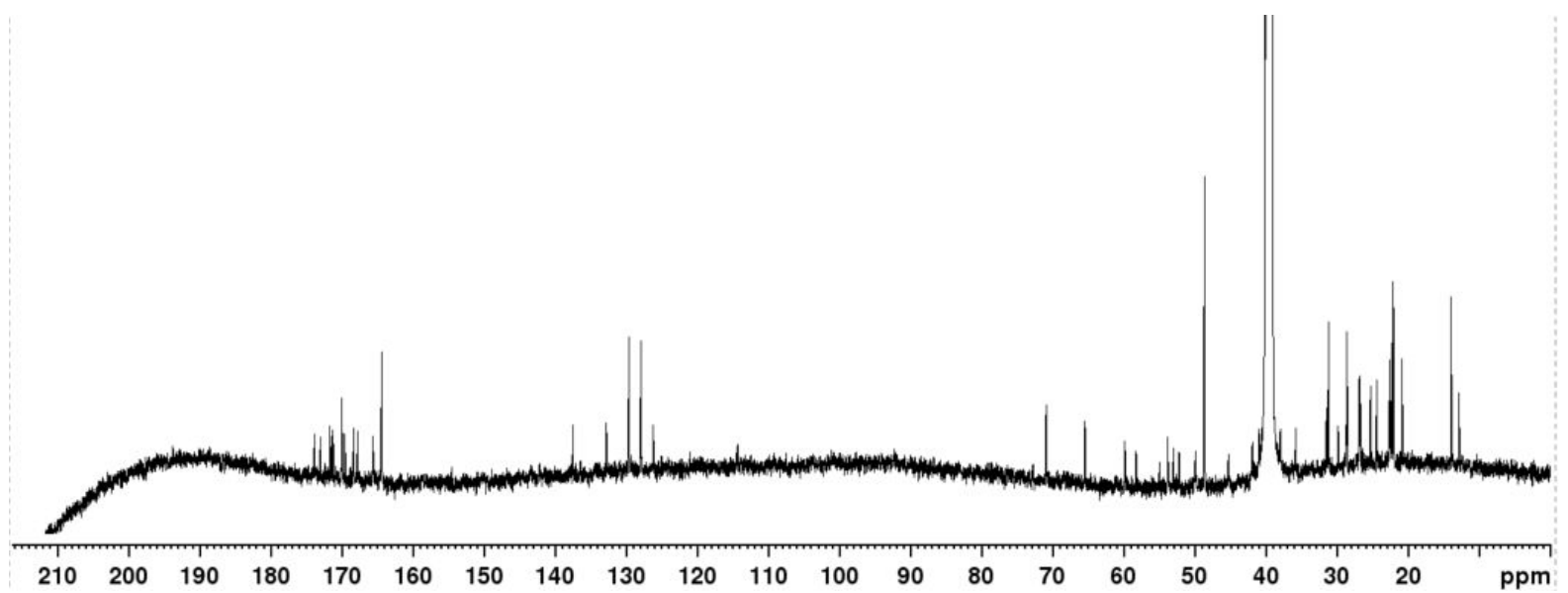

Figure S11. ${ }^{13} \mathrm{C}-\mathrm{NMR}$ spectrum of compound $2\left(\mathrm{DMSO}_{\mathrm{d}}, 150 \mathrm{MHz}, 298 \mathrm{~K}\right)$. 
Supporting information

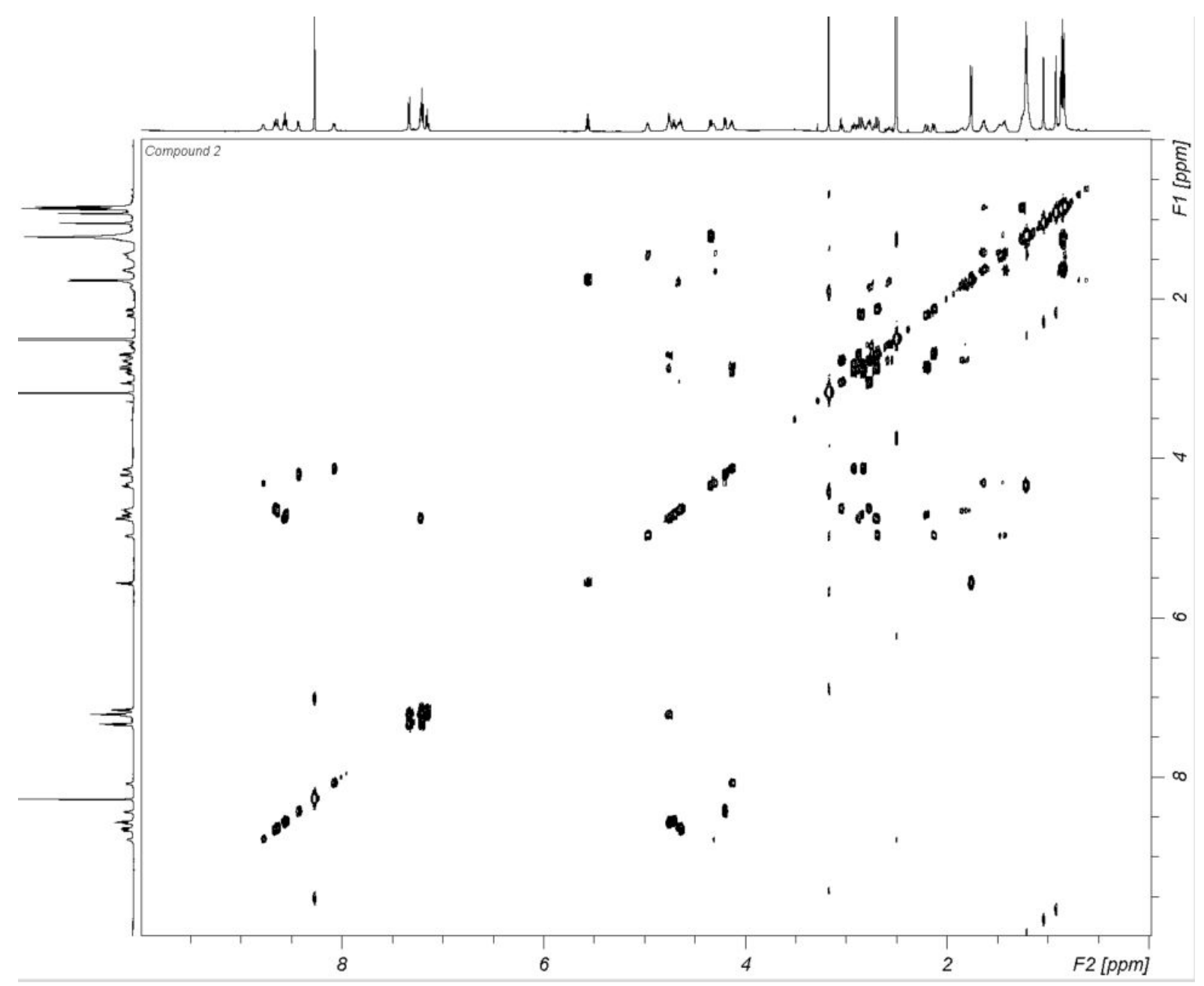

Figure S12. COSY spectrum of compound 2 (DMSO-d $\left.{ }_{6}, 600 \mathrm{MHz}, 298 \mathrm{~K}\right)$. 
Supporting information

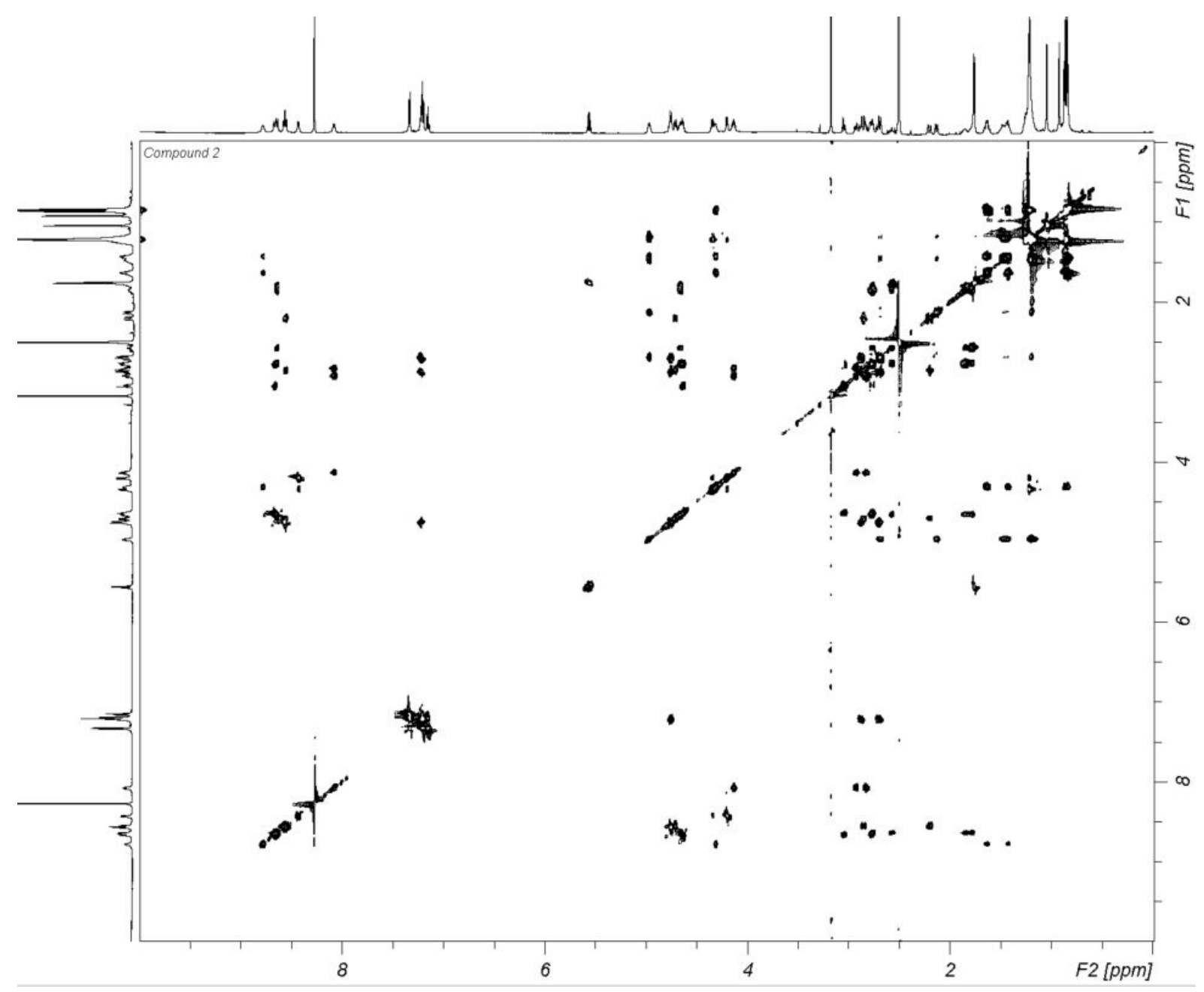

Figure S13. TOCSY spectrum of compound $2\left(\right.$ DMSO-d $\left._{6}, 600 \mathrm{MHz}, 298 \mathrm{~K}\right)$. 
Supporting information

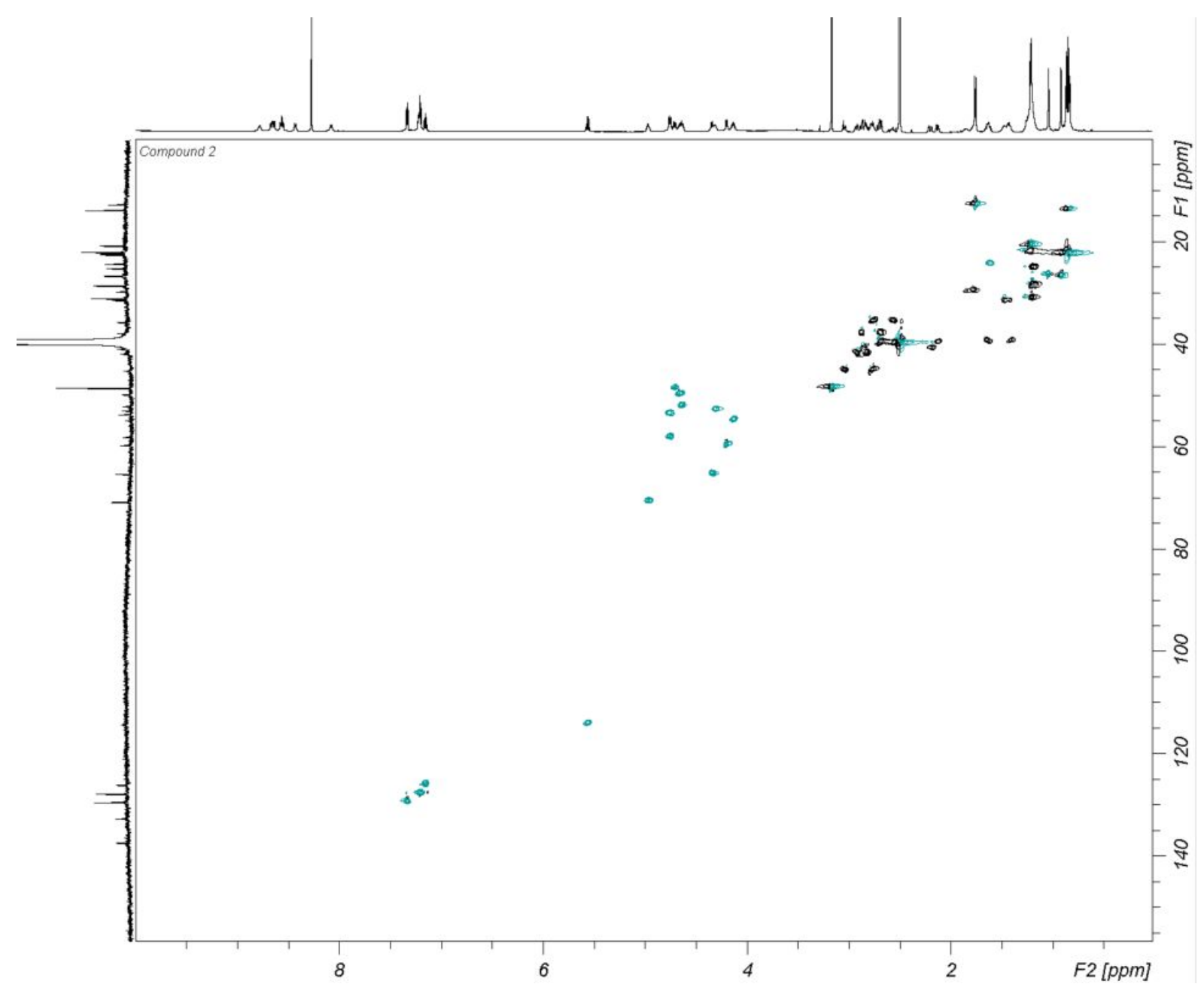

Figure S14. HSCQ spectrum of compound 2 (DMSO-d 6 , 600 MHz, 298 K). 
Supporting information

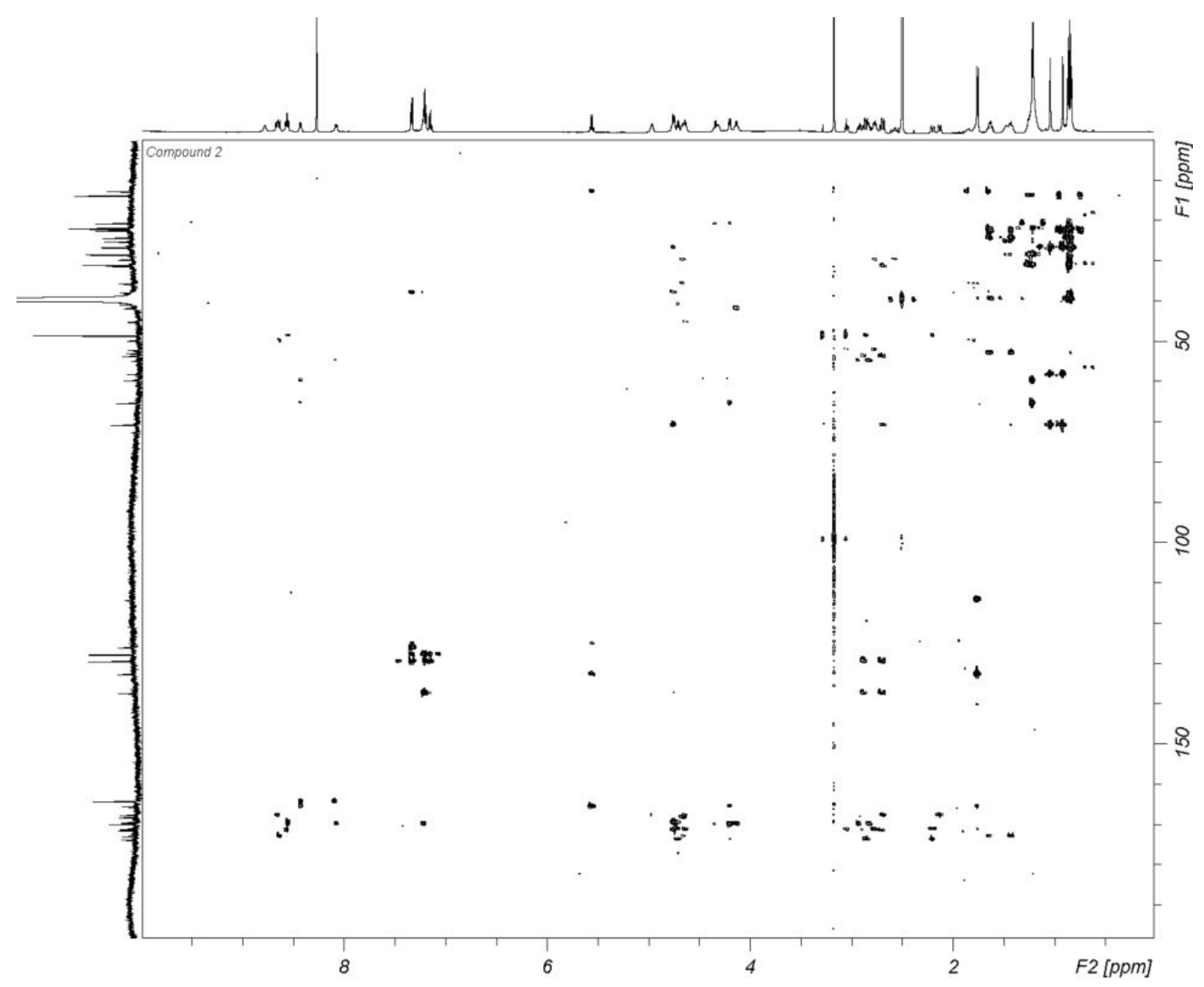

Figure S15. HMBC spectrum of compound 2 (DMSO-d $\left.{ }_{6}, 600 \mathrm{MHz}, 298 \mathrm{~K}\right)$. 
Supporting information

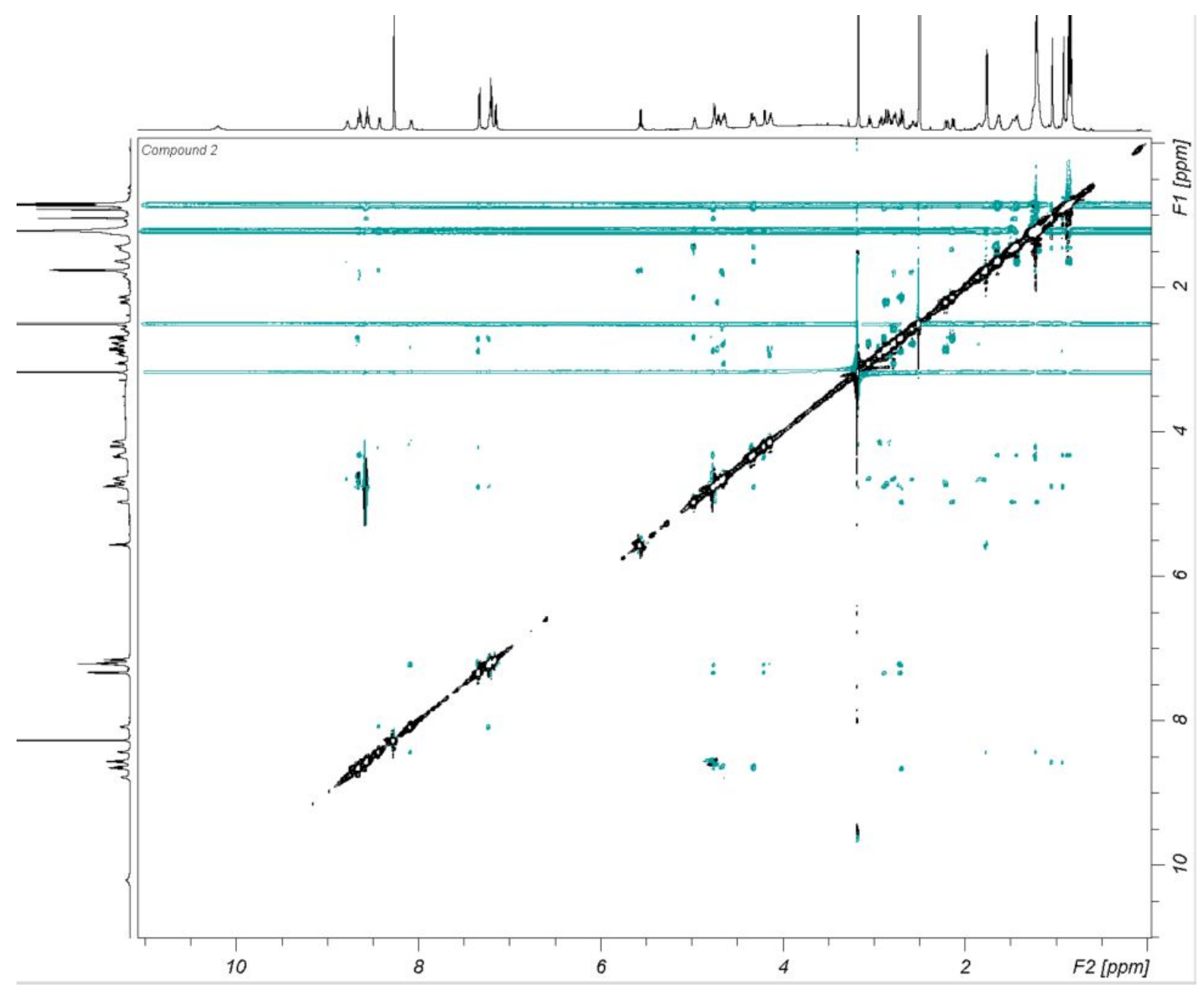

Figure S16. ROESY spectrum of compound 2 (DMSO-d 6 , $600 \mathrm{MHz}, 298 \mathrm{~K})$.

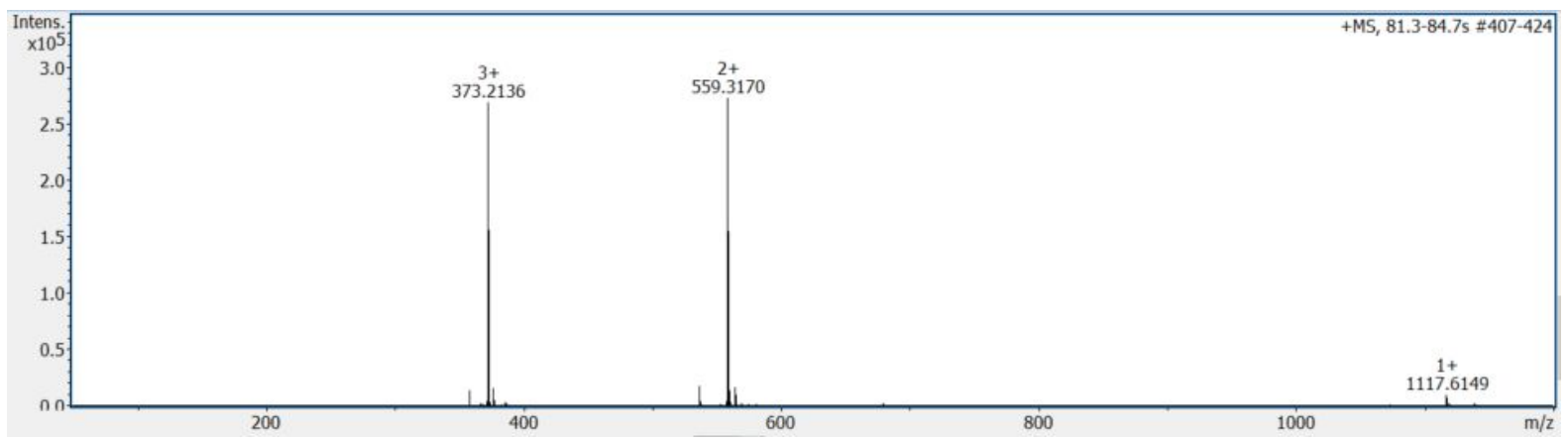

Figure S17. HRMS spectrum of compound 2. 

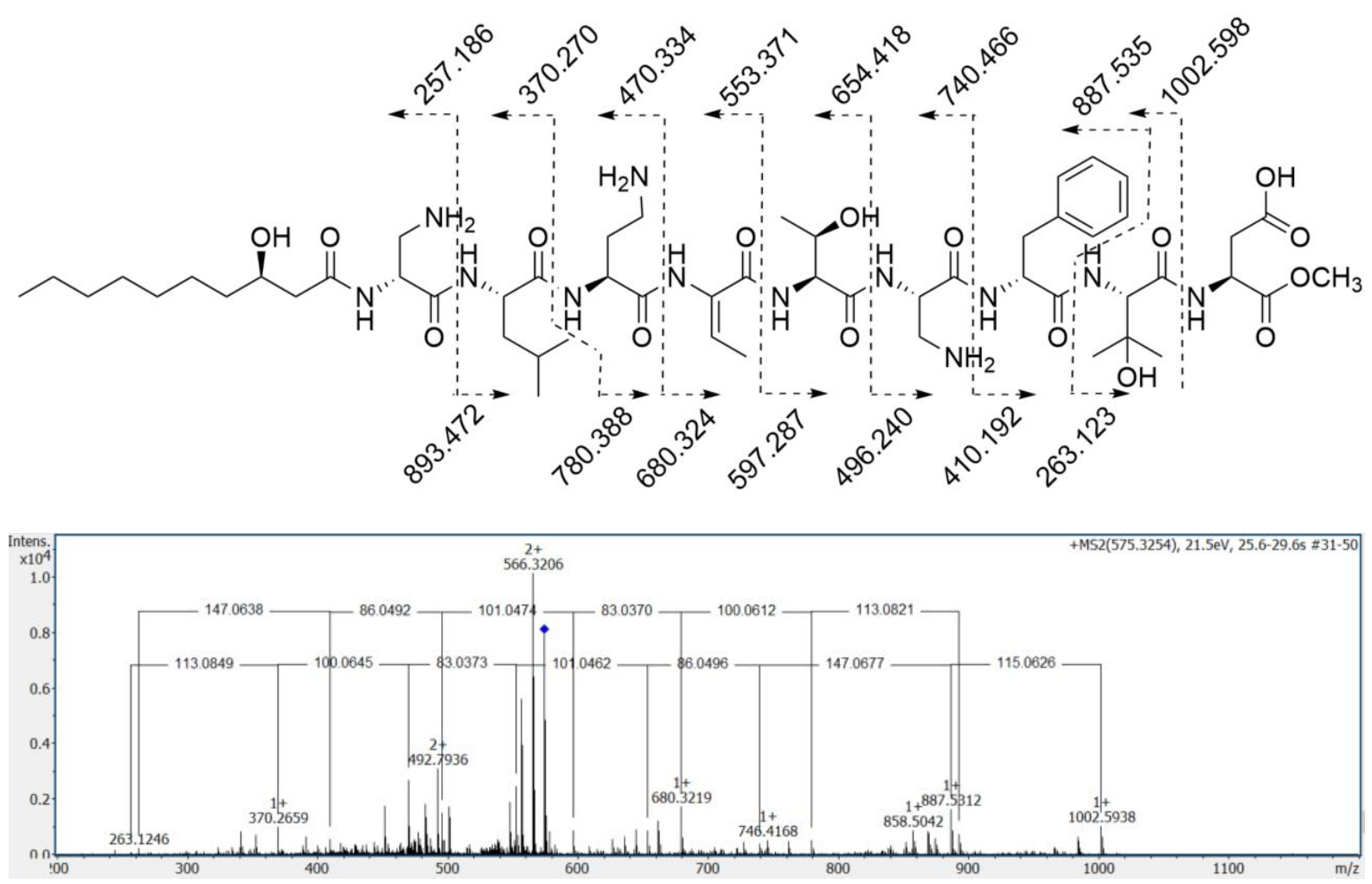

Figure S18. MSMS spectrum of compound 2 after ring-opening with $\mathrm{NaOMe}$ in $\mathrm{MeOH}$. Mass differences between Y-series ions (top) and B-series ions (bottom) are shown in the mass spectrum. Theoretical m/z-values for the observed B- and Y-series ions are shown in the structure on top. 
Table S3. ${ }^{1} \mathrm{H}$ and ${ }^{13} \mathrm{C}$ NMR-data (600 and $150 \mathrm{MHz}$, resp) for compound 3 (DMSO-d ${ }_{6}, 30^{\circ} \mathrm{C}$ )

\begin{tabular}{|c|c|c|c|c|c|c|c|}
\hline Pos. & ${ }^{13} \mathrm{C}$ & ${ }^{1} \mathbf{H}$ & Mult $(J, \mathrm{~Hz})$ & Pos. & ${ }^{13} \mathrm{C}$ & ${ }^{1} \mathbf{H}$ & Mult $(J, \mathrm{~Hz})$ \\
\hline 3OHFA & & & & Thr & & & \\
\hline 1 & 167.8 & - & - & NH & - & 8.43 & $\mathrm{~d}(7.7)$ \\
\hline \multirow[t]{2}{*}{2} & 38.8 & 2.64 & obsc & 1 & 169.3 & - & - \\
\hline & & 2.24 & obsc & 2 & 59.5 & 4.20 & $\mathrm{dd}(7.7,2.3)$ \\
\hline 3 & 70.7 & 4.95 & $\mathrm{~m}$ & 3 & 65.0 & 4.35 & obsc \\
\hline \multirow[t]{2}{*}{4} & 29.3 & 2.34 & ddd $(14.6,7.3,7.3)$ & 4 & 20.5 & 1.22 & $\mathrm{~d}(6.5)$ \\
\hline & & 2.22 & obsc & DAPA2 & & & \\
\hline 5 & 123.9 & 5.29 & $\mathrm{~m}(10.8)$ & NH & - & 8.17 & $\mathrm{~d}(8.6)$ \\
\hline 6 & 132.1 & 5.40 & $\mathrm{~m}(10.8)$ & 1 & 169.4 & - & - \\
\hline 7 & 26.4 & 1.98 & $\mathrm{~m}$ & 2 & 53.1 & 4.23 & $\operatorname{ddd}(8.6,8.6,5.8)$ \\
\hline 8 & 28.4 & 1.29 & obsc & 3 & 40.0 & 3.13 & $\mathrm{~m}$ \\
\hline 9 & 28.0 & 1.25 & obsc & & & 2.89 & obsc \\
\hline 10 & 30.8 & 1.24 & obsc & Phe & & & \\
\hline 11 & 21.7 & 1.26 & obsc & NH & - & 7.29 & $\mathrm{~d}(8.9)$ \\
\hline 12 & 13.6 & 0.86 & $\mathrm{t}(6.9)$ & 1 & 169.5 & - & - \\
\hline$\overline{\text { DAPA1 }}$ & & & & 2 & 53.5 & 4.76 & obsc \\
\hline NH & - & 8.51 & $\mathrm{~d}(9.0)$ & 3 & 37.5 & 2.89 & $\mathrm{dd}(13.6,4.3)$ \\
\hline 1 & 170.6 & - & - & & & 2.72 & $\mathrm{dd}(13.6,10.2)$ \\
\hline 2 & 50.4 & 4.76 & obsc & 4 & 137.2 & - & - \\
\hline \multirow[t]{2}{*}{3} & 43.4 & 3.18 & $\mathrm{dd}(13.1,6.0)$ & $5 / 9$ & 129.2 & 7.33 & $\mathrm{~m}$ \\
\hline & & 2.96 & $\mathrm{dd}(13.1,3.8)$ & $6 / 8$ & 127.6 & 7.21 & $\mathrm{~m}$ \\
\hline Leu & & & & 7 & 125.8 & 7.15 & $\mathrm{~m}$ \\
\hline NH & - & 8.91 & br s & 30HVal & & & \\
\hline 1 & 173.3 & - & - & NH & - & 8.53 & $\mathrm{~d}(10.0)$ \\
\hline 2 & 52.8 & 4.34 & obsc & 1 & 171.1 & - & - \\
\hline \multirow[t]{2}{*}{3} & 39.2 & 1.64 & obsc & 2 & 58.9 & 4.72 & $\mathrm{~d}(10.0)$ \\
\hline & & 1.47 & $\mathrm{~m}$ & 3 & 70.8 & - & - \\
\hline 4 & 24.1 & 1.64 & obsc & 4 & 26.5 & 1.05 & $\mathrm{~s}$ \\
\hline 5 & 21.9 & 0.88 & $\mathrm{~d}(6.1)$ & 5 & 26.5 & 0.90 & $\mathrm{~s}$ \\
\hline 6 & 22.0 & 0.86 & $\mathrm{~d}(5.7)$ & Asp & & & \\
\hline DABA & & & & NH & - & 8.53 & $\mathrm{~d}(9.6)$ \\
\hline NH & - & 8.61 & $\mathrm{~d}(9.5)$ & 1 & 170.5 & - & - \\
\hline 1 & 167.9 & - & - & 2 & 48.4 & 4.74 & obsc \\
\hline 2 & 49.5 & 4.64 & $\operatorname{ddd}(9.5,7.2,7.2)$ & 3 & 40.6 & 2.83 & $\mathrm{dd}(16.0,4.7)$ \\
\hline 3 & 29.3 & 1.81 & $\mathrm{~m}$ & & & 2.23 & obsc \\
\hline \multirow[t]{2}{*}{4} & 35.5 & 2.74 & $\mathrm{~m}$ & 4 & 173.8 & - & - \\
\hline & & 2.61 & $\mathrm{~m}$ & & & & \\
\hline \multicolumn{8}{|l|}{ ABA } \\
\hline NH & - & 10.26 & br s & & & & \\
\hline 1 & 165.6 & - & - & & & & \\
\hline 2 & 132.6 & - & - & & & & \\
\hline 3 & 114.1 & 5.57 & $\mathrm{q}(7.2)$ & & & & \\
\hline 4 & 12.5 & 1.77 & $\mathrm{~d}(7.2)$ & & & & \\
\hline
\end{tabular}


Supporting information

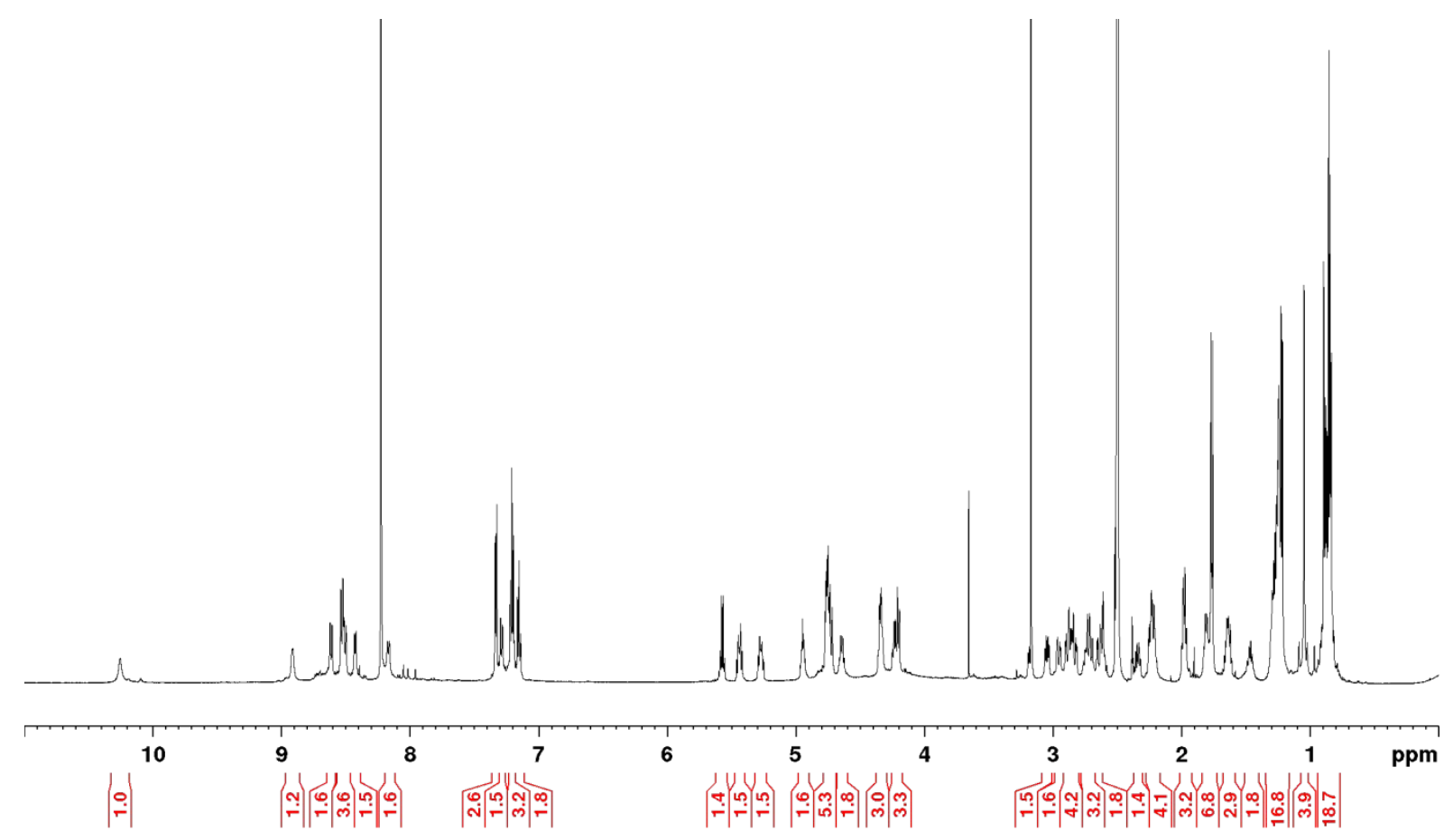

Figure S19. ${ }^{1} \mathrm{H}-\mathrm{NMR}$ spectrum of compound 3 (DMSO-d 6 , $\left.600 \mathrm{MHz}, 298 \mathrm{~K}\right)$.

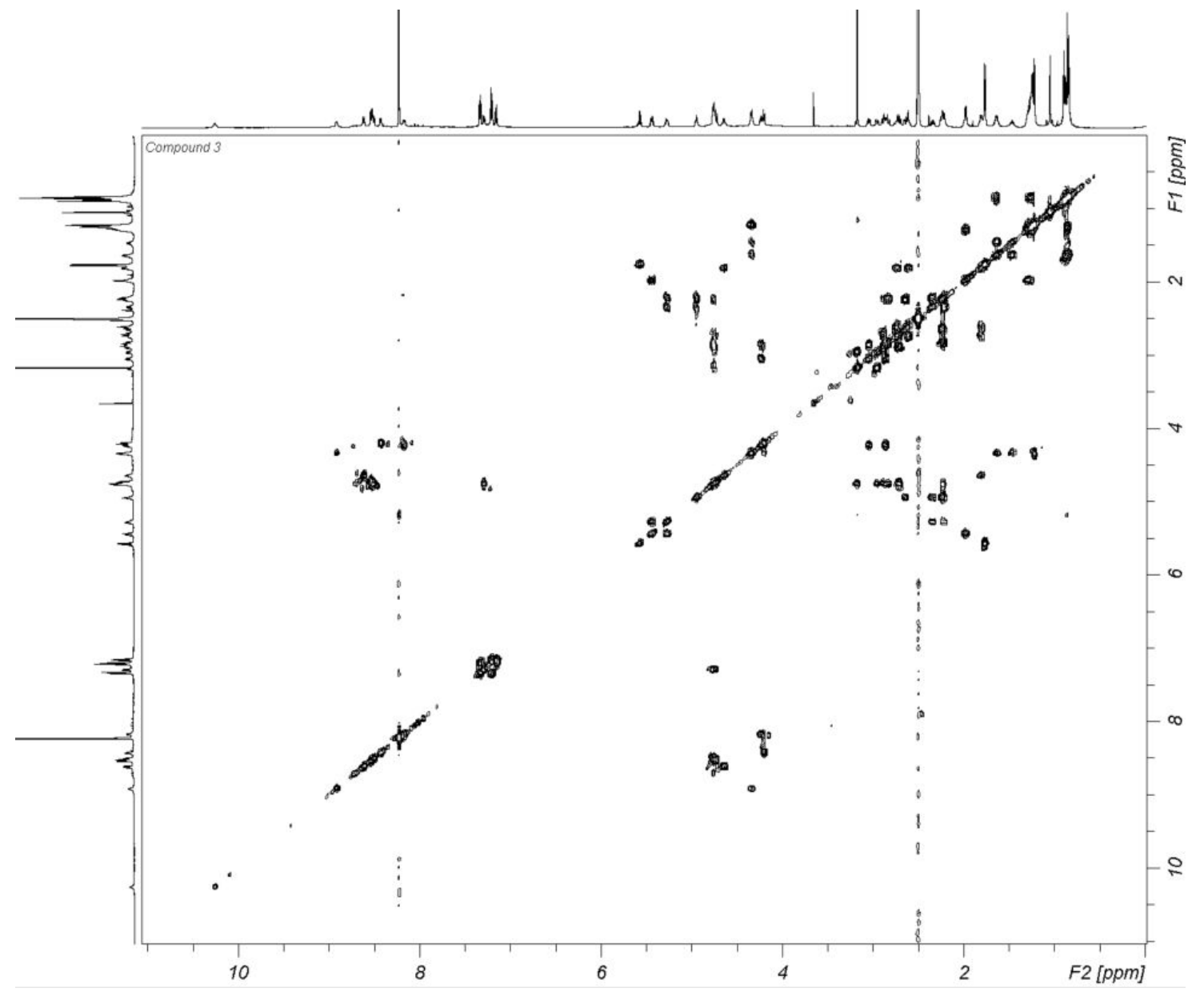

Figure S20. COSY spectrum of compound $3\left(\mathrm{DMSO}_{-} \mathrm{d}_{6}, 600 \mathrm{MHz}, 298 \mathrm{~K}\right)$. 
Supporting information

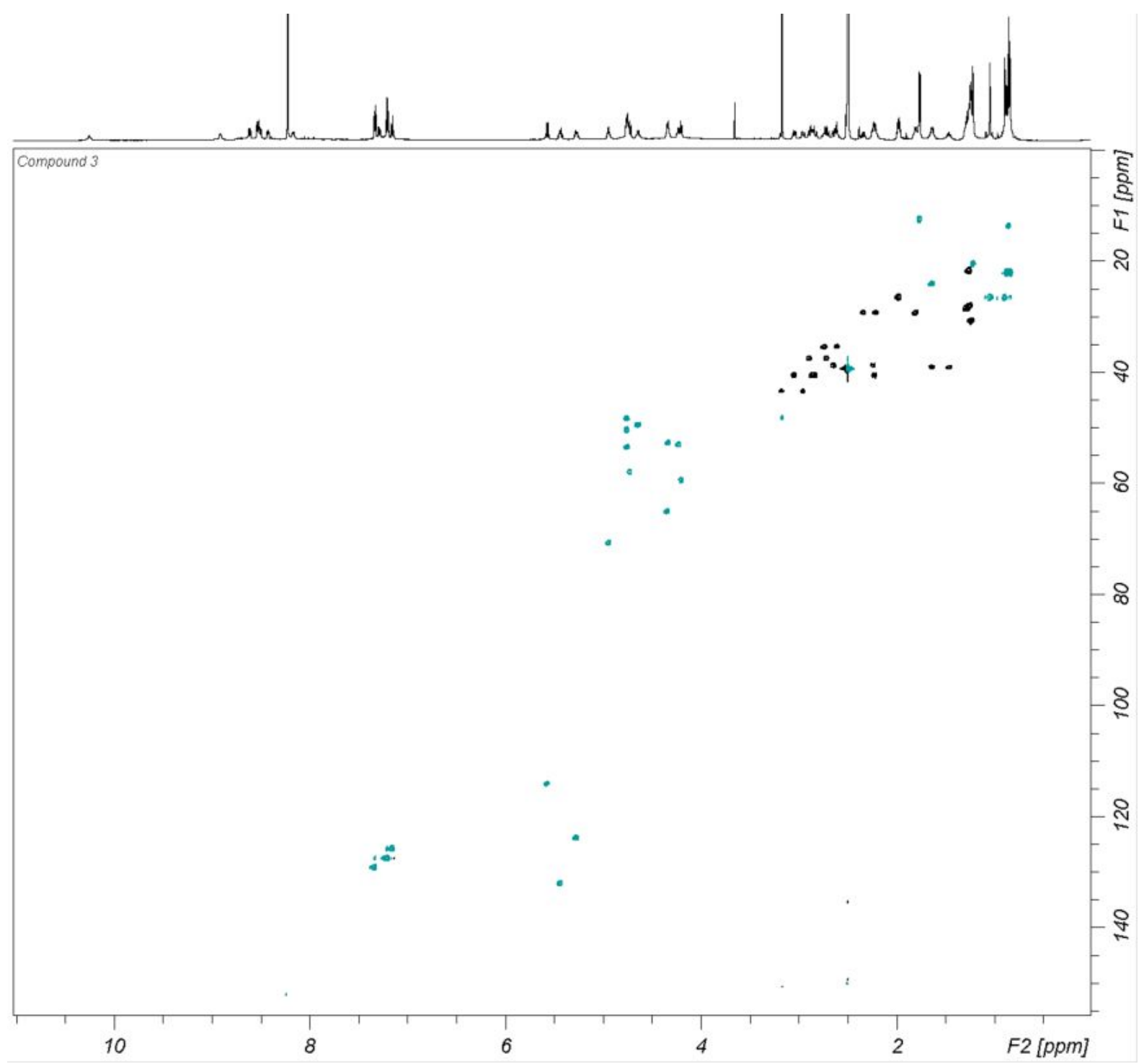

Figure S21. HSQC spectrum of compound 3 (DMSO-d 6 , 600 MHz, 298 K). 
Supporting information

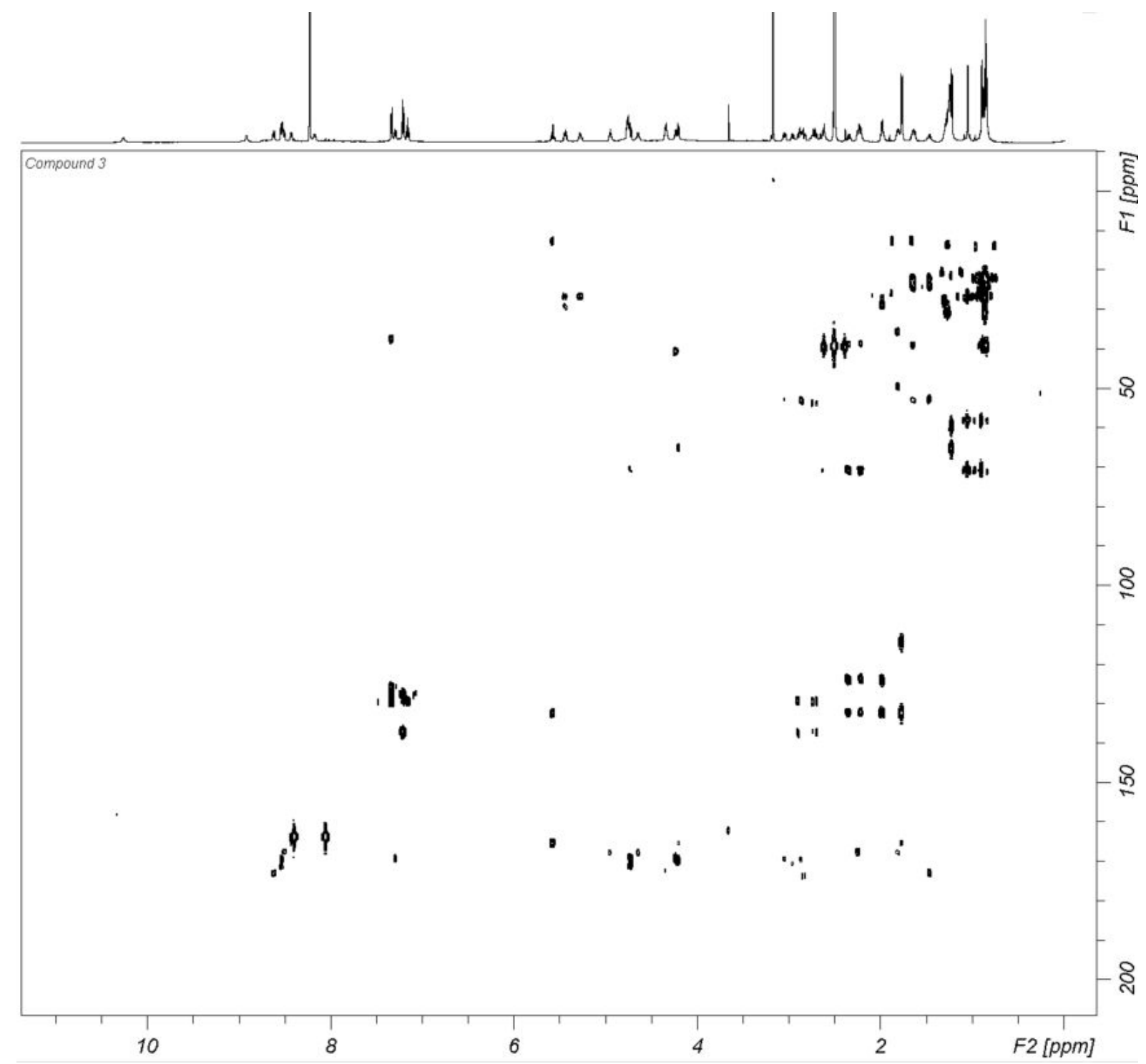

Figure S22. HMBC spectrum of compound $3\left(\right.$ DMSO-d $_{6}, 600$ MHz, $\left.298 \mathrm{~K}\right)$. 


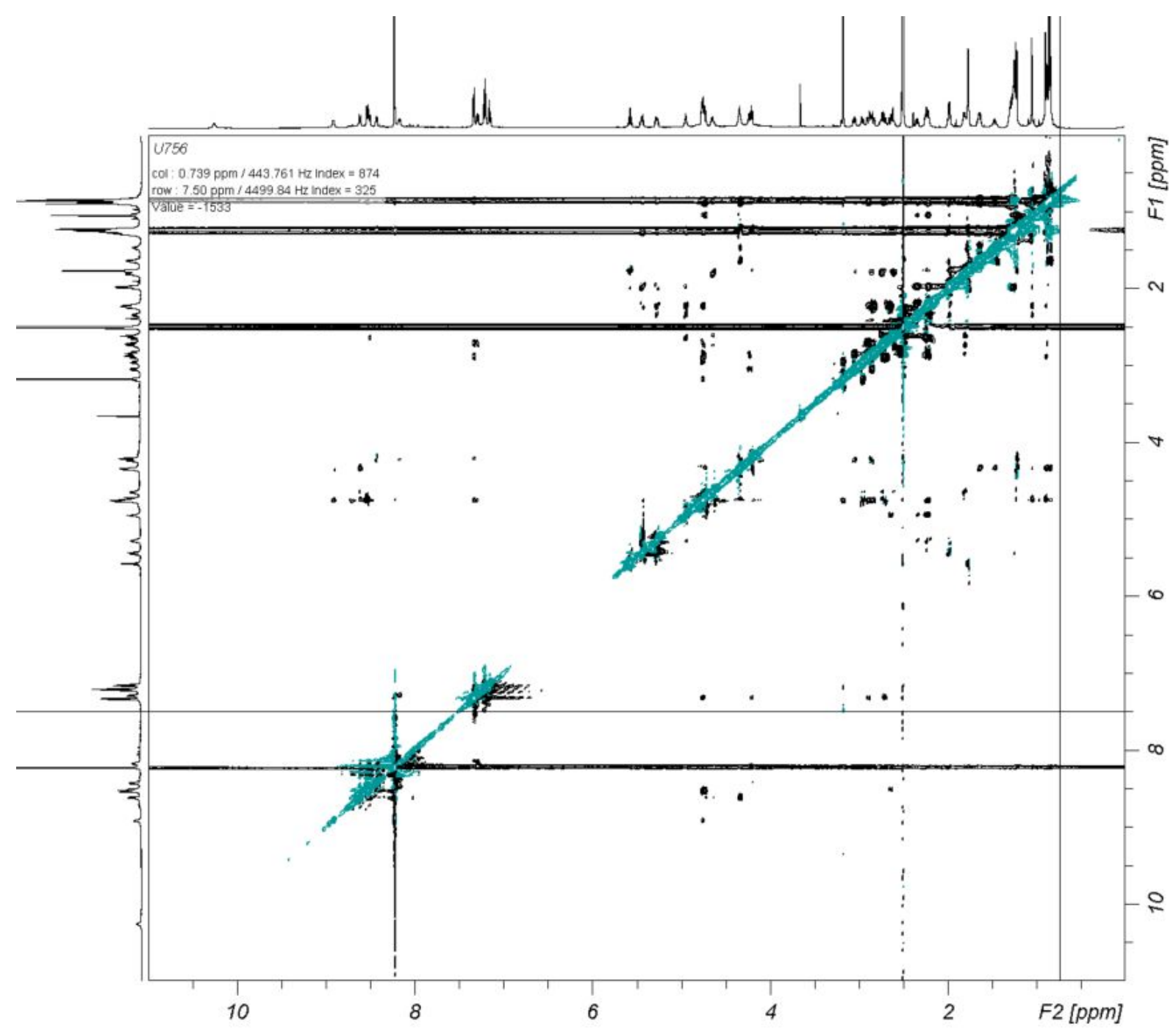

Figure S23. ROESY spectrum of compound 3 (DMSO-d $\left.{ }_{6}, 600 \mathrm{MHz}, 298 \mathrm{~K}\right)$.

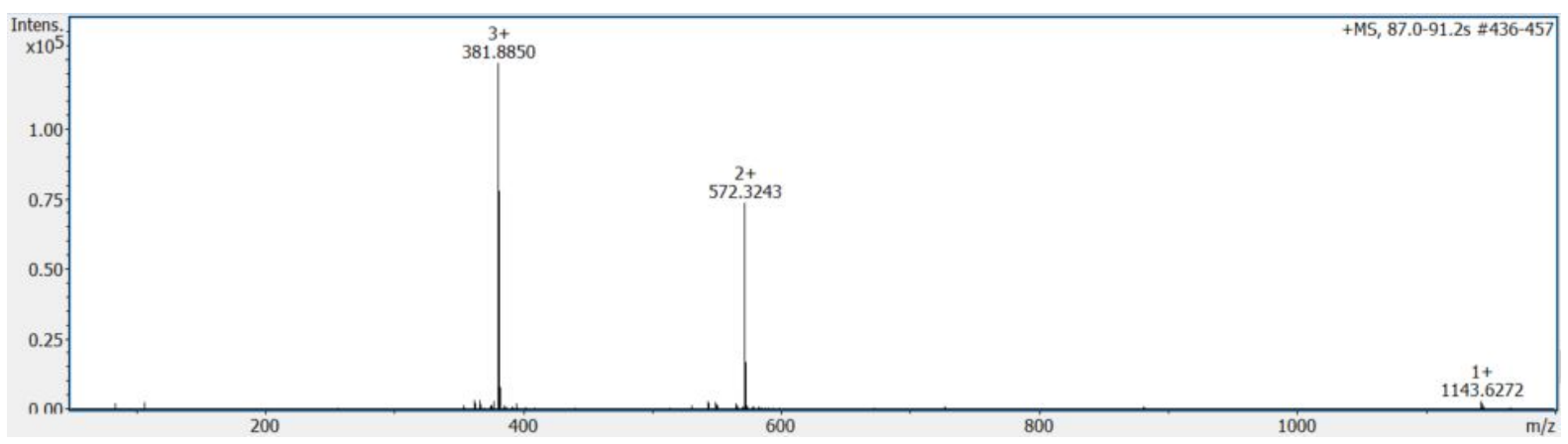

Figure S24. HRMS spectrum of compound 3. 

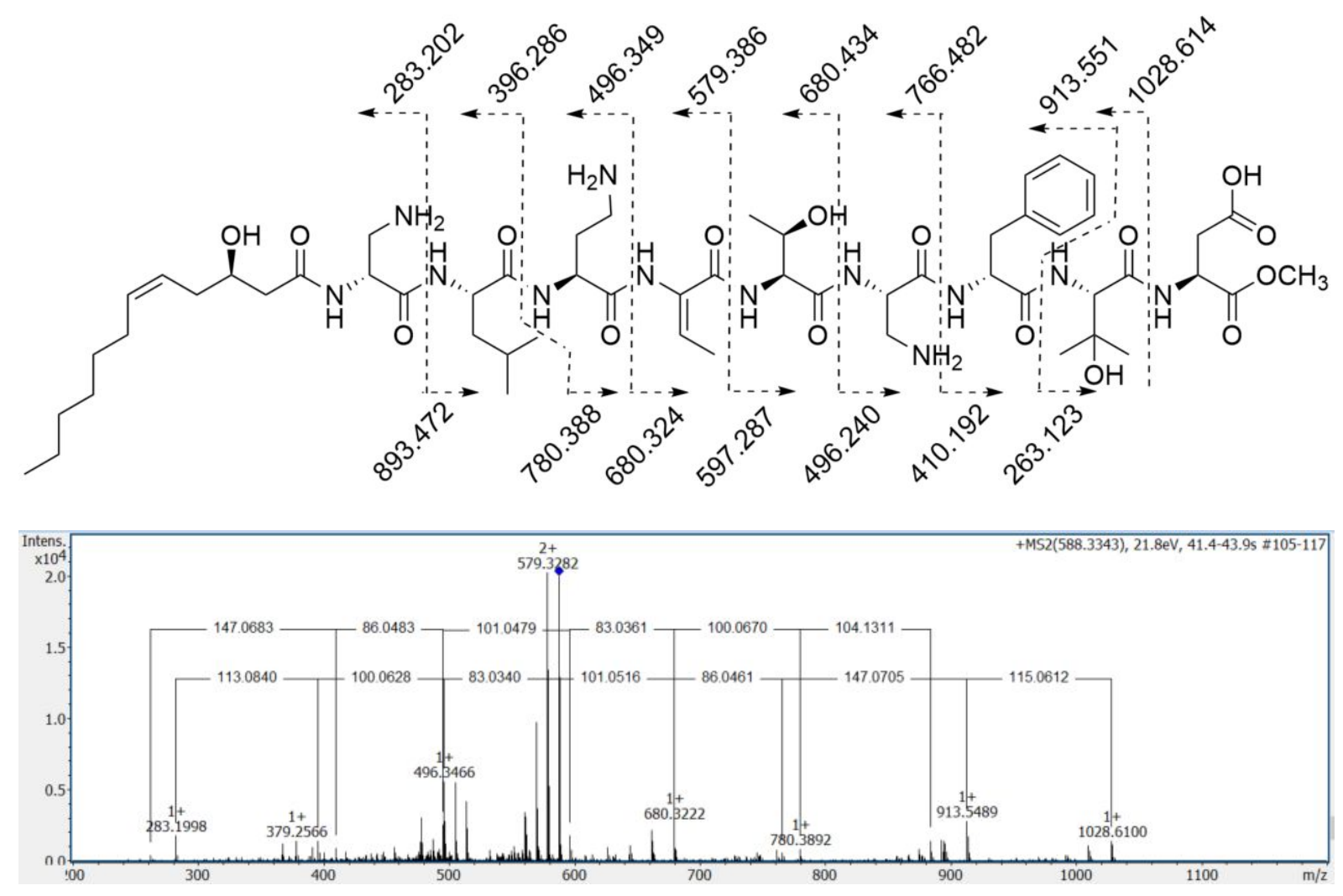

Figure S25. MSMS spectrum of compound 3 after ring-opening with $\mathrm{NaOMe}$ in $\mathrm{MeOH}$. Mass differences between $\mathrm{Y}$-series ions (top) and B-series ions (bottom) are shown in the mass spectrum. Theoretical m/z-values for the observed B- and Y-series ions are shown in the structure on top. 
Table S4. ${ }^{1} \mathrm{H}$ and ${ }^{13} \mathrm{C}$ NMR-data (600 and $150 \mathrm{MHz}$, resp) for compound $4\left(\mathrm{DMSO}-\mathrm{d}_{6}, 30^{\circ} \mathrm{C}\right)$

\begin{tabular}{|c|c|c|c|c|c|c|c|}
\hline Pos. & ${ }^{13} \mathrm{C}$ & ${ }^{1} \mathrm{H}$ & Mult $(J, \mathbf{H z})$ & Pos. & ${ }^{13} \mathrm{C}$ & ${ }^{1} \mathrm{H}$ & Mult $(J, \mathrm{~Hz})$ \\
\hline 3OHFA & & & & Thr & & & \\
\hline 1 & 167.6 & - & - & NH & - & 8.44 & $d(7.7)$ \\
\hline \multirow[t]{2}{*}{2} & 39.4 & 2.70 & obsc & 1 & 169.7 & - & - \\
\hline & & 2.16 & $\mathrm{dd}(13.6,3.2)$ & 2 & 59.5 & 4.20 & $\mathrm{dd}(7.7,2.3)$ \\
\hline 3 & 70.6 & 4.95 & $\mathrm{~m}$ & 3 & 65.0 & 4.35 & $\mathrm{dq}(2.5,6.5)$ \\
\hline 4 & 31.2 & 1.45 & $\mathrm{~m}$ & 4 & 20.4 & 1.23 & $\mathrm{~d}(6.5)$ \\
\hline 5 & 28.0 & 1.20 & obsc & DAPA2 & & & \\
\hline 6 & 28.0 & 1.20 & obsc & NH & - & 8.18 & $\mathrm{~d}(8.7)$ \\
\hline 7 & 28.0 & 1.20 & obsc & 1 & 169.2 & - & - \\
\hline 8 & 30.8 & 1.20 & obsc & 2 & 53.4 & 4.24 & $\operatorname{ddd}(8.7,8.7,5.4)$ \\
\hline 9 & 21.5 & 1.24 & obsc & 3 & 40.6 & 3.05 & $\mathrm{dd}(13.1,5.4)$ \\
\hline 10 & 13.5 & 0.85 & $\mathrm{t}(7.1)$ & & & 2.87 & $\mathrm{dd}(13.1,9.0)$ \\
\hline DAPA1 & & & & Phe & & & \\
\hline NH & - & 8.65 & $\mathrm{~d}(9.8)$ & NH & - & 7.20 & $\mathrm{~d}(9.0)$ \\
\hline 1 & 170.4 & - & - & 1 & 171.1 & - & - \\
\hline 2 & 50.3 & 4.77 & $\mathrm{~m}$ & 2 & 53.3 & 4.76 & obsc \\
\hline \multirow[t]{2}{*}{3} & 44.0 & 3.19 & $\mathrm{dd}(13.5,5.5)$ & 3 & 37.8 & 2.83 & $\mathrm{dd}(13.1,5.1)$ \\
\hline & & 2.94 & $\mathrm{dd}(13.5,3.7)$ & & & 2.72 & obsc \\
\hline Leu & & & & 4 & 136.9 & - & - \\
\hline NH & - & 8.91 & br d (4.4) & $5 / 9$ & 129.1 & 7.30 & $\mathrm{~m}$ \\
\hline 1 & 173.0 & - & - & $6 / 8$ & 127.6 & 7.20 & $\mathrm{~m}$ \\
\hline 2 & 53.0 & 4.28 & $\mathrm{~m}$ & 7 & 125.8 & 7.15 & $\mathrm{~m}$ \\
\hline \multirow[t]{2}{*}{3} & 39.2 & 1.64 & $\mathrm{~m}$ & Val & & & \\
\hline & & 1.50 & $\mathrm{~m}$ & NH & - & 8.60 & $\mathrm{~d}(9.7)$ \\
\hline 4 & 24.0 & 1.70 & $\mathrm{~m}$ & 1 & 169.8 & - & - \\
\hline 5 & 22.2 & 0.91 & $\mathrm{~d}(6.4)$ & 2 & 56.2 & 4.60 & $\operatorname{dd}(9.7,7.2)$ \\
\hline 6 & 22.2 & 0.86 & $\mathrm{~d}(6.6)$ & 3 & 30.5 & 1.79 & obsc \\
\hline DABA & & & & 4 & 17.7 & 0.69 & $\mathrm{~d}(6.8)$ \\
\hline NH & - & 8.67 & $\mathrm{~d}(9.6)$ & 5 & 18.6 & 0.61 & $\mathrm{~d}(6.8)$ \\
\hline 1 & 168.1 & - & - & $\overline{\text { Asp }}$ & & & \\
\hline 2 & 49.4 & 4.63 & $\mathrm{~m}$ & NH & - & 8.48 & $\mathrm{~d}(9.8)$ \\
\hline 3 & 29.0 & 1.82 & obsc & 1 & n.d. & - & - \\
\hline \multirow[t]{2}{*}{4} & 35.4 & 2.73 & obsc & 2 & 48.5 & 4.73 & $\operatorname{ddd}(9.8,4.2,4.2)$ \\
\hline & & 2.61 & obsc & 3 & 40.7 & 2.83 & obsc \\
\hline$\overline{\mathbf{A B A}}$ & & & & & & 2.22 & $\mathrm{dd}(15.6,4.2)$ \\
\hline NH & - & 10.23 & br s & 4 & 174.6 & - & - \\
\hline 1 & 165.4 & - & - & & & & \\
\hline 2 & 132.4 & - & - & & & & \\
\hline 3 & 114.3 & 5.58 & $\mathrm{q}(7.3)$ & & & & \\
\hline 4 & 12.5 & 1.77 & $\mathrm{~d}(7.3)$ & & & & \\
\hline
\end{tabular}


Supporting information

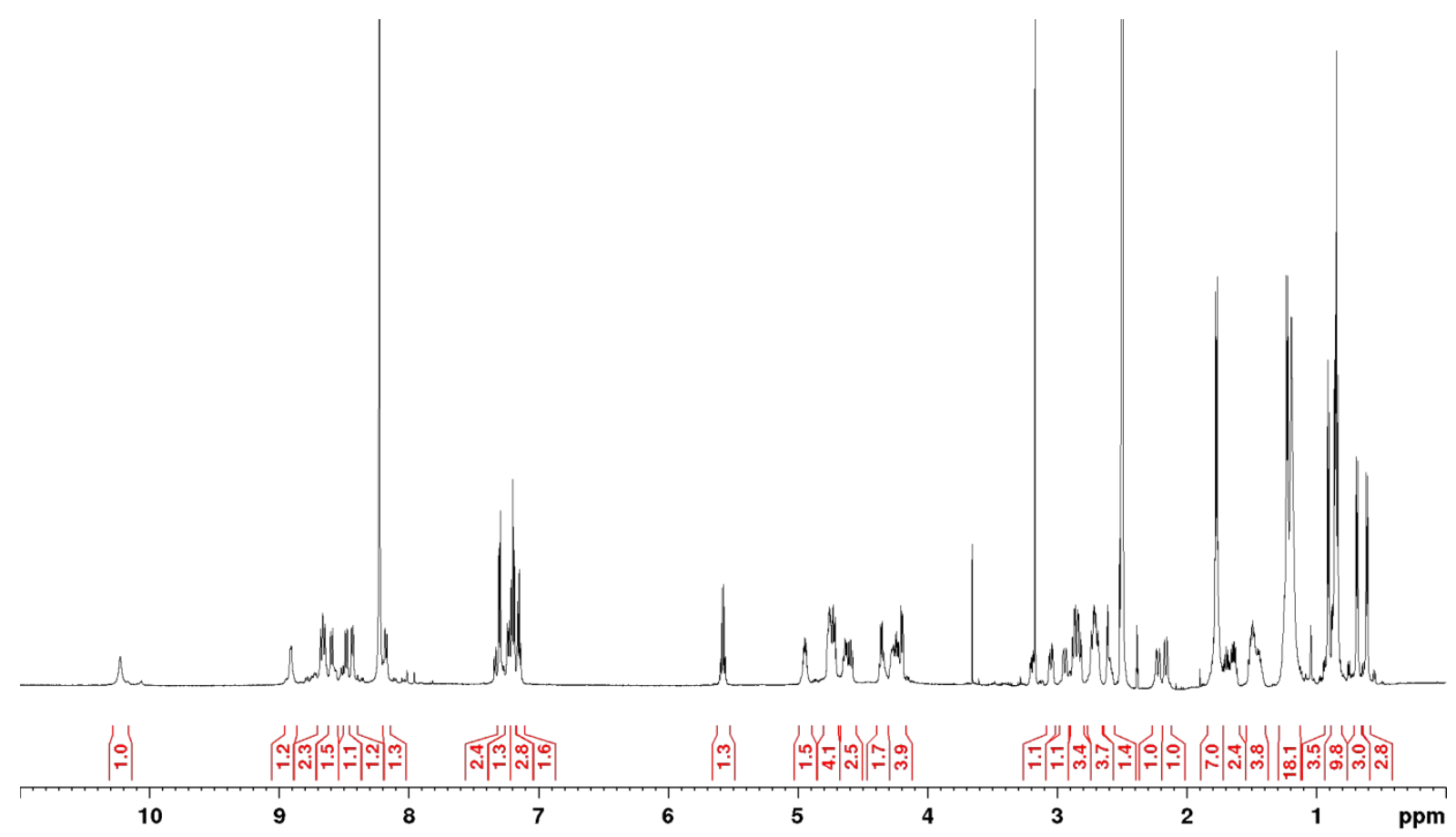

Figure S26. ${ }^{1} \mathrm{H}-\mathrm{NMR}$ spectrum of compound 4 (DMSO-d 6 , $\left.600 \mathrm{MHz}, 298 \mathrm{~K}\right)$.

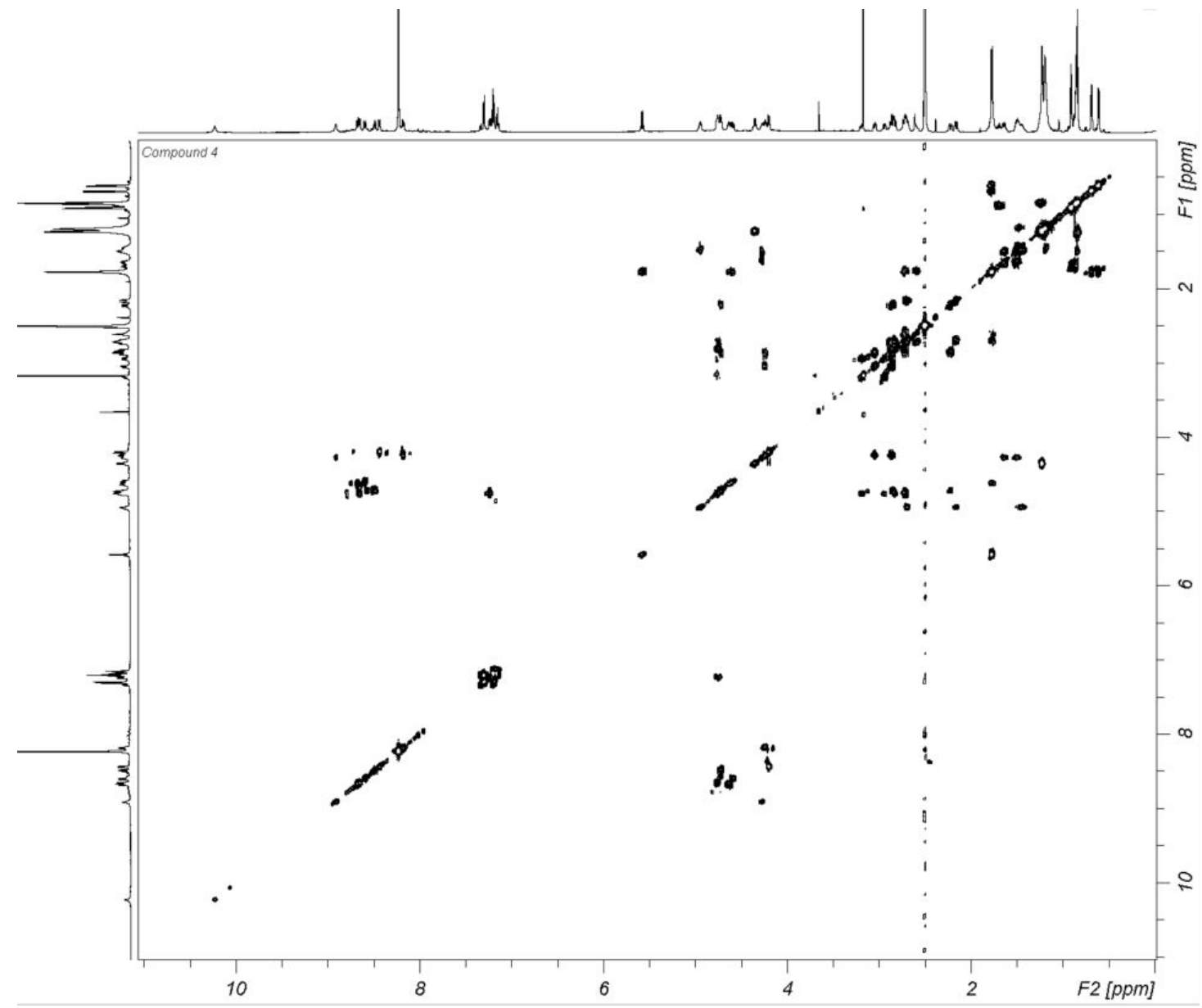

Figure S27. COSY spectrum of compound 4 (DMSO-d $\left.{ }_{6}, 600 \mathrm{MHz}, 298 \mathrm{~K}\right)$. 
Supporting information

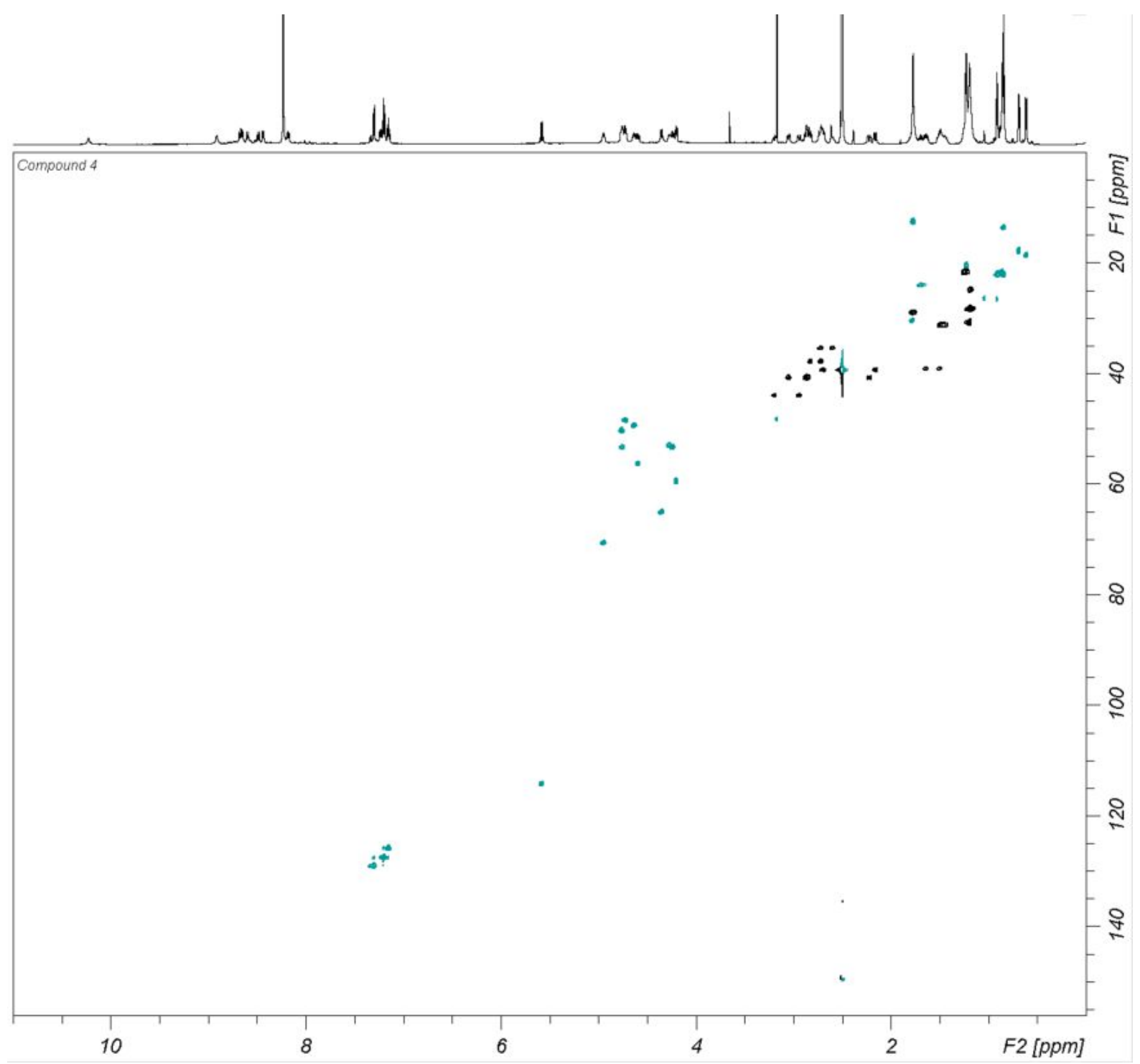

Figure S28. HSQC spectrum of compound 4 (DMSO-d 6 , 600 MHz, $298 \mathrm{~K})$. 
Supporting information

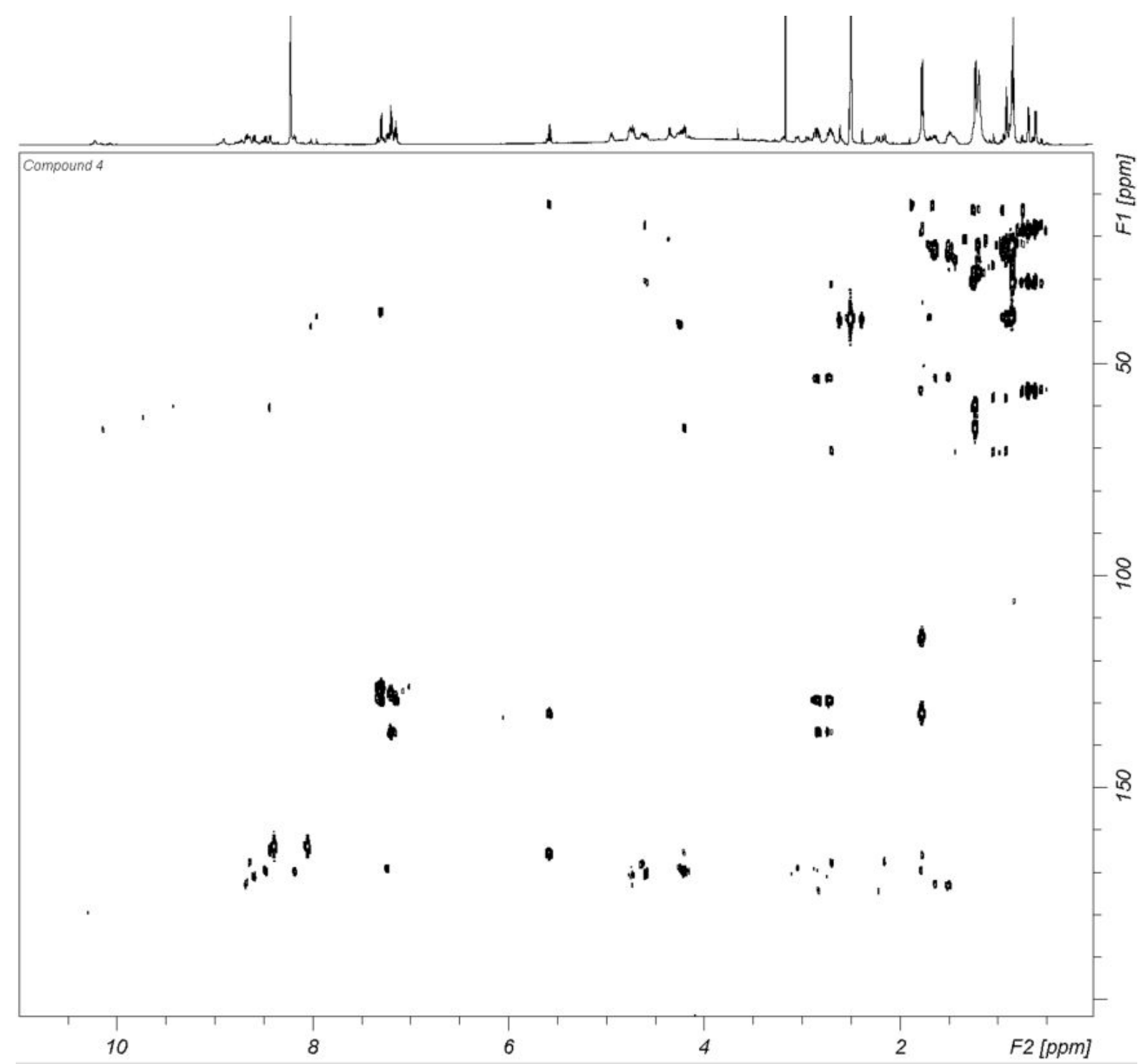

Figure S29. HMBC spectrum of compound 4 (DMSO-d ${ }_{6}, 600$ MHz, 298 K). 


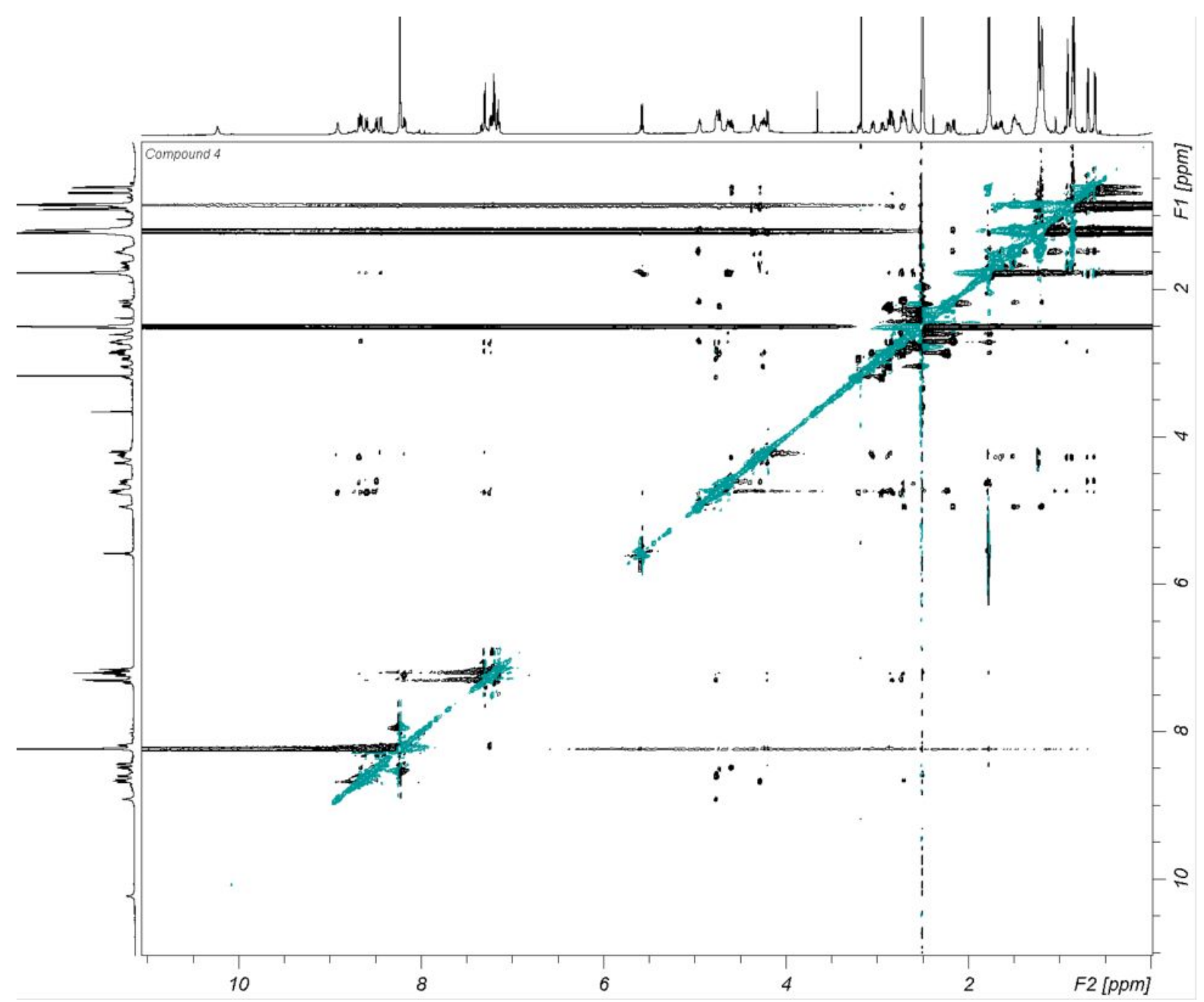

Figure S30. ROESY spectrum of compound 4 (DMSO-d 6 , $600 \mathrm{MHz}, 298 \mathrm{~K}$ ).

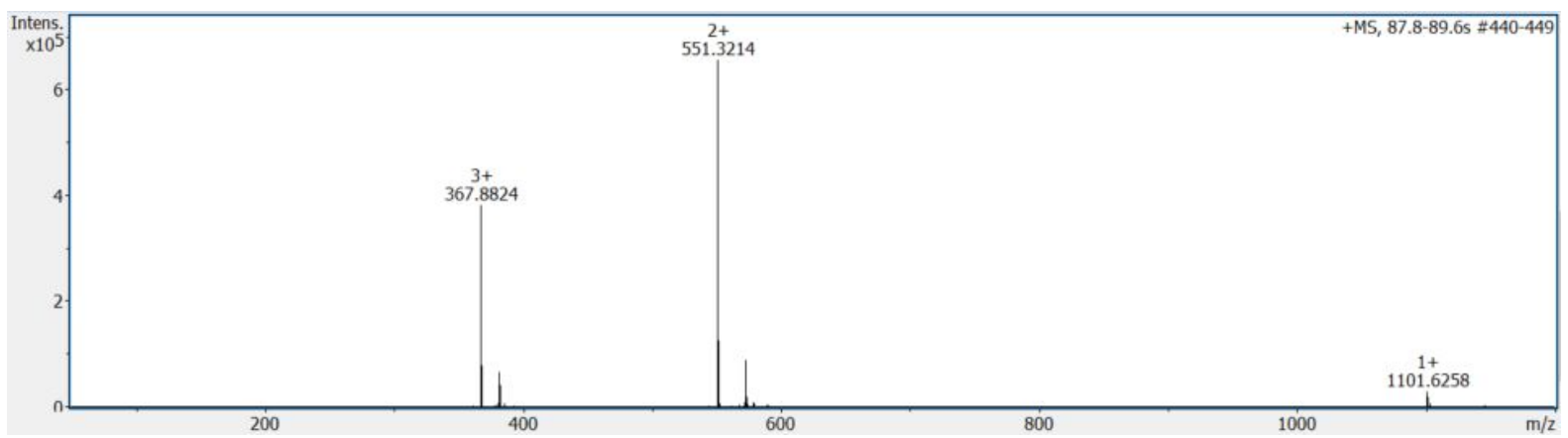

Figure S31. HR-MS spectrum of compound 4. 

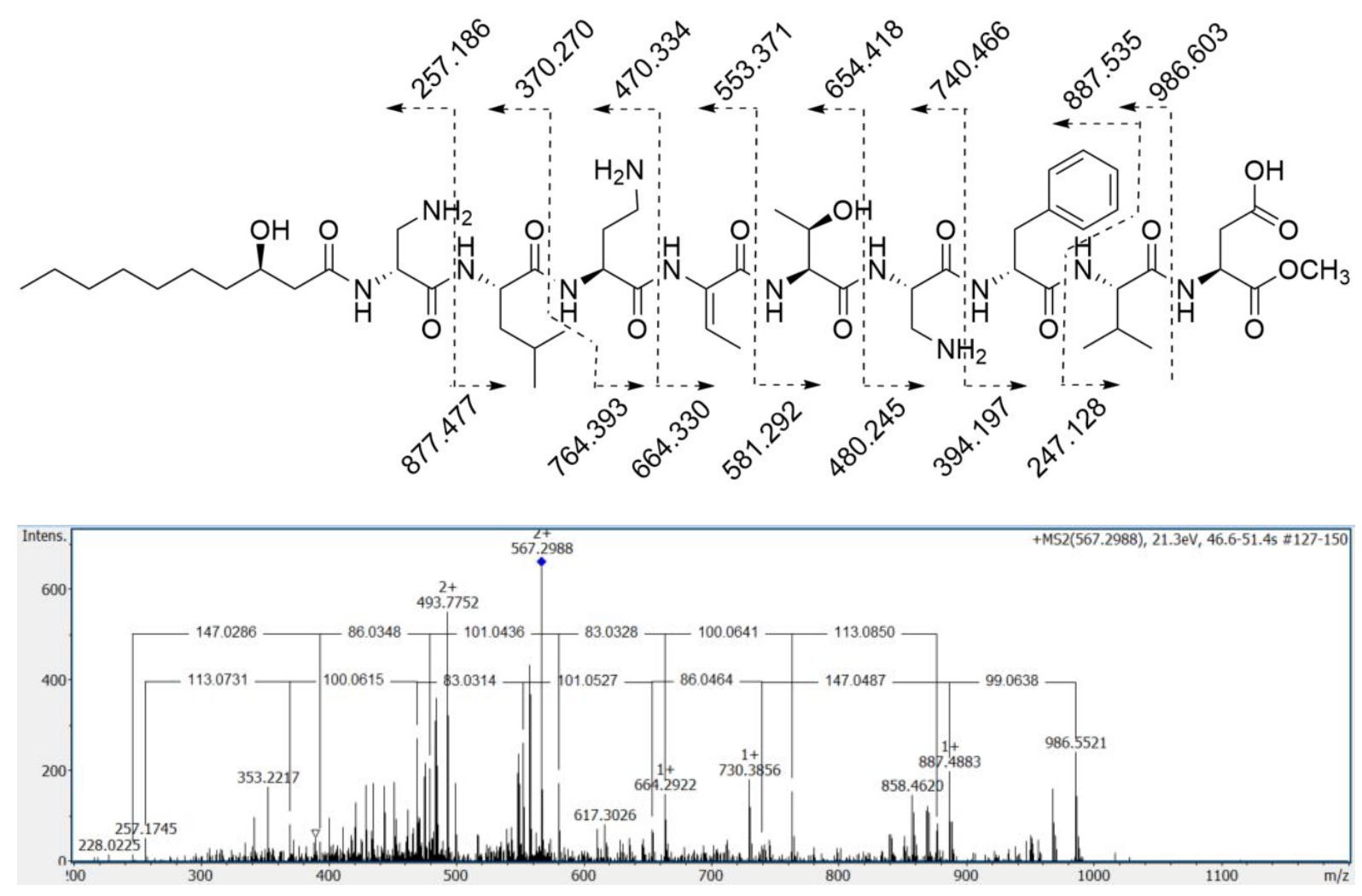

Figure S32. MSMS spectrum of compound 4 after treatment with $\mathrm{NaOMe}$ in $\mathrm{MeOH}$. Mass differences between Y-series ions (top) and B-series ions (bottom) are shown in the mass spectrum. Theoretical $\mathrm{m} / \mathrm{z}$-values for the observed B- and Y-series ions are shown in the structure on top. 
Table S5. ${ }^{1} \mathrm{H}$ and ${ }^{13} \mathrm{C}$ NMR-data (600 and $150 \mathrm{MHz}$, resp) for compound 5 (DMSO-d ${ }_{6} 30^{\circ} \mathrm{C}$ )

\begin{tabular}{|c|c|c|c|c|c|c|c|}
\hline Pos. & ${ }^{13} \mathrm{C}$ & ${ }^{1} \mathbf{H}$ & Mult $(J, \mathbf{H z})$ & Pos. & ${ }^{13} \mathrm{C}$ & ${ }^{1} \mathbf{H}$ & Mult $(J, \mathrm{~Hz})$ \\
\hline 3OHFA & & & & Thr & & & \\
\hline 1 & 168.2 & - & - & NH & - & 8.42 & $\mathrm{~d}(7.7)$ \\
\hline \multirow[t]{2}{*}{2} & 39.4 & 2.69 & $\mathrm{dd}(13.6,4.1)$ & 1 & 169.7 & - & - \\
\hline & & 2.15 & $\mathrm{dd}(13.6,3.0)$ & 2 & 59.6 & 4.20 & $\mathrm{dd}(7.7,2.3)$ \\
\hline 3 & 70.6 & 4.94 & $\mathrm{~m}$ & 3 & 65.1 & 4.35 & $\mathrm{dq}(2.3,6.4)$ \\
\hline 4 & 31.3 & 1.46 & obsc & 4 & 20.5 & 1.23 & $\mathrm{~d}(6.4)$ \\
\hline 5 & 26.2 & 1.19 & obsc & DAPA2 & & & \\
\hline 6 & 28.8 & 1.19 & obsc & NH & - & 8.16 & $\mathrm{~d}(9.2)$ \\
\hline 7 & 24.9 & 1.19 & obsc & 1 & 169.4 & - & - \\
\hline 8 & 38.0 & 1.10 & $\mathrm{~m}$ & 2 & 53.9 & 4.22 & $\mathrm{~m}$ \\
\hline 9 & 27.0 & 1.47 & obsc & 3 & 41.0 & 3.01 & br d (13.1) \\
\hline 10 & 22.2 & 0.83 & $d(6.6)$ & & & 2.86 & obsc \\
\hline 11 & 22.2 & 0.83 & $\mathrm{~d}(6.6)$ & Phe & & & \\
\hline DAPA1 & & & & NH & - & 7.22 & obsc \\
\hline NH & - & 8.66 & $\mathrm{~d}(8.4)$ & 1 & 170.7 & - & - \\
\hline 1 & 169.0 & - & - & 2 & 53.3 & 4.76 & obsc \\
\hline 2 & 48.4 & 4.72 & obsc & 3 & 37.9 & 2.82 & $\mathrm{dd}(13.3,5.0)$ \\
\hline \multirow[t]{2}{*}{3} & 44.3 & 3.18 & br d (13.1) & & & 2.72 & obsc \\
\hline & & 2.91 & br d (13.1) & 4 & 137.0 & - & - \\
\hline Leu & & & & $5 / 9$ & 129.1 & 7.30 & $\mathrm{~m}$ \\
\hline NH & - & 8.86 & br s & $6 / 8$ & 127.6 & 7.20 & $\mathrm{~m}$ \\
\hline 1 & 172.9 & - & - & 7 & 125.8 & 7.15 & $\mathrm{~m}$ \\
\hline 2 & 52.9 & 4.27 & $\mathrm{~m}$ & Val & & & \\
\hline \multirow[t]{2}{*}{3} & 39.2 & 1.64 & $\mathrm{~m}$ & NH & - & 8.59 & $\mathrm{~d}(9.5)$ \\
\hline & & 1.50 & obsc & 1 & 170.3 & - & - \\
\hline 4 & 24.0 & 1.69 & $\mathrm{~m}$ & 2 & 56.3 & 4.60 & $\mathrm{dd}(9.5,7.2)$ \\
\hline 5 & 22.1 & 0.91 & $\mathrm{~d}(6.5)$ & 3 & 30.5 & 1.78 & obsc \\
\hline 6 & 21.8 & 0.86 & $\mathrm{~d}(6.5)$ & 4 & 17.7 & 0.69 & $\mathrm{~d}(6.9)$ \\
\hline$\overline{\text { DABA }}$ & & & & 5 & 18.6 & 0.62 & $\mathrm{~d}(6.9)$ \\
\hline NH & - & 8.67 & $\mathrm{~d}(9.3)$ & $\overline{\text { Asp }}$ & & & \\
\hline 1 & 168.1 & - & - & NH & - & 8.49 & $\mathrm{~d}(9.8)$ \\
\hline 2 & 49.5 & 4.63 & $\mathrm{~m}$ & 1 & n.d. & - & - \\
\hline 3 & 29.1 & 1.77 & obsc & 2 & 48.4 & 4.72 & obsc \\
\hline \multirow[t]{2}{*}{4} & 35.5 & 2.73 & obsc & 3 & 40.8 & 2.87 & obsc \\
\hline & & 2.60 & obsc & & & 2.22 & $\mathrm{dd}(15.7,4.0)$ \\
\hline$\overline{\mathrm{ABA}}$ & & & & 4 & n.d. & - & - \\
\hline NH & - & 10.20 & br s & & & & \\
\hline 1 & 165.5 & - & - & & & & \\
\hline 2 & 132.8 & - & - & & & & \\
\hline 3 & 114.4 & 5.58 & $\mathrm{q}(7.3)$ & & & & \\
\hline 4 & 12.5 & 1.77 & $\mathrm{~d}(7.3)$ & & & & \\
\hline
\end{tabular}


Supporting information

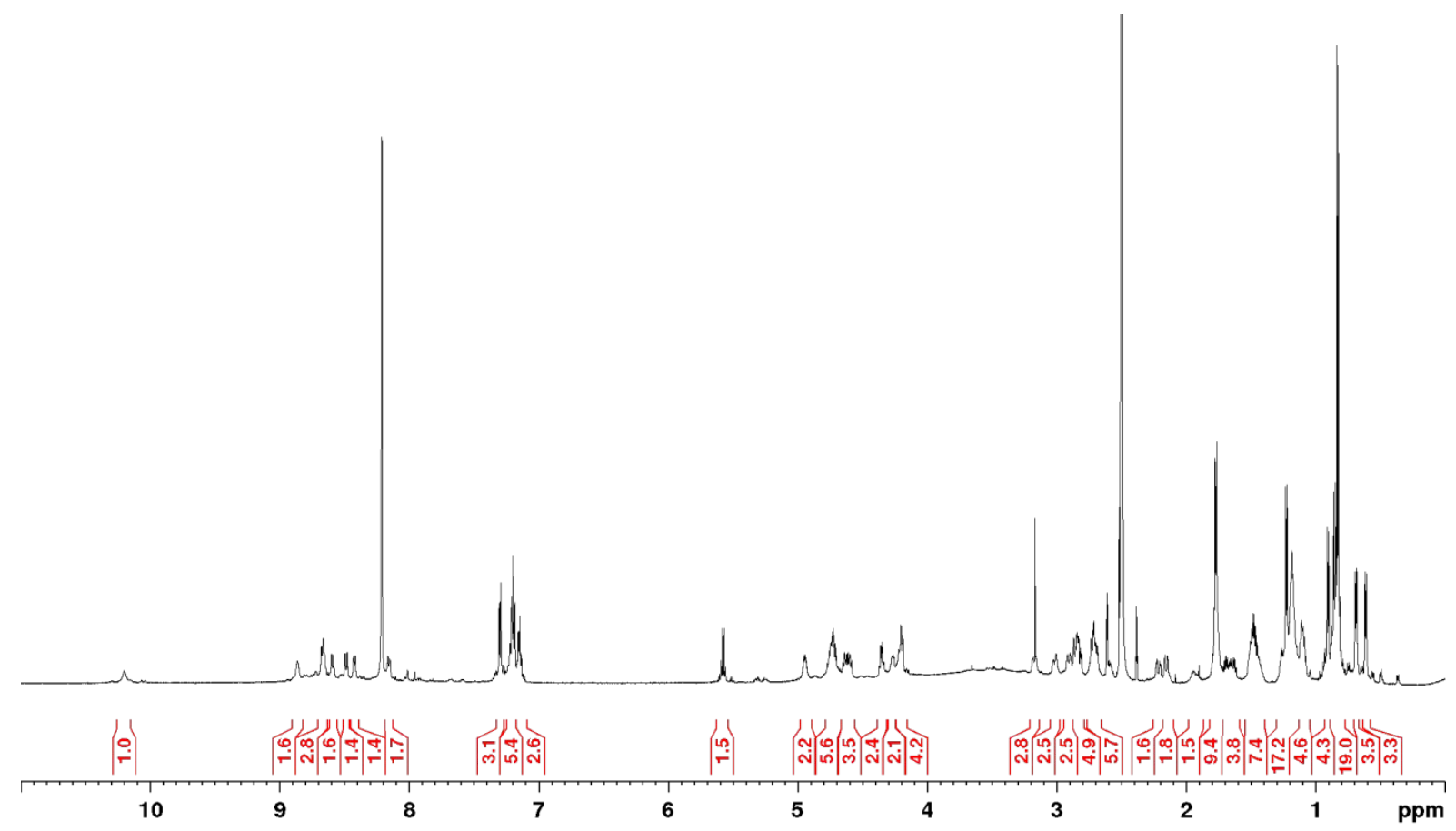

Figure S33. ${ }^{1} \mathrm{H}-\mathrm{NMR}$ spectrum of compound $\mathbf{5}\left(\mathrm{DMSO}^{\mathrm{d}} \mathrm{d}_{6}, 600 \mathrm{MHz}, 298 \mathrm{~K}\right)$.

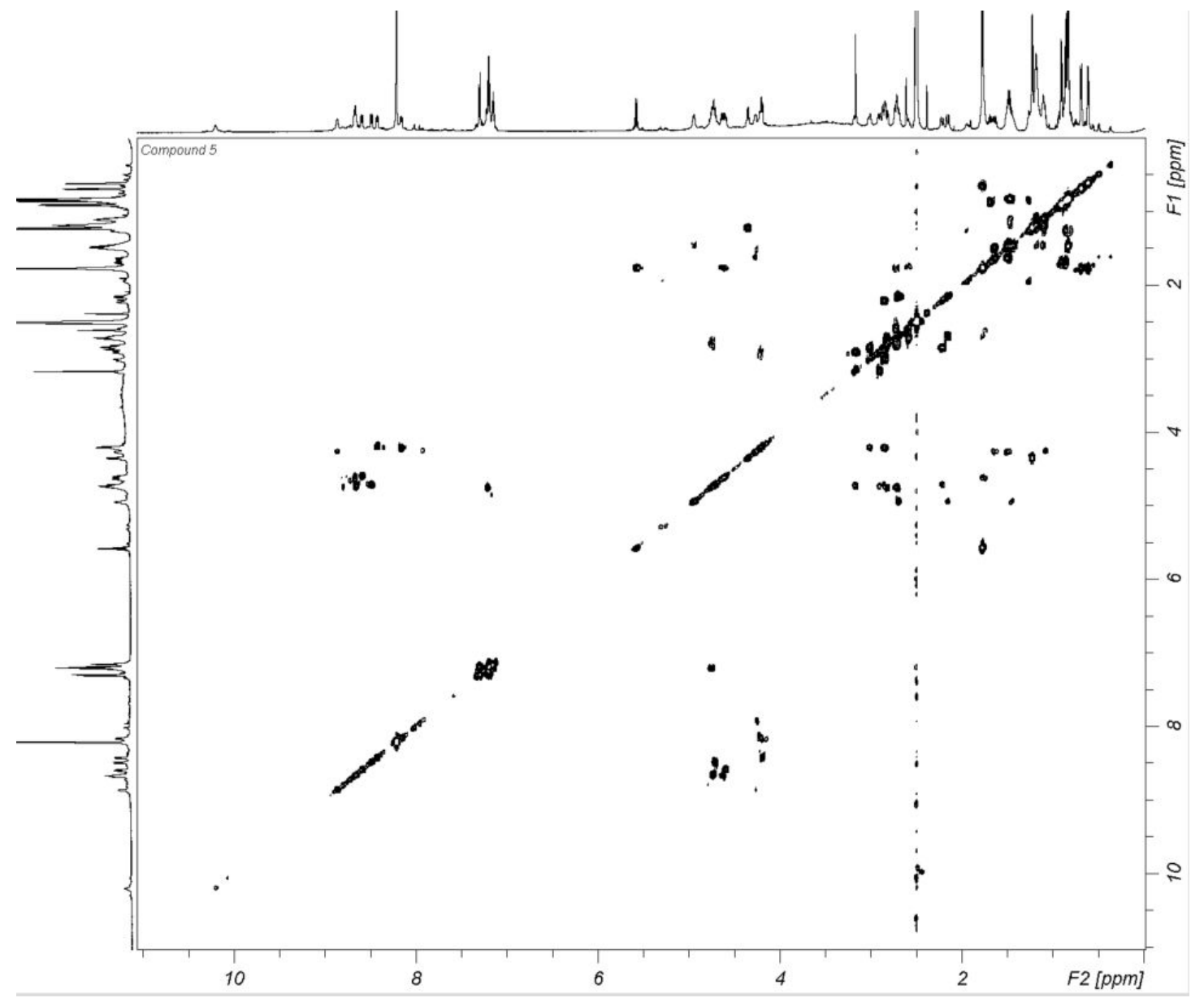

Figure S34. COSY spectrum of compound $5\left(D M S O-d_{6}, 600 \mathrm{MHz}, 298 \mathrm{~K}\right)$. 
Supporting information

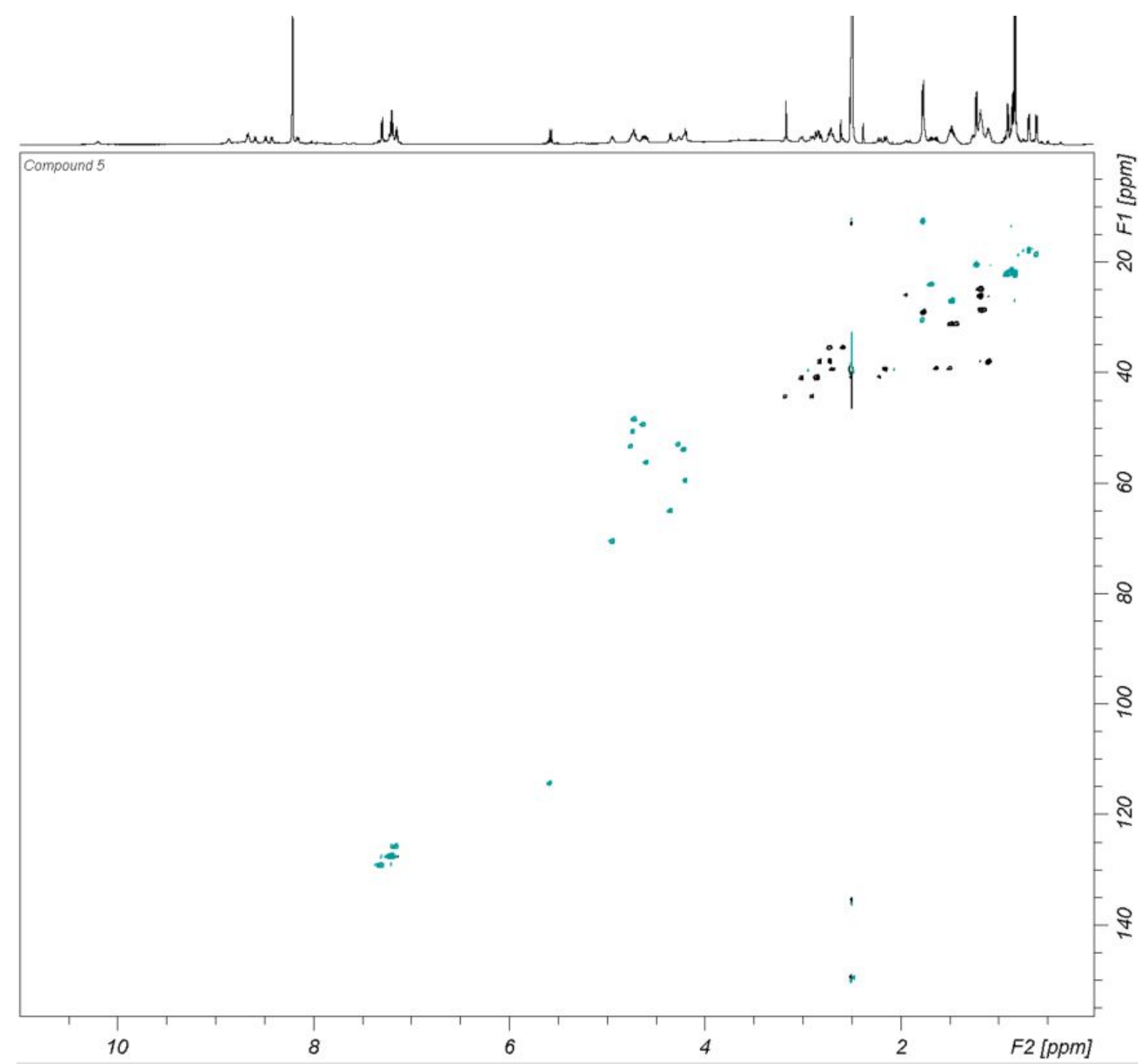

Figure S35. HSQC spectrum of compound 5 (DMSO-d 6 , 600 MHz, $298 \mathrm{~K})$. 


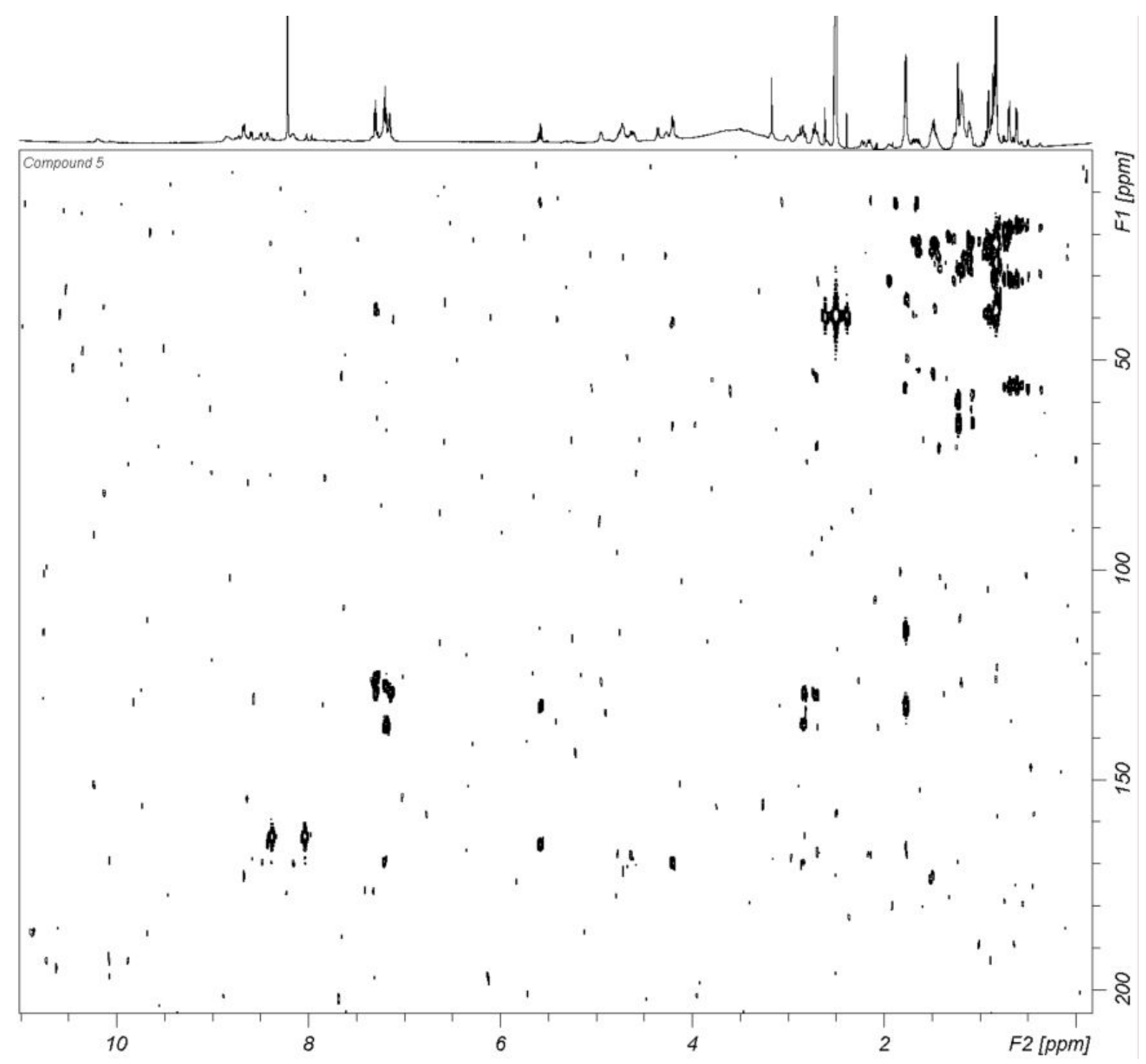

Figure S36. HMBC spectrum of compound 5 (DMSO-d ${ }_{6}, 600$ MHz, 298 K). 


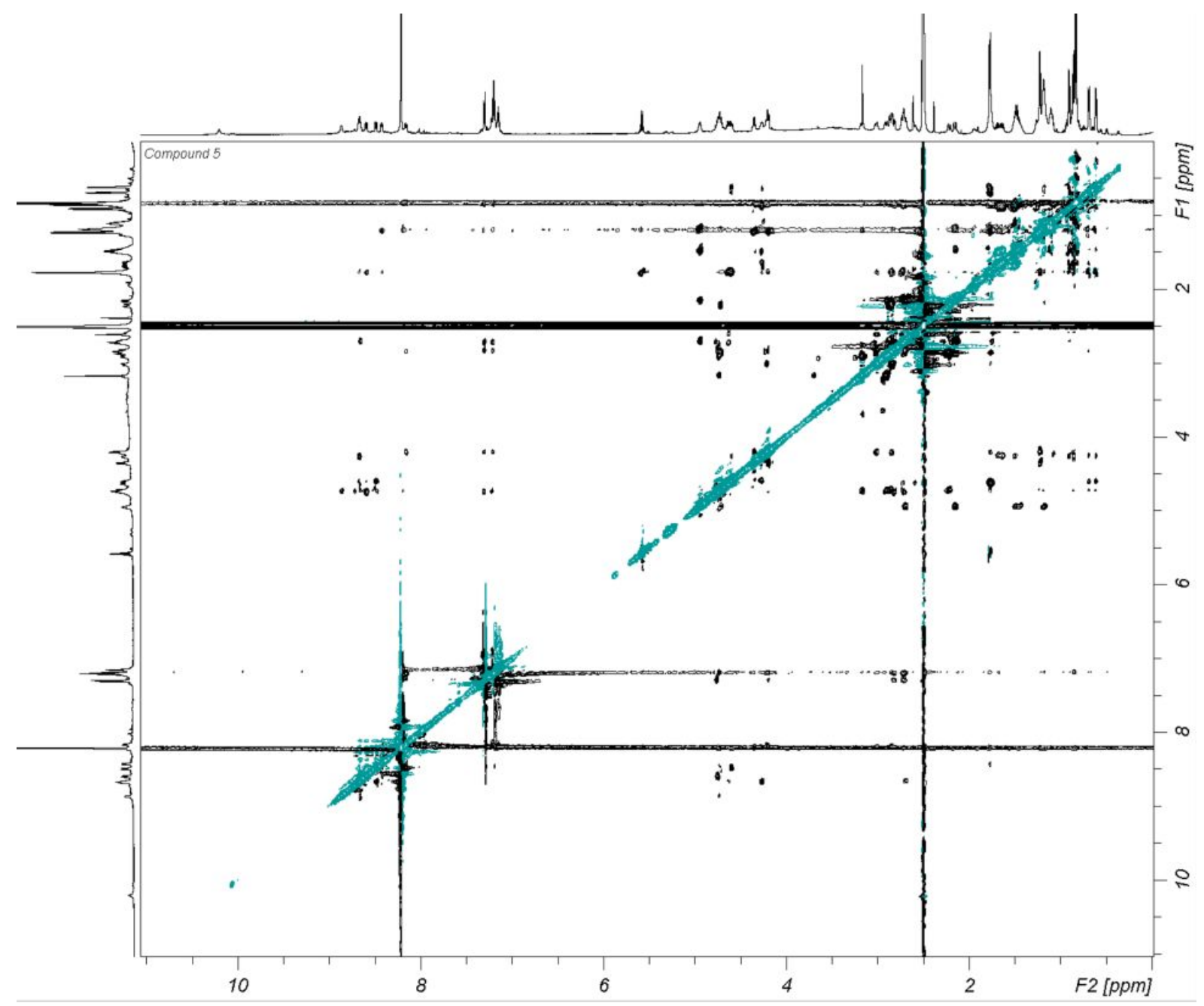

Figure S37. ROESY spectrum of compound 5 (DMSO-d 6 , 600 MHz, $298 \mathrm{~K}$ ).

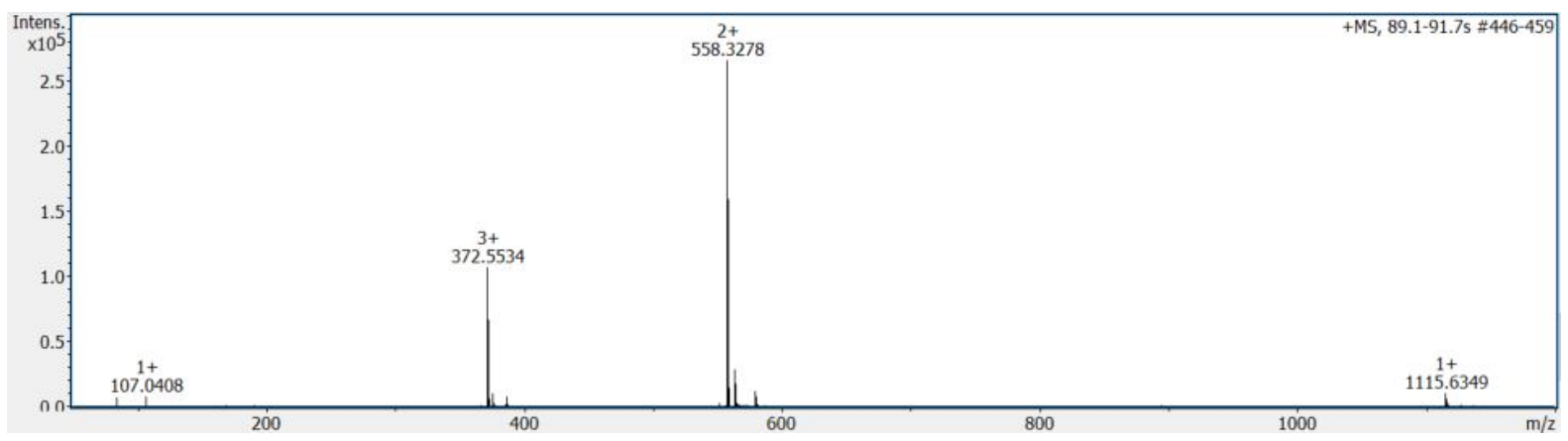

Figure S38. HRMS spectrum of compound 5. 

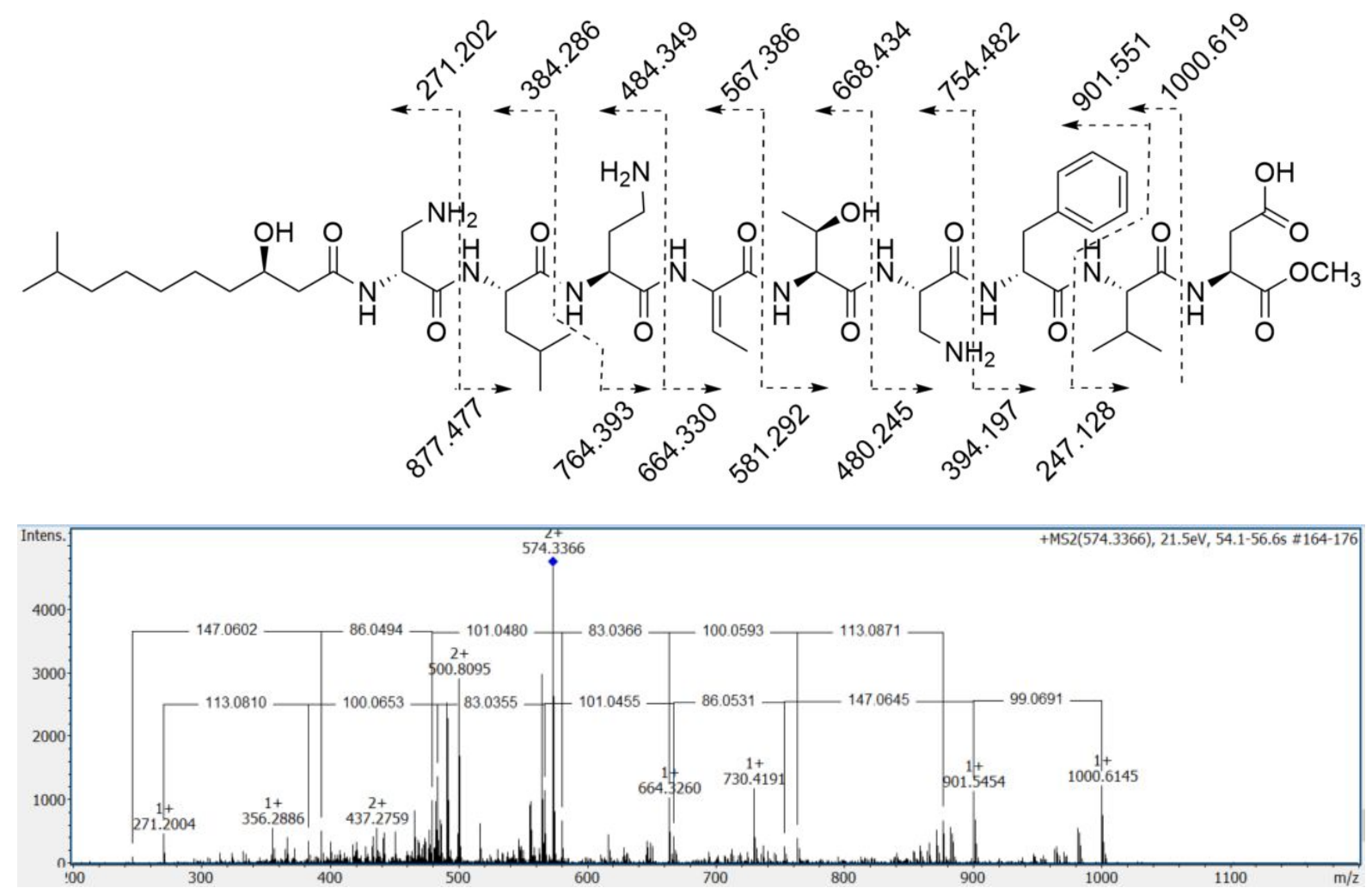

Figure S39. MSMS spectrum of compound 5 after treatment with $\mathrm{NaOMe}$ in $\mathrm{MeOH}$. Mass differences between Y-series ions (top) and B-series ions (bottom) are shown in the mass spectrum. Theoretical $\mathrm{m} / \mathrm{z}$-values for the observed B- and Y-series ions are shown in the structure on top. 
Table S6. ${ }^{1} \mathrm{H}$ and ${ }^{13} \mathrm{C}$ NMR-data (600 and $150 \mathrm{MHz}$, resp) for compound 6 (DMSO-d ${ }_{6}, 30^{\circ} \mathrm{C}$ )

\begin{tabular}{|c|c|c|c|c|c|c|c|}
\hline Pos. & ${ }^{13} \mathrm{C}$ & ${ }^{1} \mathrm{H}$ & Mult $(J, \mathrm{~Hz})$ & Pos. & ${ }^{13} \mathrm{C}$ & ${ }^{1} \mathbf{H}$ & Mult $(J, \mathbf{H z})$ \\
\hline 3OHFA & & & & Thr & & & \\
\hline 1 & 167.7 & - & - & NH & - & 8.44 & $\mathrm{~d}(7.9)$ \\
\hline \multirow[t]{2}{*}{2} & 39.4 & 2.69 & obsc & 1 & 170.0 & - & - \\
\hline & & 2.12 & $\mathrm{dd}(13.3,3.2)$ & 2 & 59.4 & 4.20 & $\mathrm{dd}(7.9,2.3)$ \\
\hline 3 & 70.5 & 4.96 & $\mathrm{~m}$ & 3 & 65.1 & 4.34 & $\mathrm{dq}(2.3,6.5)$ \\
\hline \multirow[t]{2}{*}{4} & 31.1 & 1.47 & obsc & 4 & 20.5 & 1.22 & $\mathrm{~d}(6.5)$ \\
\hline & & 1.44 & obsc & DAPA2 & & & \\
\hline 5 & 26.4 & 1.21 & obsc & NH & - & 8.06 & $\mathrm{~d}(8.5)$ \\
\hline 6 & 28.7 & 1.20 & obsc & 1 & 170.1 & - & - \\
\hline 7 & 28.7 & 1.20 & obsc & 2 & 54.7 & 4.13 & $\operatorname{ddd}(8.5,8.5,5.1)$ \\
\hline 8 & 28.7 & 1.20 & obsc & 3 & 41.6 & 2.91 & obsc \\
\hline 9 & 25.0 & 1.20 & obsc & & & 2.84 & obsc \\
\hline 10 & 38.1 & 1.13 & $\mathrm{~m}$ & Phe & & & \\
\hline 11 & 27.0 & 1.49 & $\mathrm{~m}$ & NH & - & 7.23 & obsc \\
\hline 12 & 22.2 & 0.85 & $\mathrm{~d}(6.7)$ & 1 & 171.6 & - & - \\
\hline 13 & 22.2 & 0.85 & $d(6.7)$ & 2 & 53.4 & 4.76 & $\operatorname{ddd}(9.9,9.9,4.3)$ \\
\hline DAPA1 & & & & 3 & 37.6 & 2.88 & obsc \\
\hline NH & - & 8.68 & $\mathrm{~d}(8.9)$ & & & 2.70 & obsc \\
\hline 1 & 171.4 & - & - & 4 & 137.1 & - & - \\
\hline 2 & 51.9 & 4.63 & ddd $(8.9,4.7,4.7)$ & $5 / 9$ & 129.3 & 7.33 & $\mathrm{~m}$ \\
\hline \multirow[t]{2}{*}{3} & 45.0 & 3.04 & $\mathrm{dd}(13.1,4.7)$ & $6 / 8$ & 127.6 & 7.20 & $\mathrm{~m}$ \\
\hline & & 2.77 & obsc & 7 & 125.9 & 7.15 & $\mathrm{~m}$ \\
\hline Leu & & & & OHVal & & & \\
\hline NH & - & 8.78 & br s & NH & - & 8.55 & $d(9.7)$ \\
\hline 1 & 172.8 & - & - & 1 & 169.6 & - & - \\
\hline 2 & 52.6 & 4.32 & obsc & 2 & 57.9 & 4.77 & $\mathrm{~d}(9.6)$ \\
\hline \multirow[t]{2}{*}{3} & 39.2 & 1.63 & obsc & 3 & 70.6 & - & - \\
\hline & & 1.42 & $\mathrm{~m}$ & 4 & 26.5 & 1.04 & $\mathrm{~s}$ \\
\hline 4 & 24.1 & 1.62 & obsc & 5 & 26.6 & 0.92 & $\mathrm{~s}$ \\
\hline 5 & 22.0 & 0.87 & $\mathrm{~d}(6.4)$ & $\overline{\text { Asp }}$ & & & \\
\hline 6 & 22.3 & 0.83 & $\mathrm{~d}(6.5)$ & NH & - & 8.57 & $\mathrm{~d}(9.7)$ \\
\hline$\overline{\text { DABA }}$ & & & & 1 & 172.3 & - & - \\
\hline NH & - & 8.63 & $\mathrm{~d}(9.7)$ & 2 & 48.3 & 4.70 & $\operatorname{ddd}(9.7,3.8,3.8)$ \\
\hline 1 & 168.4 & - & - & 3 & 40.6 & 2.85 & $\mathrm{~m}$ \\
\hline 2 & 49.5 & 4.66 & $\mathrm{~m}$ & & & 2.20 & $\mathrm{~d}(16.0,3.8)$ \\
\hline \multirow[t]{2}{*}{3} & 29.5 & 1.84 & $\mathrm{~m}$ & & & & \\
\hline & & 1.79 & $\mathrm{~m}$ & 4 & 173.4 & - & - \\
\hline 4 & 35.4 & $\begin{array}{l}2.76 \\
2.57\end{array}$ & $\begin{array}{l}\text { obsc } \\
\text { ddd }(11.3,4.5,4.5)\end{array}$ & & & & \\
\hline \multicolumn{8}{|l|}{$\overline{\text { ABA }}$} \\
\hline NH & - & 10.21 & br s & & & & \\
\hline 1 & 165.4 & - & - & & & & \\
\hline 2 & 132.7 & - & - & & & & \\
\hline 3 & 113.9 & 5.56 & $\mathrm{q}(7.3)$ & & & & \\
\hline 4 & 12.5 & 1.76 & $\mathrm{~d}(7.3)$ & & & & \\
\hline
\end{tabular}


Supporting information

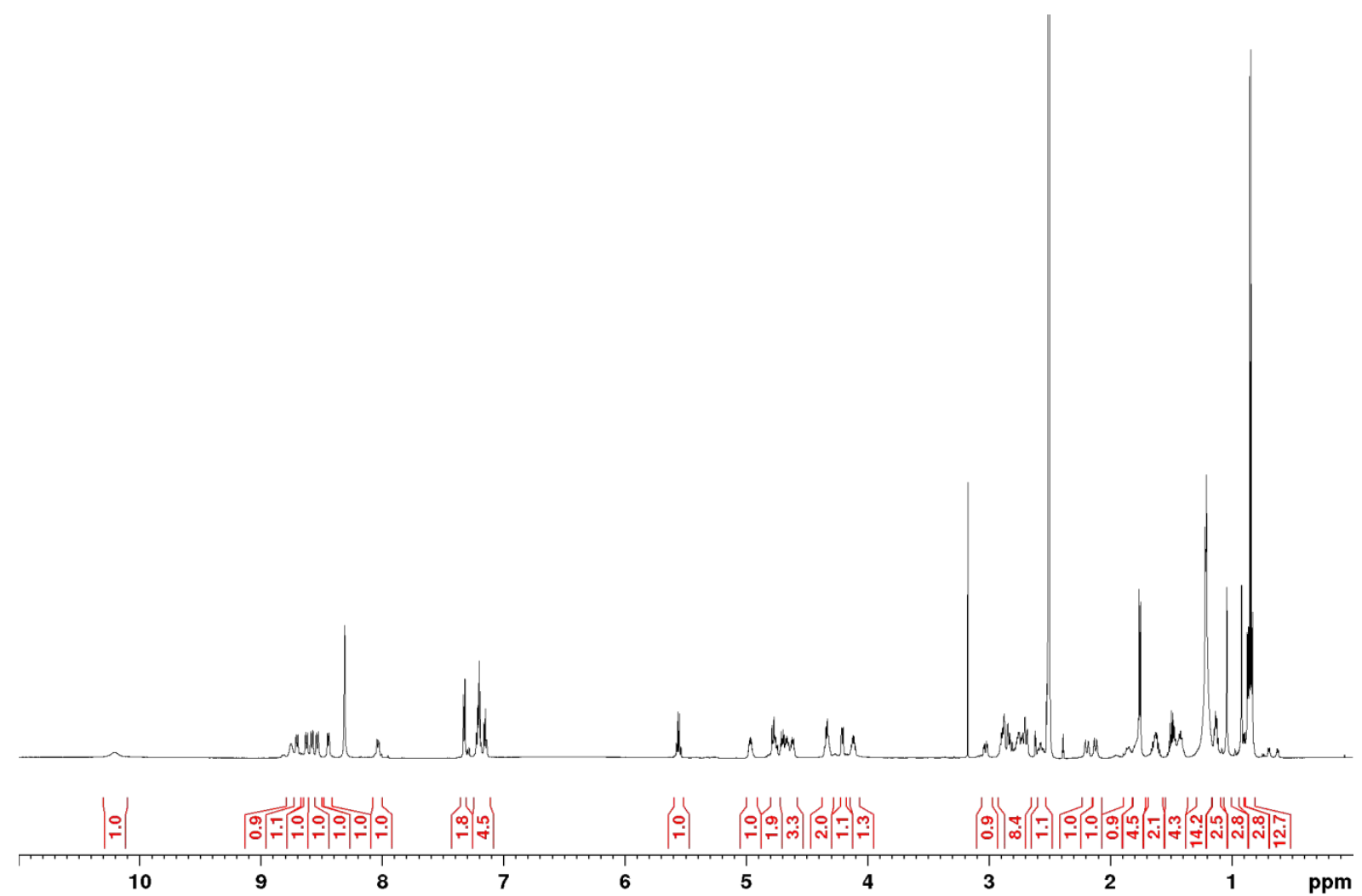

Figure S40. ${ }^{1} \mathrm{H}-\mathrm{NMR}$ spectrum of compound 6 (DMSO-d $\left.{ }_{6}, 600 \mathrm{MHz}, 298 \mathrm{~K}\right)$.

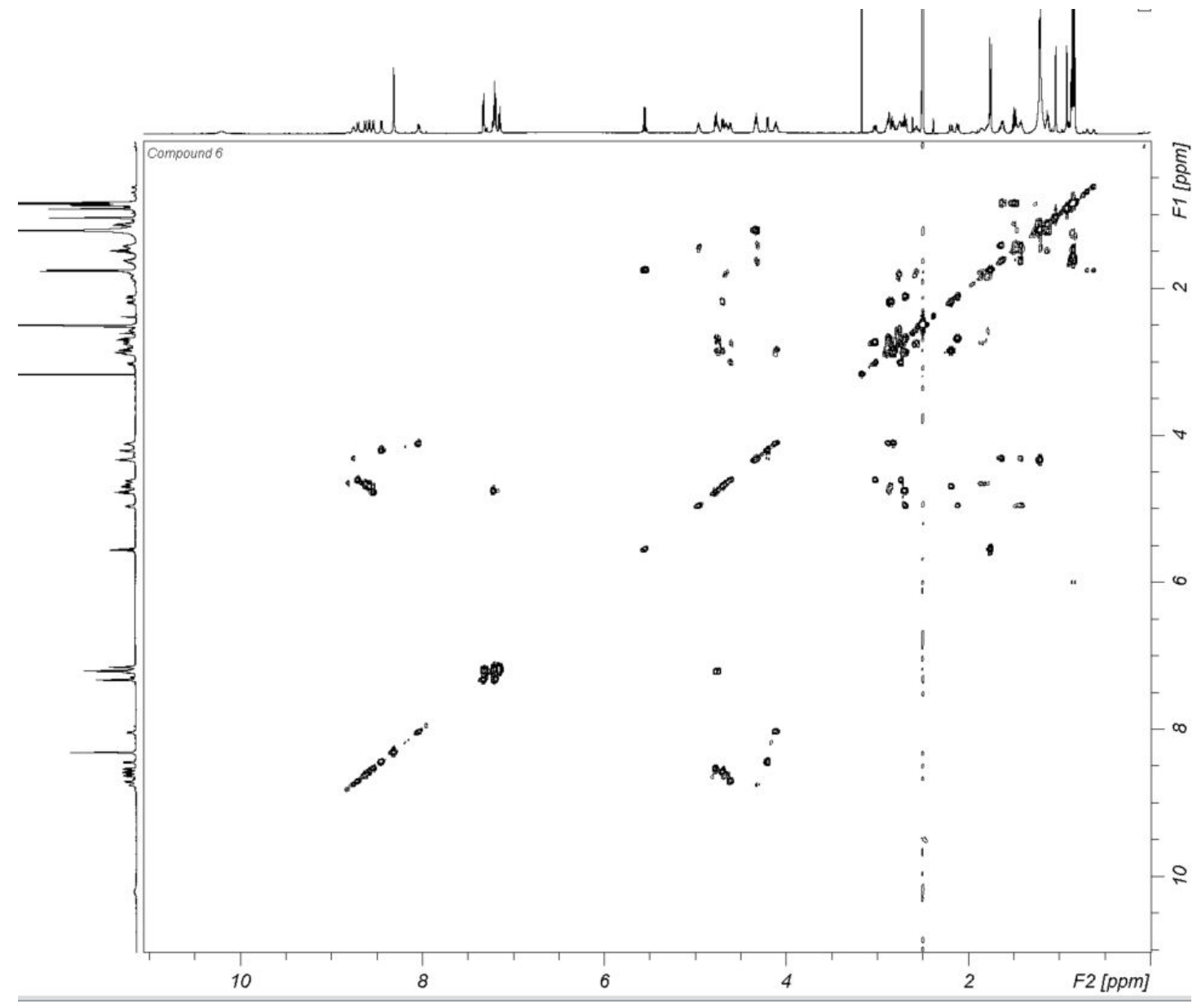


Figure S41. COSY spectrum of compound 6 (DMSO-d 6 , 600 MHz, 298 K).

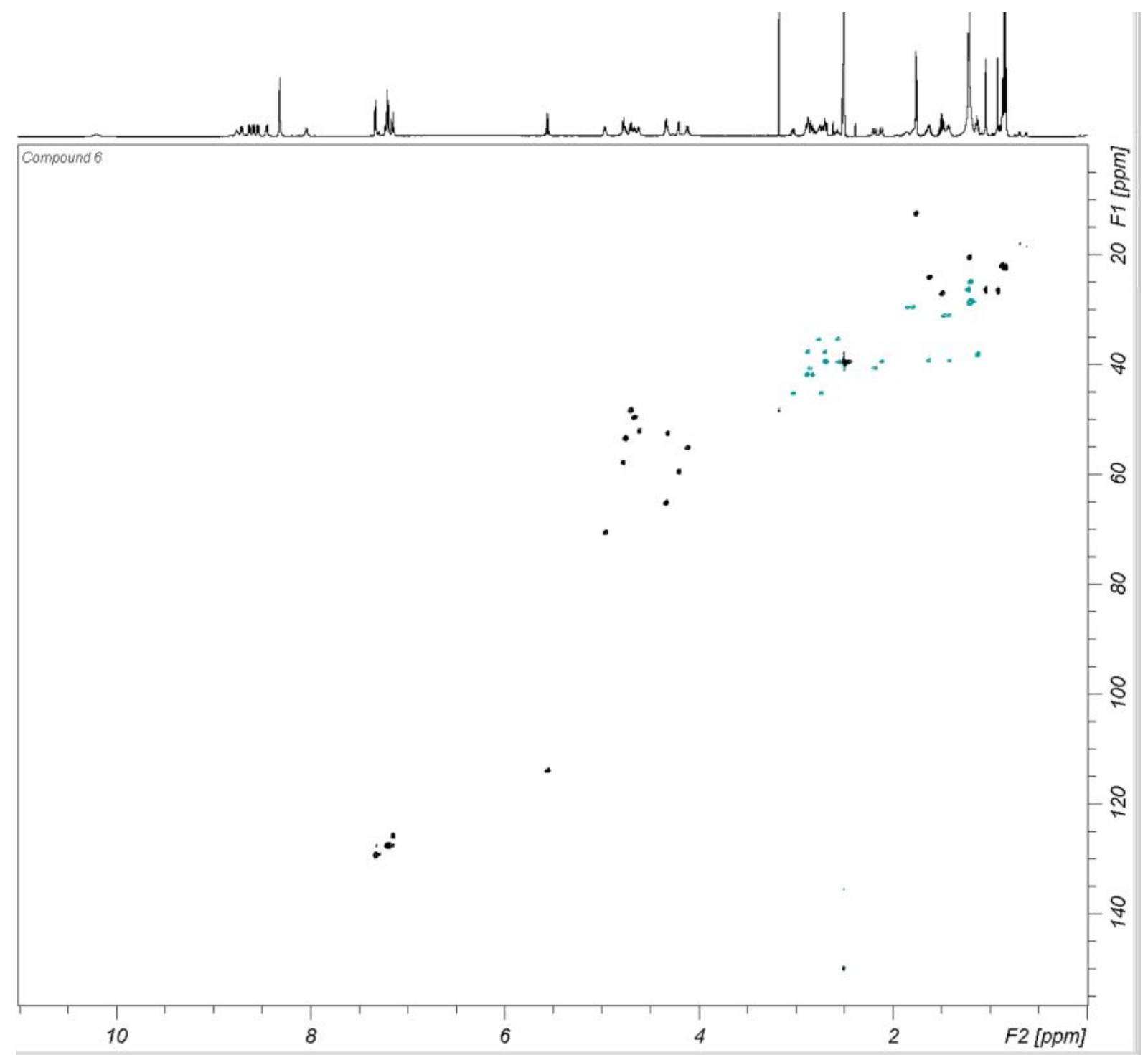

Figure S42. HSQC spectrum of compound 6 (DMSO-d 6 , $600 \mathrm{MHz}, 298 \mathrm{~K})$. 
Supporting information

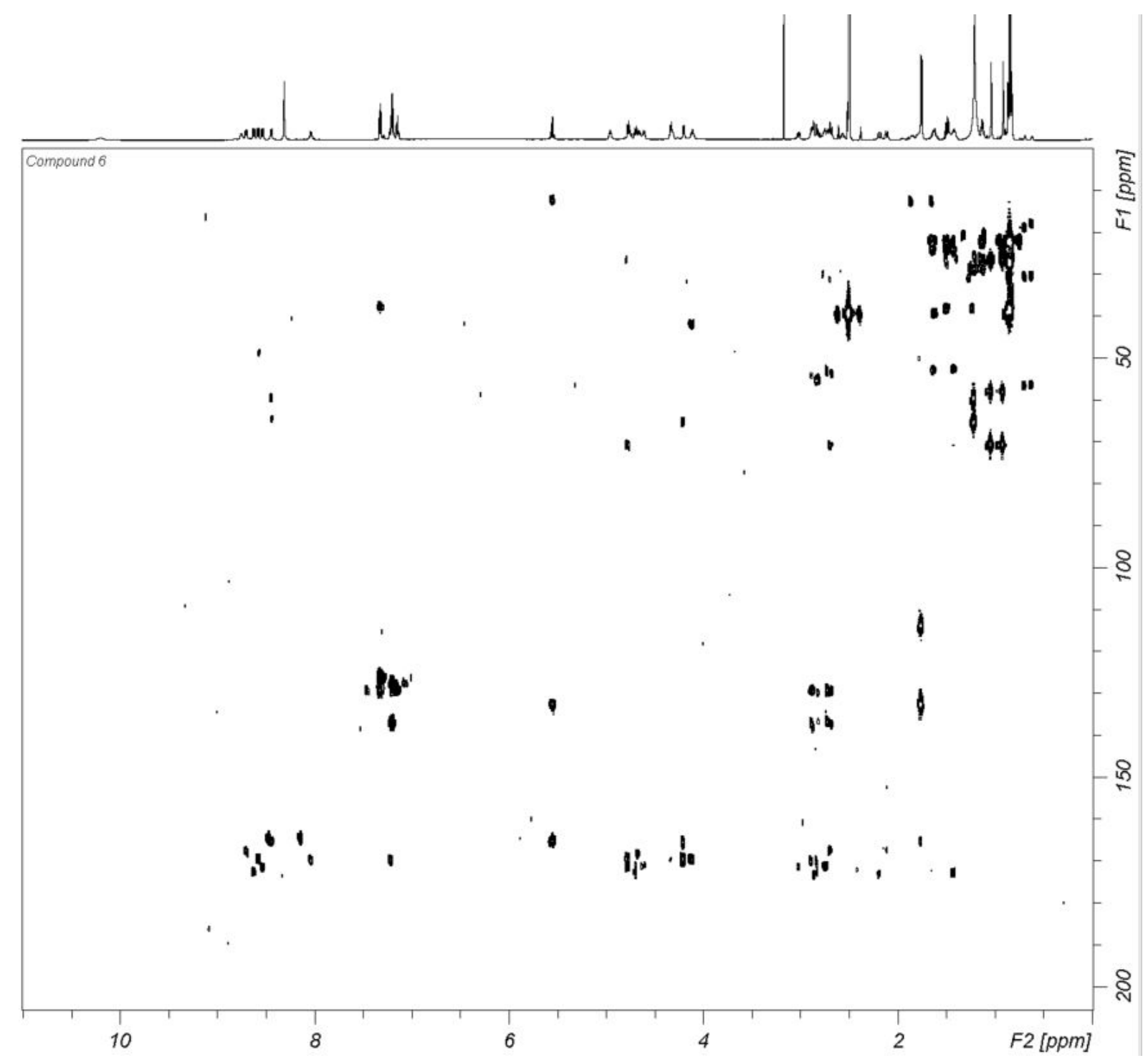

Figure S43. HMBC spectrum of compound 6 (DMSO-d 6 , 600 MHz, $298 \mathrm{~K}$ ). 


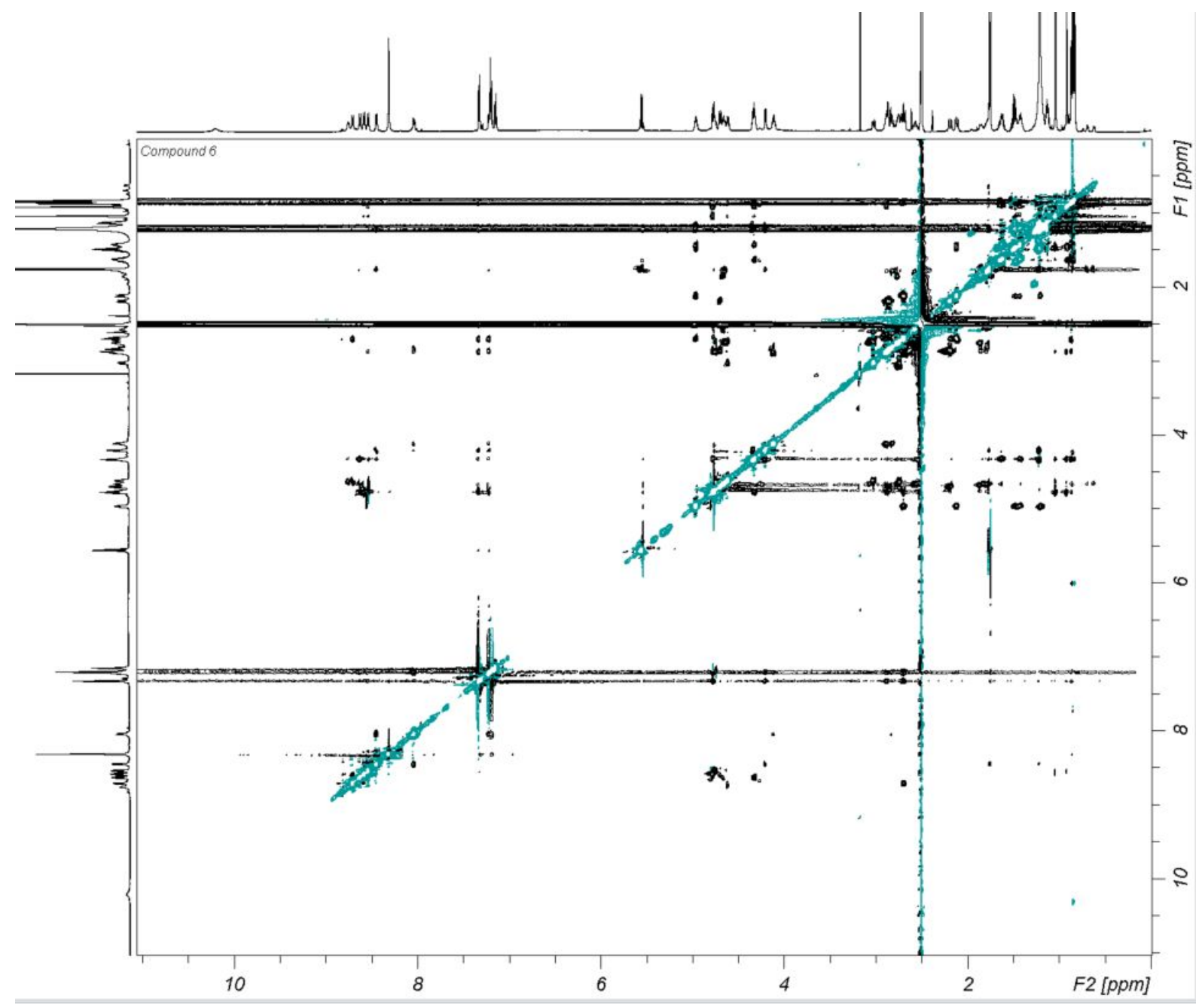

Figure S44. ROESY spectrum of compound 6 (DMSO-d $\left.\mathrm{d}_{6}, 600 \mathrm{MHz}, 298 \mathrm{~K}\right)$.

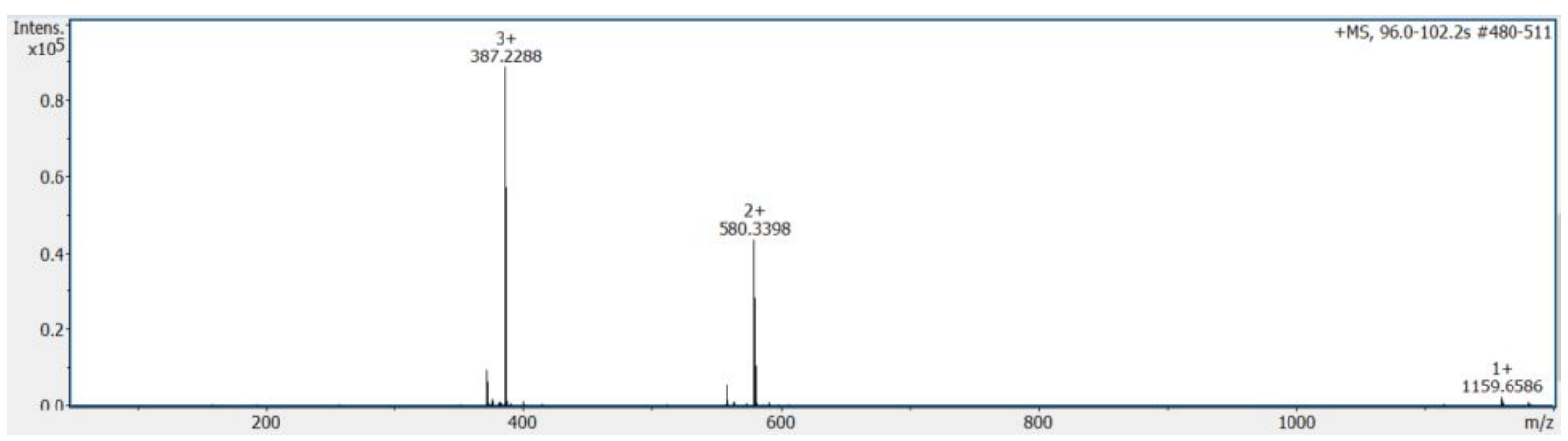

Figure S45. HRMS spectrum of compound 6. 

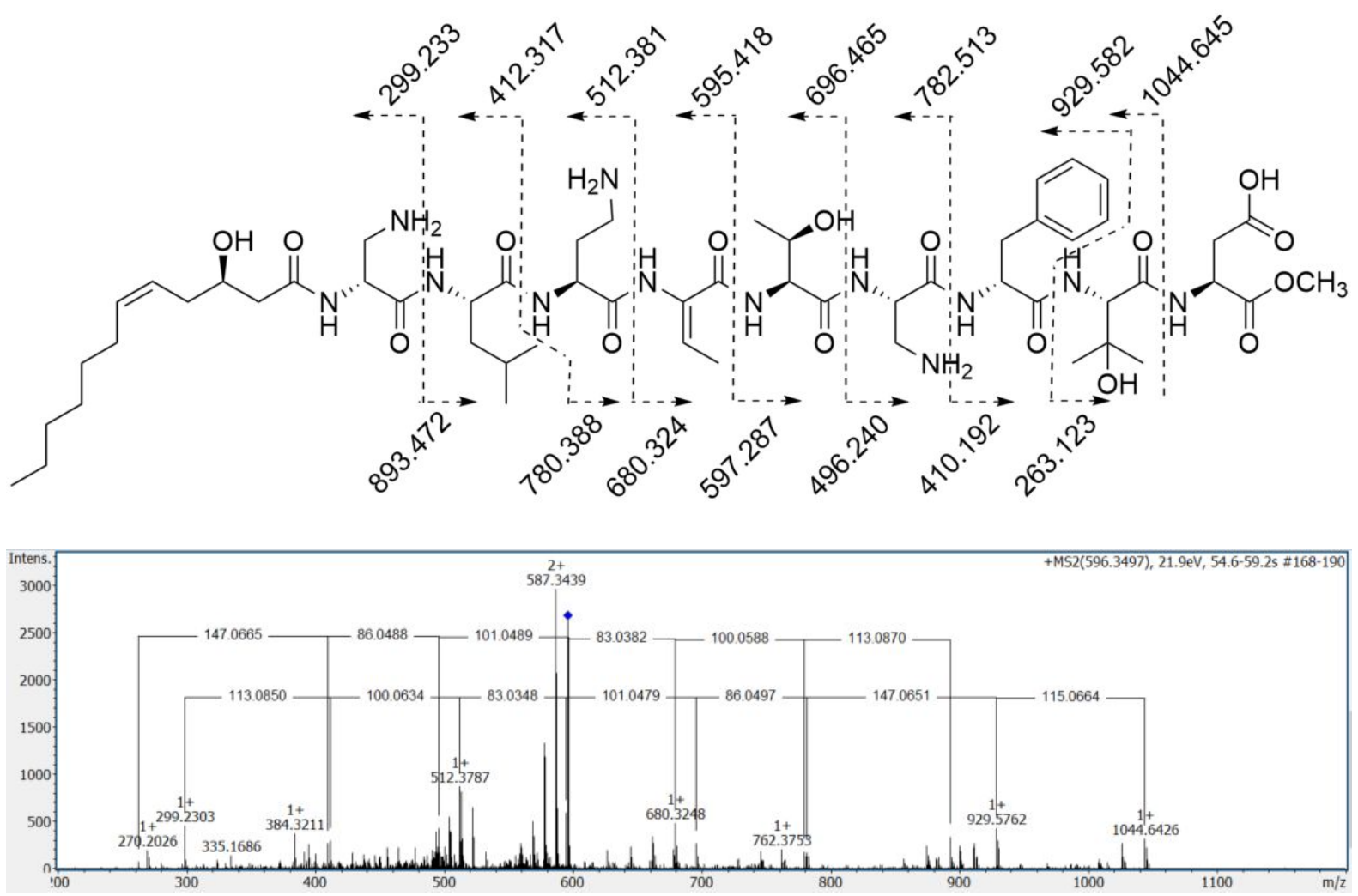

Figure S46. MSMS spectrum of compound 6 after treatment with $\mathrm{NaOMe}$ in $\mathrm{MeOH}$. Mass differences between $\mathrm{Y}$-series ions (top) and B-series ions (bottom) are shown in the mass spectrum. Theoretical $\mathrm{m} / \mathrm{z}$-values for the observed B- and Y-series ions are shown in the structure on top. 
Table S7. ${ }^{1} \mathrm{H}$ and ${ }^{13} \mathrm{C}$ NMR-data (600 and $150 \mathrm{MHz}$, resp) for compound $7\left(\mathrm{DMSO}-\mathrm{d}_{6}, 30^{\circ} \mathrm{C}\right)$

\begin{tabular}{|c|c|c|c|c|c|c|c|}
\hline Pos. & ${ }^{13} \mathrm{C}$ & ${ }^{1} \mathbf{H}$ & Mult $(J, \mathbf{H z})$ & Pos. & ${ }^{13} \mathrm{C}$ & ${ }^{1} \mathrm{H}$ & Mult $(J, \mathbf{H z})$ \\
\hline 3OHFA & & & & Thr & & & \\
\hline 1 & 167.5 & - & - & NH & - & 8.45 & $\mathrm{~d}(7.4)$ \\
\hline \multirow[t]{2}{*}{2} & 39.4 & 2.71 & obsc & 1 & 169.8 & - & - \\
\hline & & 2.16 & br d (13.4) & 2 & 59.6 & 4.20 & $\mathrm{dd}(7.7,2.4)$ \\
\hline 3 & 70.5 & 4.96 & $\mathrm{~m}$ & 3 & 65.0 & 4.35 & $\mathrm{dq}(2.5,6.5)$ \\
\hline 4 & 30.8 & 1.50 & obsc & 4 & 20.5 & 1.23 & $\mathrm{~d}(6.5)$ \\
\hline 5 & 38.0 & 1.17 & $\mathrm{~m}$ & DAPA2 & & & \\
\hline 6 & 24.2 & 1.95 & obsc & NH & - & 8.19 & $d(8.6)$ \\
\hline 7 & 129.7 & 5.31 & $\mathrm{~m}(11)$ & 1 & 169.2 & - & - \\
\hline 8 & 128.5 & 5.24 & $\mathrm{~m}(11)$ & 2 & 53.3 & 4.25 & obsc \\
\hline 9 & 25.9 & 1.93 & obsc & 3 & 40.7 & 3.05 & br d (12.7) \\
\hline 10 & 25.0 & 1.25 & obsc & & & 2.87 & obsc \\
\hline 11 & 26.8 & 1.51 & obsc & Phe & & & \\
\hline 12 & 22.0 & 0.86 & $\mathrm{~d}(6.6)$ & NH & - & 7.25 & $\mathrm{~d}(8.7)$ \\
\hline 13 & 22.0 & 0.86 & $\mathrm{~d}(6.6)$ & 1 & 170.6 & - & - \\
\hline$\overline{\text { DAPA1 }}$ & & & & 2 & 53.3 & 4.76 & obsc \\
\hline NH & - & 8.65 & $\mathrm{~d}(8.9)$ & 3 & 37.8 & 2.83 & obsc \\
\hline 1 & 170.9 & - & - & & & 2.72 & obsc \\
\hline 2 & 50.2 & 4.77 & $\mathrm{~m}$ & 4 & 137.0 & - & - \\
\hline \multirow[t]{2}{*}{3} & 44.0 & 3.20 & br d $(13.4,4.8)$ & $5 / 9$ & 129.2 & 7.30 & $\mathrm{~m}$ \\
\hline & & 2.96 & br d (13.4) & $6 / 8$ & 127.6 & 7.20 & $\mathrm{~m}$ \\
\hline Leu & & & & 7 & 125.9 & 7.15 & $\mathrm{~m}$ \\
\hline NH & - & 8.92 & br s & Val & & & \\
\hline 1 & 173.2 & - & - & NH & - & 8.58 & $\mathrm{~d}(9.7)$ \\
\hline 2 & 53.0 & 4.29 & $\mathrm{~m}$ & 1 & 169.6 & - & - \\
\hline \multirow[t]{2}{*}{3} & 39.2 & 1.64 & $\mathrm{~m}$ & 2 & 56.3 & 4.59 & $\mathrm{~m}$ \\
\hline & & 1.51 & $\mathrm{~m}$ & 3 & 30.6 & 1.78 & obsc \\
\hline 4 & 24.1 & 1.70 & $\mathrm{~m}$ & 4 & 17.7 & 0.68 & $\mathrm{~d}(6.9)$ \\
\hline 5 & 22.0 & 0.91 & $\mathrm{~d}(6.5)$ & 5 & 18.6 & 0.61 & $\mathrm{~d}(6.7)$ \\
\hline 6 & 22.0 & 0.86 & $\mathrm{~d}(6.7)$ & Asp & & & \\
\hline DABA & & & & NH & - & 8.48 & $\mathrm{~d}(9.7)$ \\
\hline NH & - & 8.67 & $\mathrm{~d}(9.6)$ & 1 & 169.7 & - & - \\
\hline 1 & 168.1 & - & - & 2 & 48.4 & 4.72 & obsc \\
\hline 2 & 49.5 & 4.63 & $\mathrm{~m}$ & 3 & 40.8 & 2.86 & obsc \\
\hline 3 & 29.0 & 1.78 & obsc & & & 2.23 & br dd $(15.7,4.1)$ \\
\hline \multirow[t]{2}{*}{4} & 35.5 & 2.72 & obsc & 4 & n.d. & - & - \\
\hline & & 2.60 & obsc & & & & \\
\hline \multicolumn{8}{|l|}{ ABA } \\
\hline NH & - & 10.23 & br s & & & & \\
\hline 1 & 165.4 & - & - & & & & \\
\hline 2 & 132.6 & - & - & & & & \\
\hline 3 & 114.4 & 5.58 & $\mathrm{q}(7.3)$ & & & & \\
\hline 4 & 12.5 & 1.77 & $\mathrm{~d}(7.3)$ & & & & \\
\hline
\end{tabular}


Supporting information

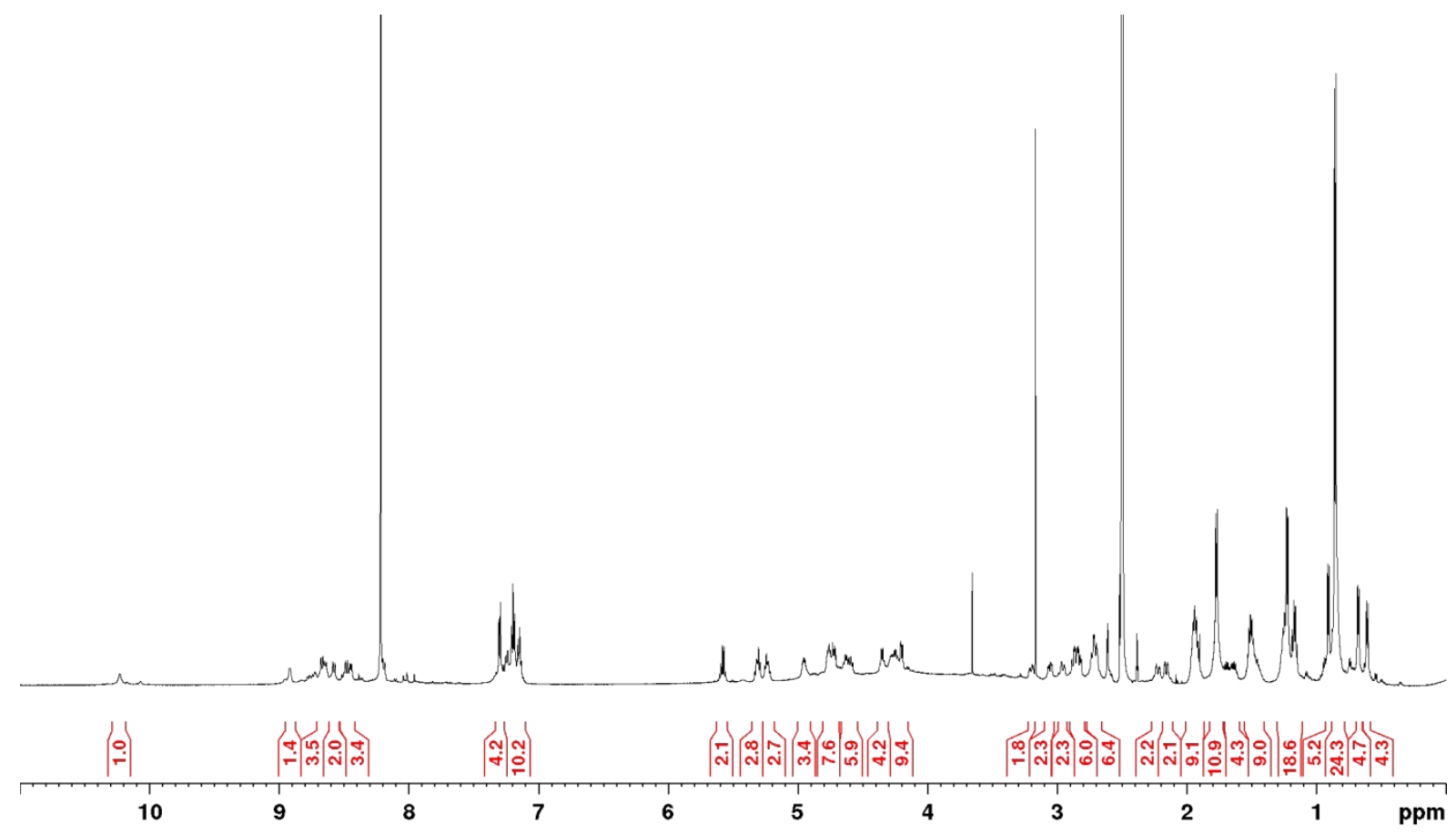

Figure S47. ${ }^{1} \mathrm{H}-\mathrm{NMR}$ spectrum of compound 7 (DMSO-d 6 , $\left.600 \mathrm{MHz}, 298 \mathrm{~K}\right)$.

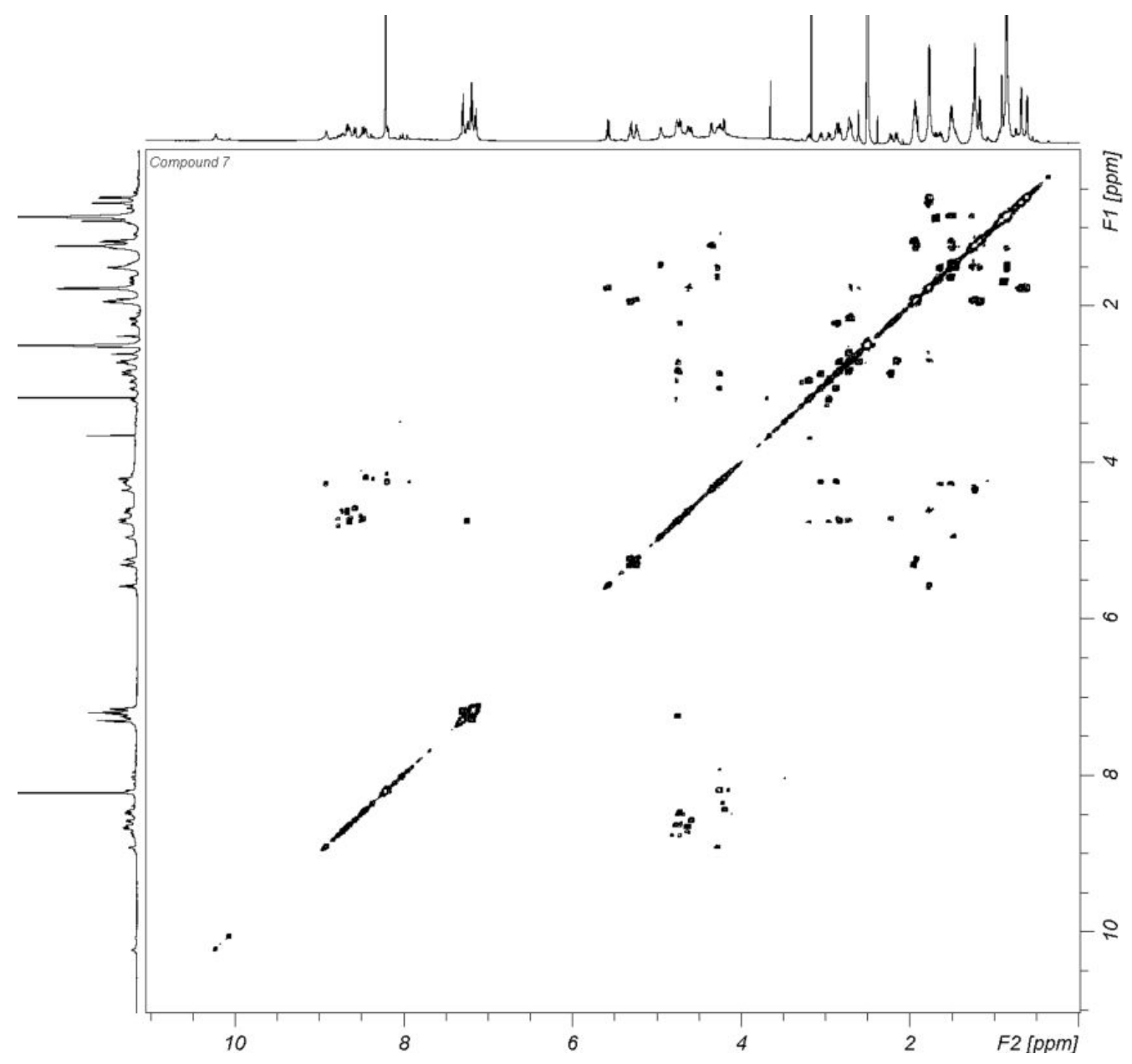

Figure S48. COSY spectrum of compound 7 (DMSO-d $\left.\mathrm{d}_{6}, 600 \mathrm{MHz}, 298 \mathrm{~K}\right)$. 
Supporting information

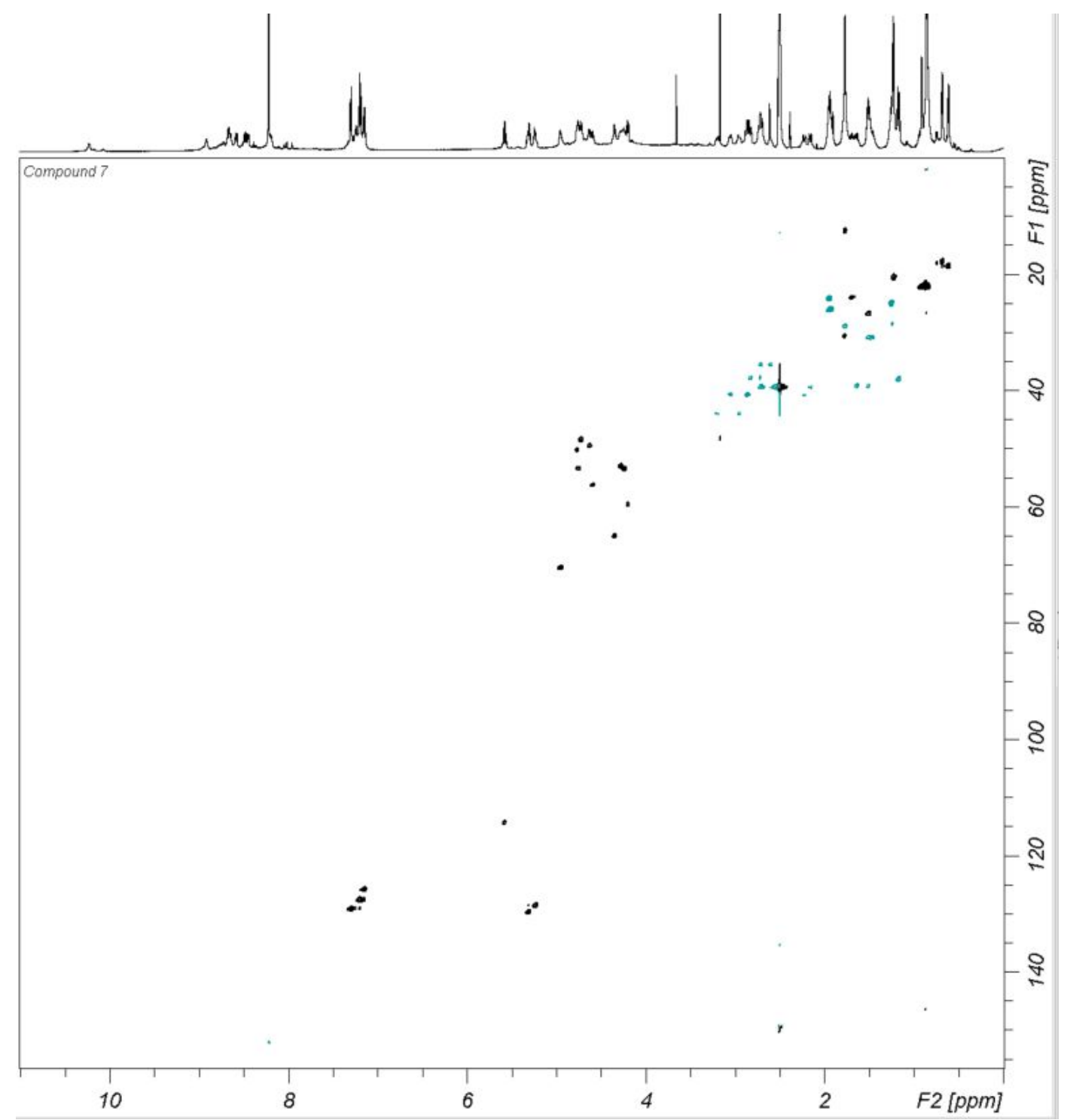

Figure S49. HSQC spectrum of compound 7 (DMSO-d 6 , 600 MHz, 298 K). 
Supporting information

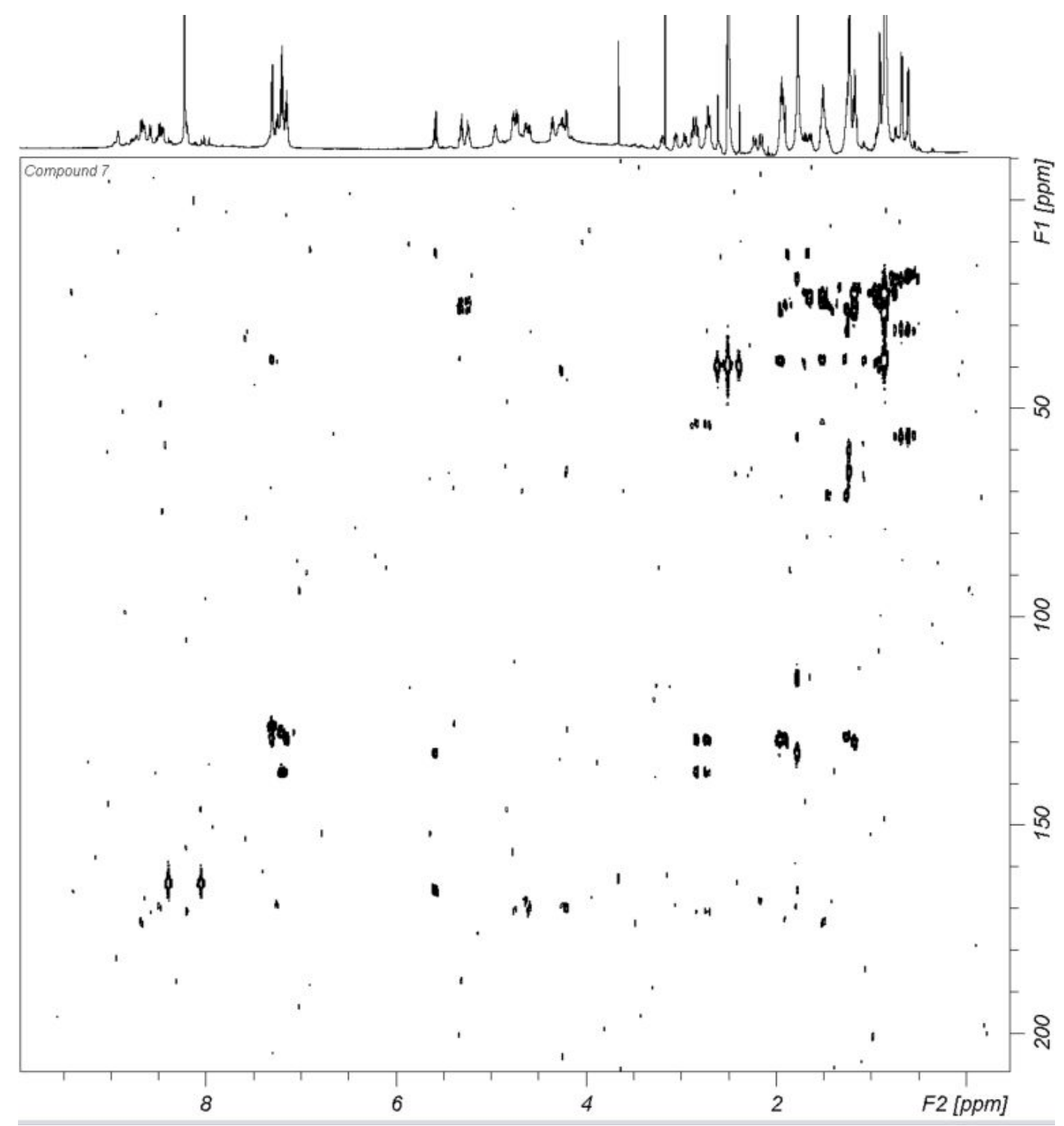

Figure S50. HMBC spectrum of compound 7 (DMSO-d ${ }_{6}, 600$ MHz, $\left.298 \mathrm{~K}\right)$. 


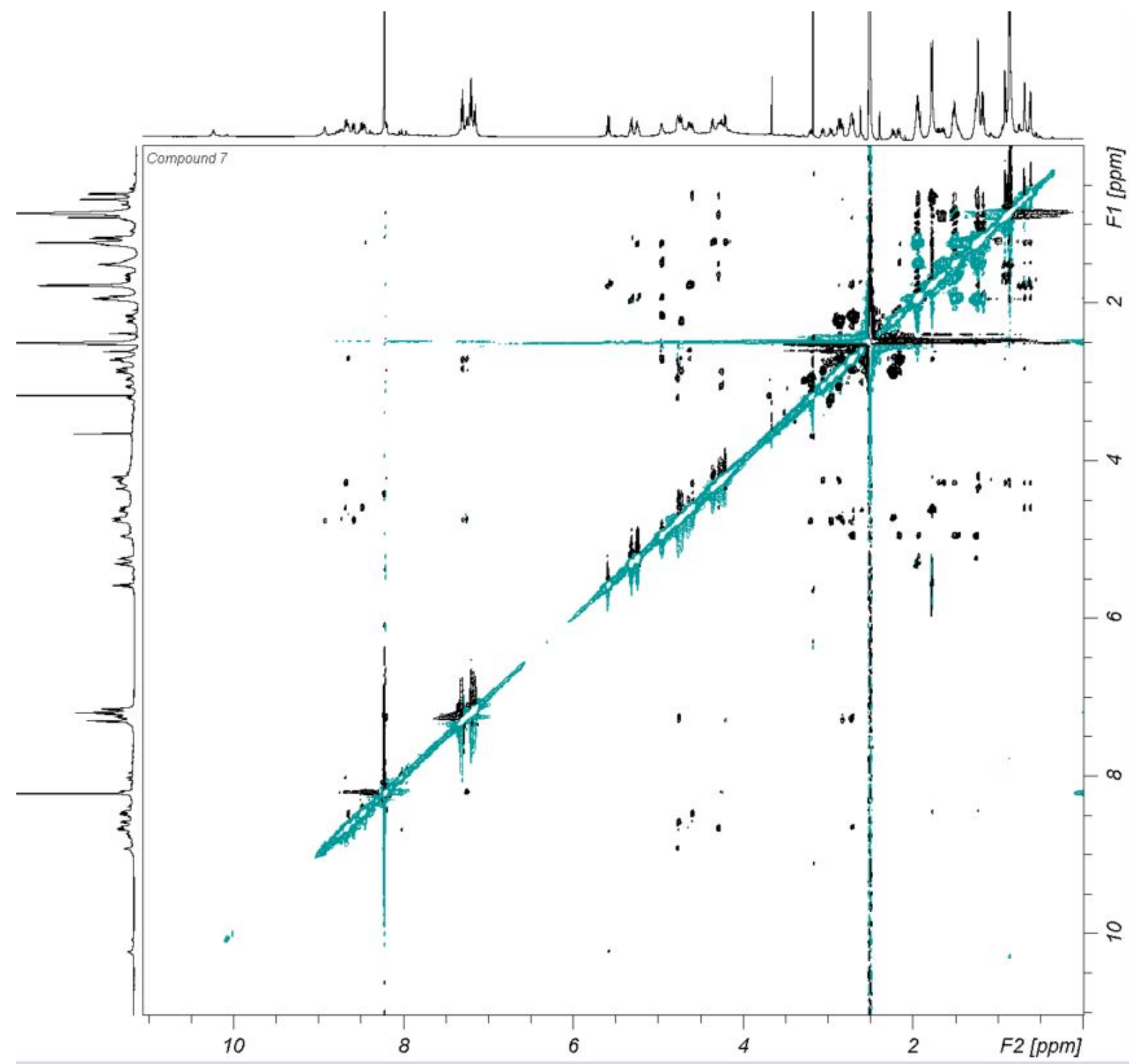

Figure S51. ROESY spectrum of compound 7 (DMSO-d 6 , $600 \mathrm{MHz}, 298 \mathrm{~K}$ ).

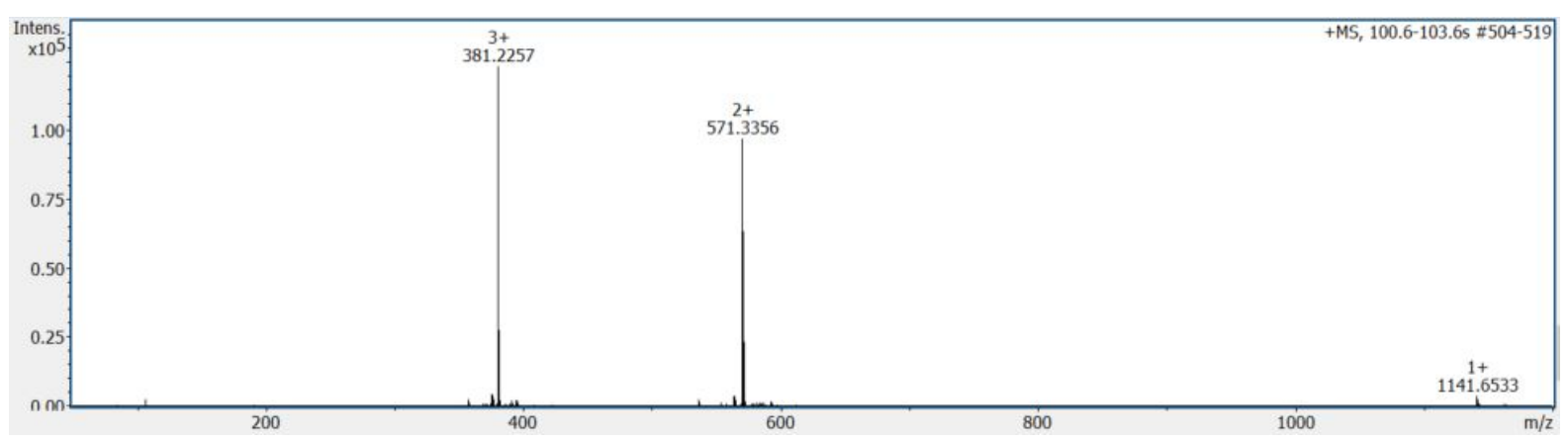

Figure S52. HRMS spectrum of compound 7. 

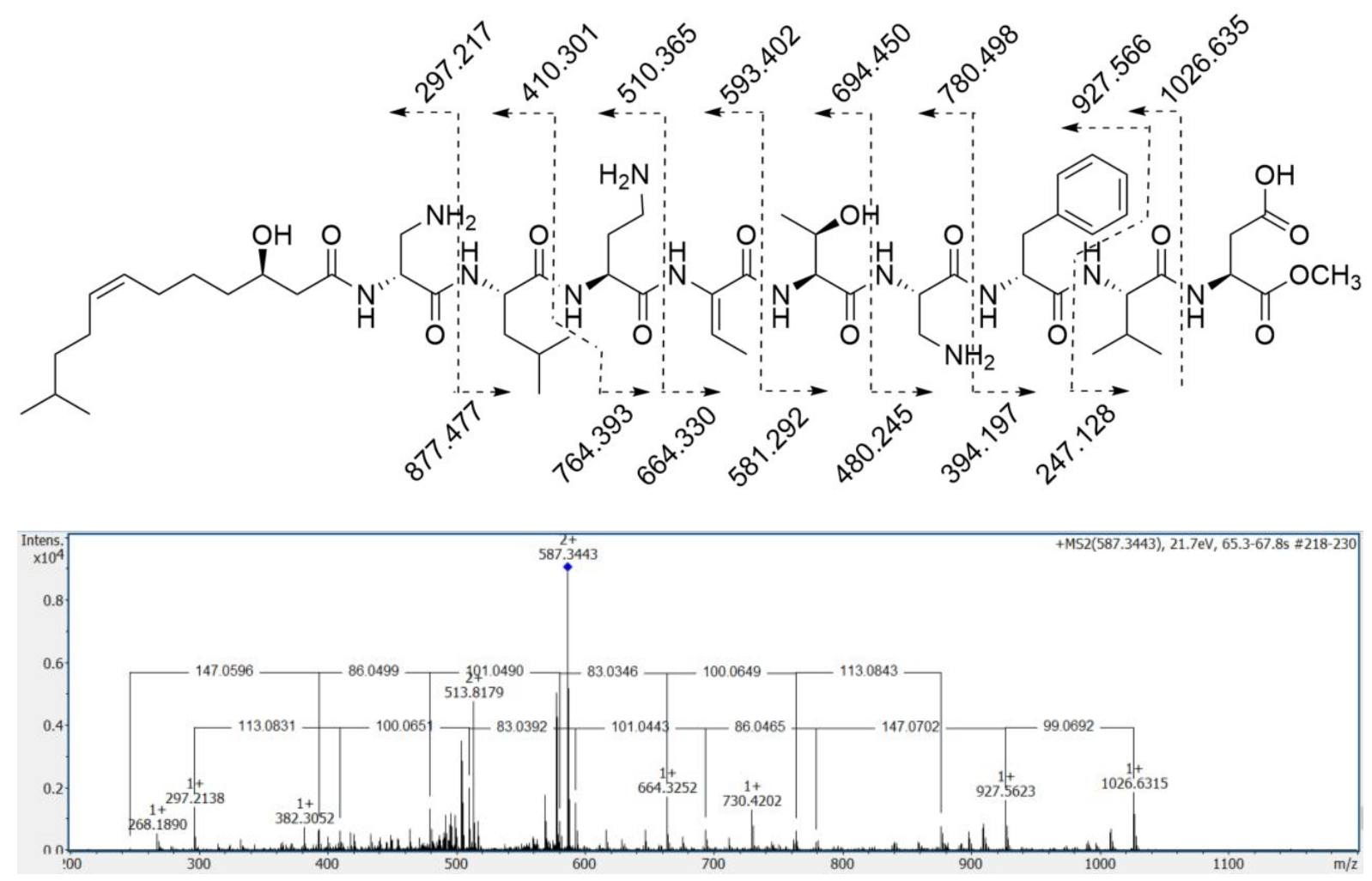

Figure S53. MSMS spectrum of compound 7 after treatment with $\mathrm{NaOMe}$ in $\mathrm{MeOH}$. Mass differences between Y-series ions (top) and B-series ions (bottom) are shown in the mass spectrum. Theoretical m/z-values for the observed B- and Y-series ions are shown in the structure on top. 


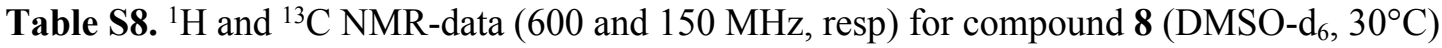

\begin{tabular}{|c|c|c|c|c|c|c|c|}
\hline Pos. & ${ }^{13} \mathrm{C}$ & ${ }^{1} \mathbf{H}$ & Mult $(J, \mathbf{H z})$ & Pos. & ${ }^{13} \mathrm{C}$ & ${ }^{1} \mathbf{H}$ & Mult $(J, \mathbf{H z})$ \\
\hline 3OHFA & & & & Thr & & & \\
\hline 1 & n.d. & - & - & NH & - & 8.45 & $d(7.6)$ \\
\hline \multirow[t]{2}{*}{2} & 38.7 & 2.66 & br dd $(14.0,4.0)$ & 1 & 170.1 & - & - \\
\hline & & 2.23 & br d (14.0) & 2 & 59.5 & 4.20 & $\mathrm{dd}(7.7,2.4)$ \\
\hline 3 & 70.6 & 4.93 & $\mathrm{~m}$ & 3 & 65.0 & 4.35 & $\mathrm{dq}(2.4,6.5)$ \\
\hline \multirow[t]{2}{*}{4} & 29.2 & 2.34 & $\mathrm{~m}$ & 4 & 20.5 & 1.23 & $\mathrm{~d}(6.5)$ \\
\hline & & 2.17 & $\mathrm{~m}$ & DAPA2 & & & \\
\hline 5 & 124.0 & 5.24 & $\mathrm{~m}(11)$ & NH & - & 8.19 & $\mathrm{~d}(8.4)$ \\
\hline 6 & 131.9 & 5.42 & $\mathrm{~m}(11)$ & 1 & n.d. & - & - \\
\hline 7 & 26.5 & 1.96 & $\mathrm{~m}$ & 2 & 53.2 & 4.25 & $\mathrm{~m}$ \\
\hline 8 & 28.7 & 1.25 & $\mathrm{~m}$ & 3 & 40.6 & 3.06 & br d (12.4) \\
\hline 9 & 26.0 & 1.23 & obsc & & & 2.86 & obsc \\
\hline 10 & 37.9 & 1.12 & $\mathrm{~m}$ & Phe & & & \\
\hline 11 & 27.1 & 1.49 & $\mathrm{~m}$ & NH & - & 7.25 & $\mathrm{~d}(8.8)$ \\
\hline 12 & 22.1 & 0.84 & $\mathrm{~d}(6.6)$ & 1 & n.d. & - & - \\
\hline 13 & 22.1 & 0.84 & $\mathrm{~d}(6.6)$ & 2 & 53.4 & 4.74 & obsc \\
\hline$\overline{\text { DAPA1 }}$ & & & & 3 & 37.8 & 2.82 & obsc \\
\hline NH & - & 8.61 & obsc & & & 2.72 & obsc \\
\hline 1 & n.d. & - & - & 4 & 137.2 & - & - \\
\hline 2 & 50.1 & 4.77 & $\mathrm{~m}$ & $5 / 9$ & 129.1 & 7.30 & $\mathrm{~m}$ \\
\hline \multirow[t]{2}{*}{3} & 43.6 & 3.23 & br d (12.0) & $6 / 8$ & 127.5 & 7.20 & $\mathrm{~m}$ \\
\hline & & 2.98 & br d (12.0) & 7 & 125.8 & 7.15 & $\mathrm{~m}$ \\
\hline Leu & & & & Val & & & \\
\hline NH & - & 8.93 & br s & NH & - & 8.60 & obsc \\
\hline 1 & 172.8 & - & - & 1 & n.d. & - & - \\
\hline 2 & 52.9 & 4.29 & $\mathrm{~m}$ & 2 & 56.4 & 4.57 & $\mathrm{~m}$ \\
\hline \multirow[t]{2}{*}{3} & 39.2 & 1.63 & $\mathrm{~m}$ & 3 & 30.4 & 1.78 & obsc \\
\hline & & 1.50 & obsc & 4 & 17.9 & 0.65 & $\mathrm{~d}(6.7)$ \\
\hline 4 & 24.0 & 1.68 & $\mathrm{~m}$ & 5 & 18.6 & 0.65 & $\mathrm{~d}(6.7)$ \\
\hline 5 & 22.0 & 0.90 & $\mathrm{~d}(6.4)$ & Asp & & & \\
\hline 6 & 21.8 & 0.85 & $\mathrm{~d}(7.0)$ & NH & - & 8.48 & $\mathrm{~d}(9.6)$ \\
\hline$\overline{\text { DABA }}$ & & & & 1 & n.d. & - & - \\
\hline NH & - & 8.67 & $\mathrm{~d}(9.6)$ & 2 & 48.4 & 4.74 & obsc \\
\hline 1 & n.d. & - & - & 3 & 40.8 & 2.85 & obsc \\
\hline 2 & 49.4 & 4.63 & $\mathrm{~m}$ & & & 2.23 & obsc \\
\hline 3 & 29.1 & 1.78 & obsc & 4 & n.d. & - & - \\
\hline \multirow[t]{2}{*}{4} & 35.6 & 2.72 & obsc & & & & \\
\hline & & 2.61 & obsc & & & & \\
\hline \multicolumn{8}{|l|}{$\overline{\mathbf{A B A}}$} \\
\hline NH & - & 10.24 & br s & & & & \\
\hline 1 & 165.8 & - & - & & & & \\
\hline 2 & 132.6 & - & - & & & & \\
\hline 3 & 114.2 & 5.58 & $\mathrm{q}(7.3)$ & & & & \\
\hline 4 & 12.5 & 1.77 & $\mathrm{~d}(7.3)$ & & & & \\
\hline
\end{tabular}


Supporting information

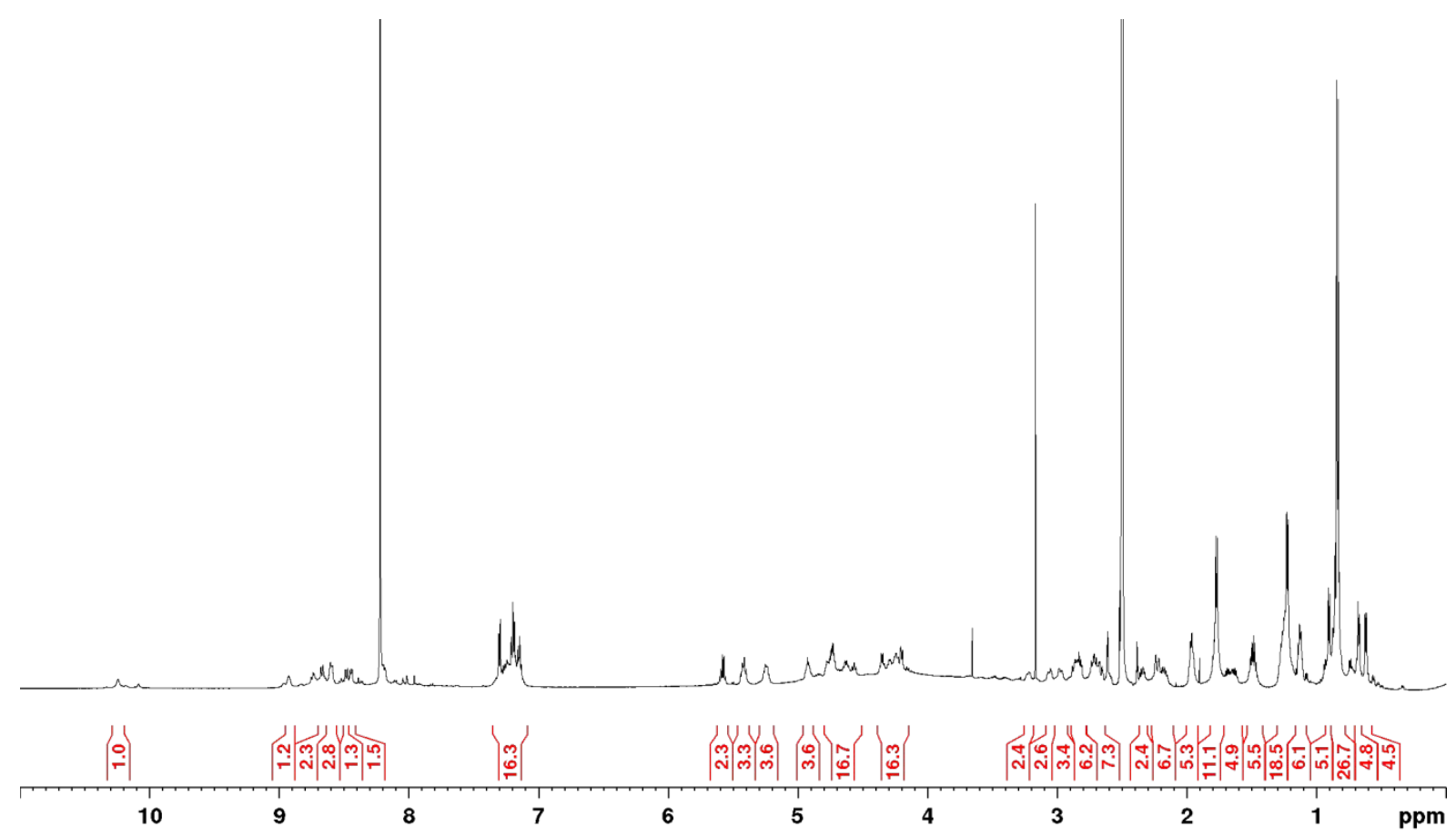

Figure S54. ${ }^{1} \mathrm{H}-\mathrm{NMR}$ spectrum of compound 8 (DMSO-d 6 , $\left.600 \mathrm{MHz}, 298 \mathrm{~K}\right)$.

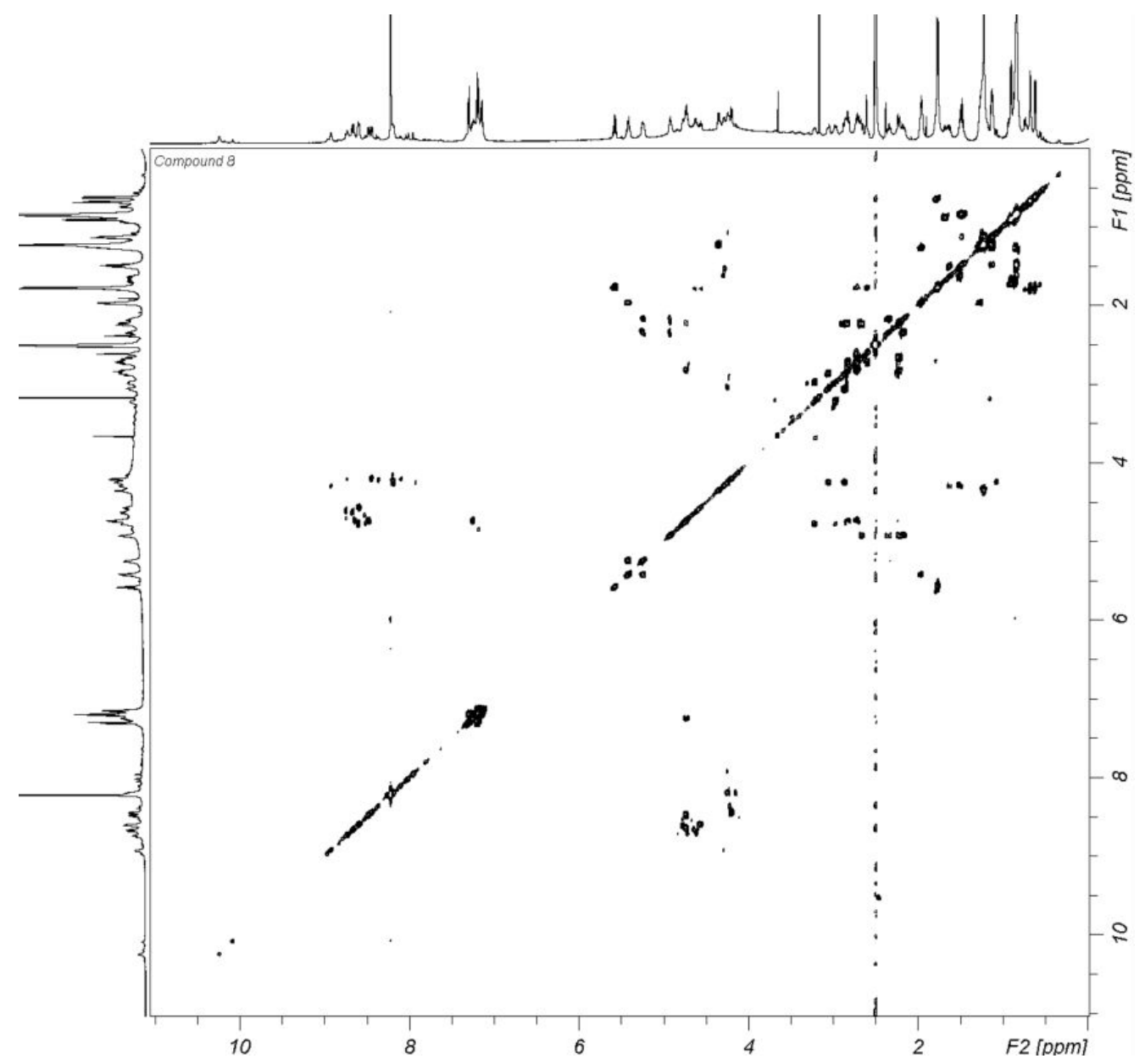

Figure S55. COSY spectrum of compound 8 (DMSO-d $\left.{ }_{6}, 600 \mathrm{MHz}, 298 \mathrm{~K}\right)$. 
Supporting information

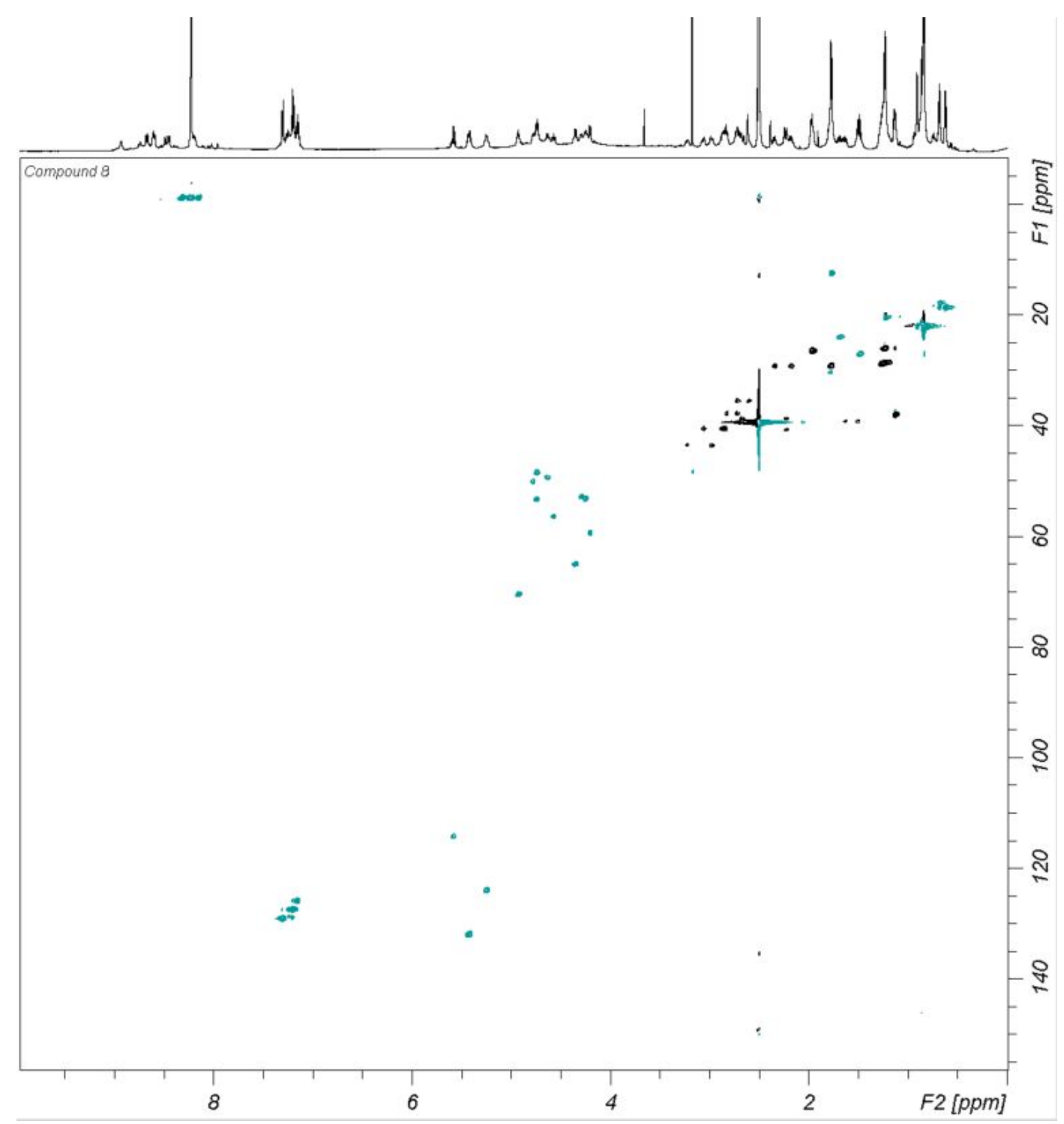

Figure S56. HSQC spectrum of compound 8 (DMSO-d ${ }_{6}, 600$ MHz, 298 K). 
Supporting information

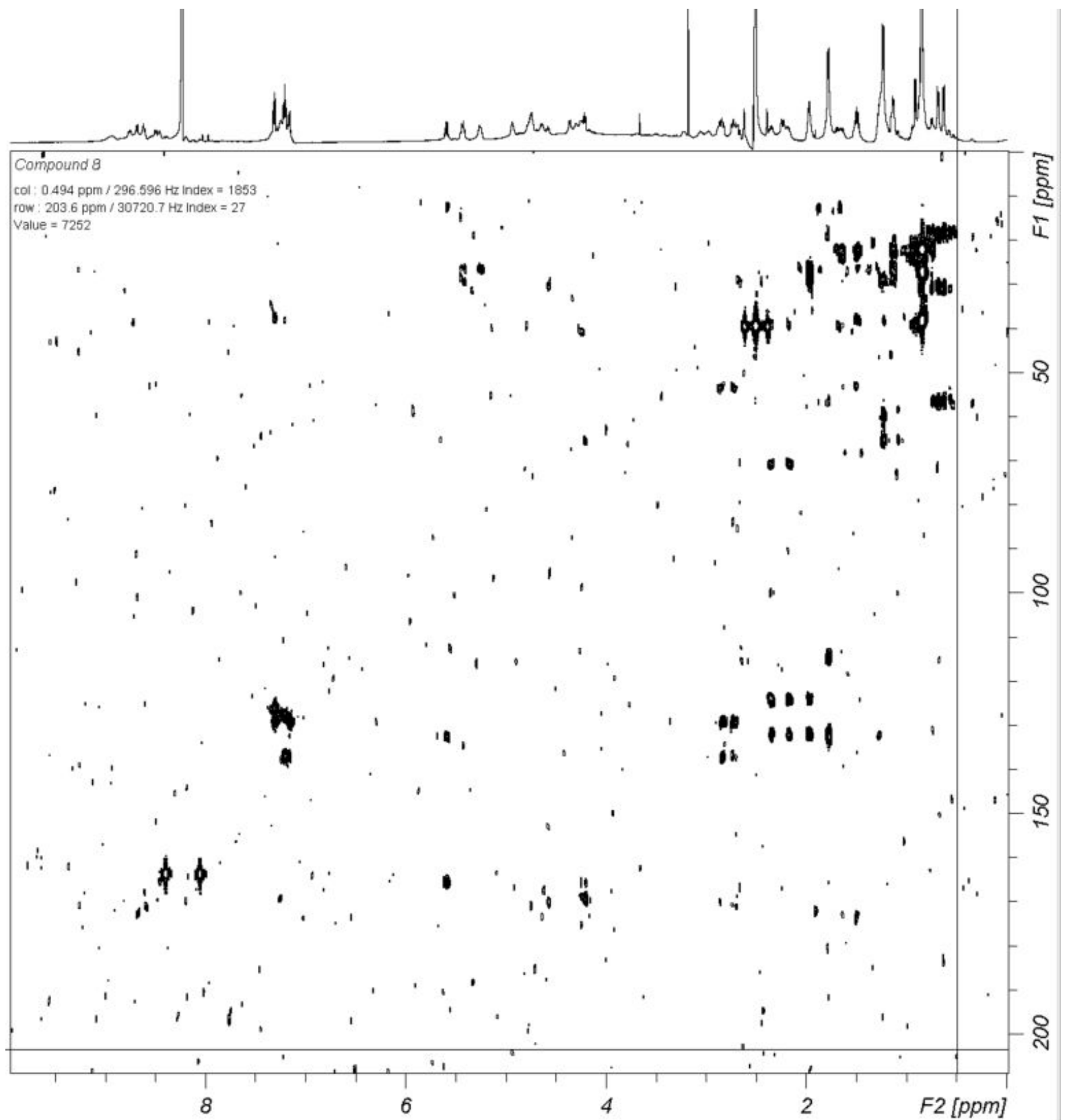

Figure S57. HMBC spectrum of compound 8 (DMSO-d 6 , $600 \mathrm{MHz}, 298 \mathrm{~K})$. 


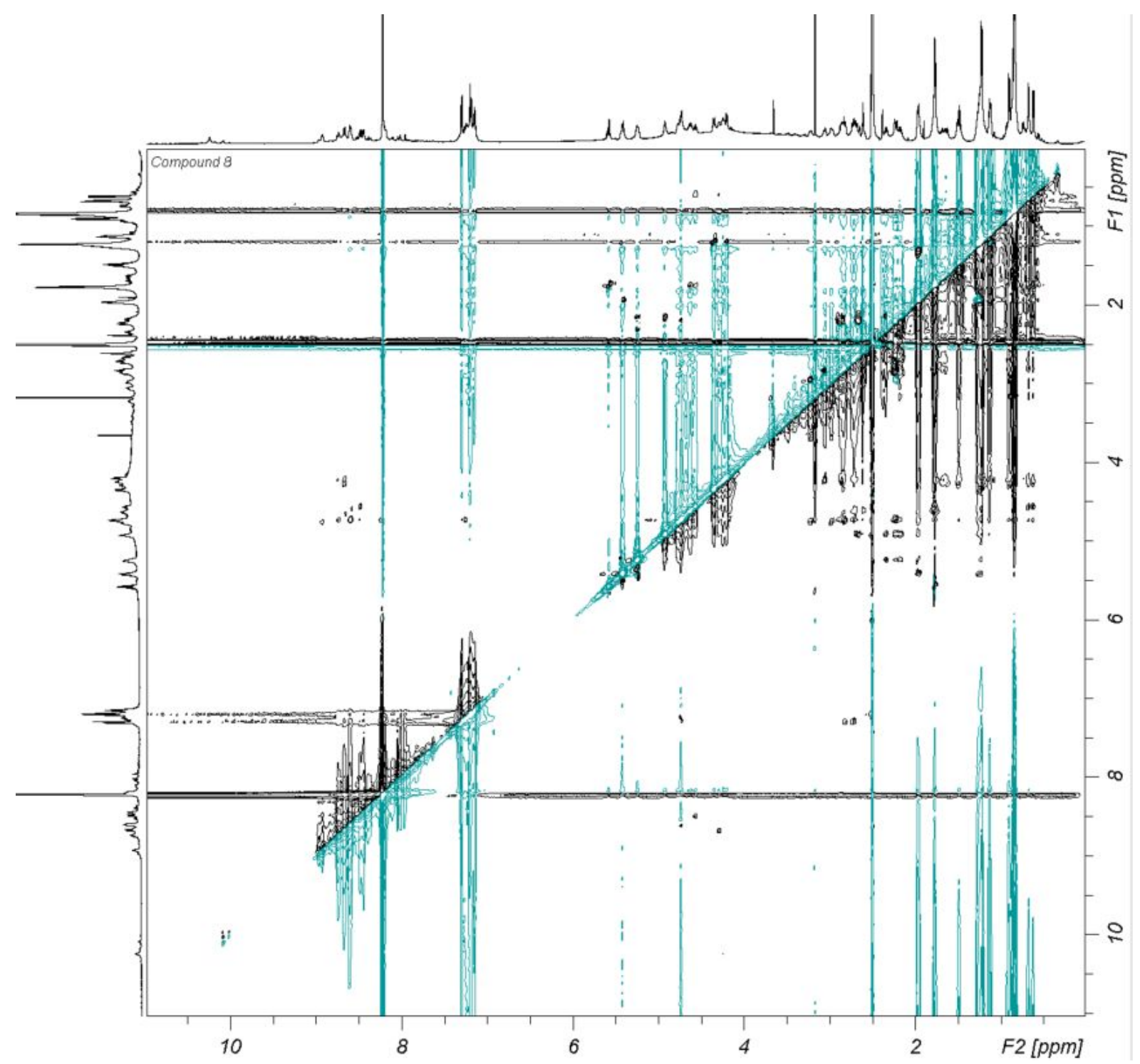

Figure S58. ROESY spectrum of compound 8 (DMSO-d 6 , $600 \mathrm{MHz}, 298 \mathrm{~K}$ ).

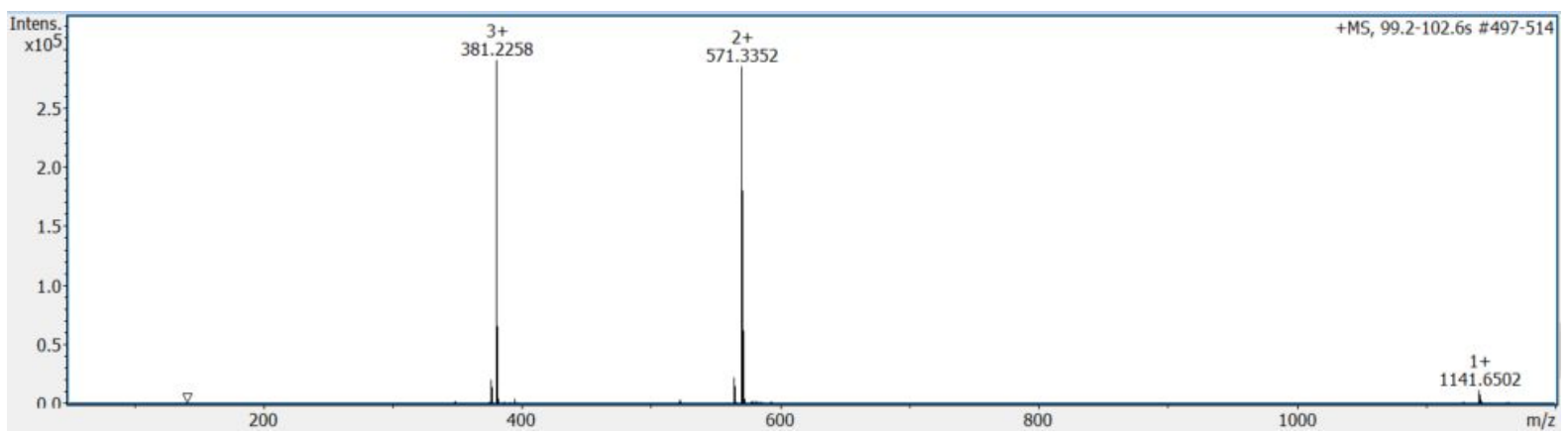

Figure S59. HRMS spectrum of compound 8. 

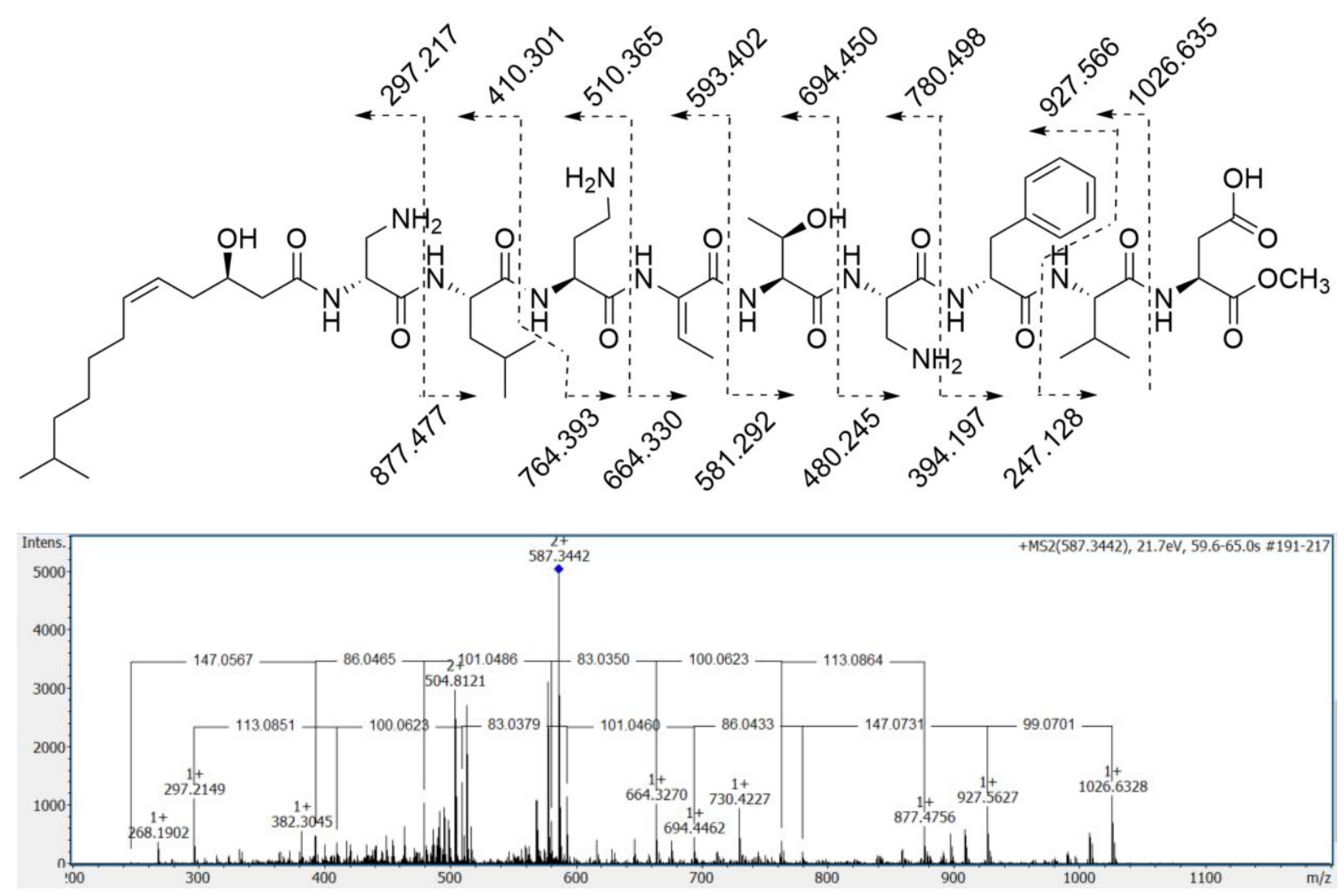

Figure S60. MSMS spectrum of compound 8 after treatment with $\mathrm{NaOMe}$ in $\mathrm{MeOH}$. Mass differences between $\mathrm{Y}$-series ions (top) and B-series ions (bottom) are shown in the mass spectrum. Theoretical m/z-values for the observed B- and Y-series ions are shown in the structure on top. 
Table S9. Retention times from advanced Marfey's analysis of compounds 1-8.

Retention times (s) for L-FDLA derivatives

$\begin{array}{ll}\text { References }^{\mathrm{a}} & \text { Isolated compounds }\end{array}$

\begin{tabular}{|c|c|c|c|c|c|c|c|c|c|c|c|c|c|c|c|c|c|c|}
\hline & $\mathbf{L}$ & D & 1 & $e^{e p i .}{ }^{b}$ & 2 & epi. & 3 & epi. & 4 & epi. & 5 & epi. & 6 & epi. & 7 & epi. & 8 & epi. \\
\hline Asp & 33 & 38 & 33 & - & 32 & - & 32 & - & 34 & - & 32 & - & 32 & - & 33 & - & 33 & 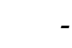 \\
\hline DAPA & 190 & 204 & 190 & 204 & 190 & 204 & 190 & 204 & 190 & 204 & 190 & 204 & 190 & 203 & 191 & 203 & 190 & 204 \\
\hline DABA & 196 & 220 & 196 & - & 196 & - & 196 & - & 196 & - & 196 & - & 196 & - & 196 & - & 196 & 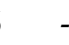 \\
\hline OHVal & 36 & 69 & 37 & - & 36 & - & 36 & - & - & - & - & - & 36 & - & - & - & - & - \\
\hline Val & 76 & 145 & - & - & - & - & - & - & 76 & - & 76 & - & - & - & 76 & - & 76 & 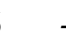 \\
\hline Leu & 104 & 186 & 104 & - & 103 & - & 104 & - & 104 & - & 104 & - & 104 & - & 104 & - & 104 & . \\
\hline Phe & 107 & 172 & 171 & 107 & 172 & 106 & 172 & 107 & 172 & - & 172 & - & 172 & 107 & 172 & - & 172 & 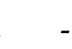 \\
\hline Thr & 31 & 58 & 32 & - & 31 & - & 31 & - & 32 & - & 31 & - & 31 & - & 31 & - & 31 & \\
\hline allo-Thr & 35 & 46 & - & - & - & - & - & - & - & - & - & - & - & - & - & - & - & 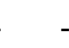 \\
\hline
\end{tabular}

${ }^{a}$ L-Amino acids were derivatized in two ways: 1) with L-FDLA and 2) with D/L-FDLA. The D-FDLA derivatives of L-amino acids are chromatographically equivalent to the L-FDLA derivatives of D-amino acids. ${ }^{\mathrm{b}}$ The alternative isomer formed by epimerization during sample preparation, as observed by incorporation of deuterium when the hydrolysis was performed in $6 \mathrm{M} \mathrm{DCl}$. 